\title{
PROJETO DE CIRCUITOS PARA GERAÇÃO DE TENSÃO DE REFERÊNCIA EM SISTEMAS RECEPTORES/TRANSMISSORES RF
}

\author{
Cristian Otsuka Hamanaka \\ Dissertação de Mestrado apresentada à \\ Escola Politécnica da Universidade de São \\ Paulo, para obtenção do Título de Mestre, \\ pelo curso de Pós Graduação em \\ Engenharia Elétrica - Área de \\ concentração: Microeletrônica.
}




\title{
PROJETO DE CIRCUITOS PARA GERAÇÃO DE TENSÃO DE REFERÊNCIA EM SISTEMAS RECEPTORES/TRANSMISSORES RF
}

\author{
Cristian Otsuka Hamanaka \\ Dissertação de Mestrado apresentada à \\ Escola Politécnica da Universidade de São \\ Paulo, para obtenção do Título de Mestre, \\ pelo curso de Pós Graduação em \\ Engenharia Elétrica - Área de \\ concentração: Microeletrônica.
}

Orientador: João Navarro Soares Júnior

São Paulo 
Ao meu pai Maurício Hiroomi Hamanaka, in memoriam, e a minha mãe aos quais devo, em grande parte, o que hoje sou. 
"Uma longa jornada começa pelo primeiro passo"

(Provérbio Chinês) 


\section{AGRADECIMENTOS}

Ao meu orientador Doutor João Navarro Soares Junior, por todo o apoio e pela oportunidade de desenvolver este trabalho.

Ao Conselho Nacional de Desenvolvimento Cientifico e Tecnológico $(\mathrm{CNPq})$, pelo apoio financeiro dado através da bolsa de mestrado.

À Fundação de Amparo à Pesquisa do Estado de São Paulo (FAPESP), pelo financiamento da fabricação dos circuitos integrados.

Ao Laboratório de Sistemas Integráveis (LSI) e ao Laboratório de Microeletrônica, pela disposição de sua infra-estrutura física para o desenvolvimento deste trabalho.

Aos professores Wilhelmus, Charry e Malu e a todos os colegas do LSI tanto da área de projetos quanto da área de processos: Alex, Angélica, Bruno, Catalina, Fernando, Murilo, Paulo, Patrick, Peter, Priscila, Rodrigo, Sérgio e Sidney.

À minha noiva por todo apoio nesta etapa da minha vida e à minha família que sempre motivou meus estudos. 
Este exemplar foi revisado e alterado em relação à versão original, sob responsabilidade única do autor e com a anuência de seu orientador.

São Paulo, 09 de Julho de 2007.

Assinatura do autor

Assinatura do orientador

\section{FICHA CATALOGRÁFICA}

\section{Hamanaka, Cristian Otsuka}

Projeto de Circuitos para Geração de Tensão de Referência em Sistemas Receptores/Transmissores RF / C.O. Hamanaka. São Paulo, 2007.

$82 \mathrm{p}$.

Dissertação (Mestrado) - Escola Politécnica da Universidade de São Paulo. Departamento de Engenharia de Sistemas Eletrônicos.

1.Microeletrônica 2.Circuitos integrados MOS 3.Circuitos Analógicos I.Universidade de São Paulo. Escola Politécnica. Departamento de Engenharia de Sistemas Eletrônicos II.t. 


\section{SUMÁRIO}

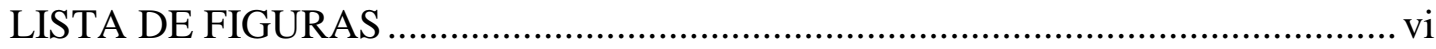

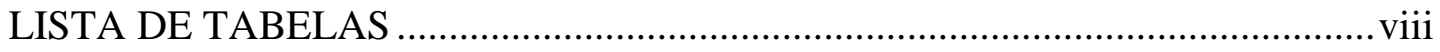

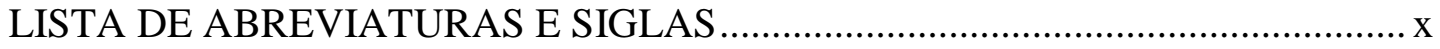

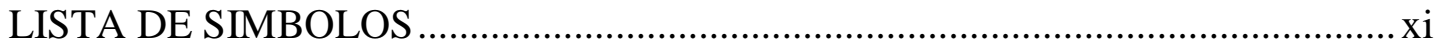

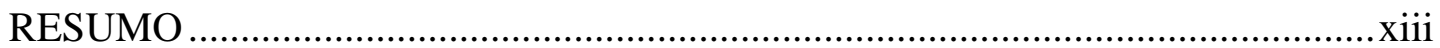

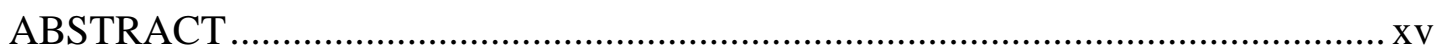

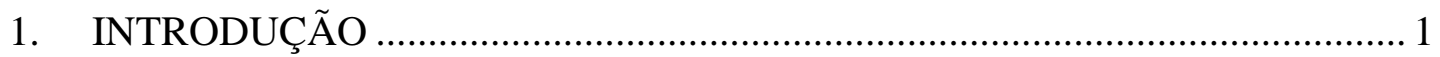

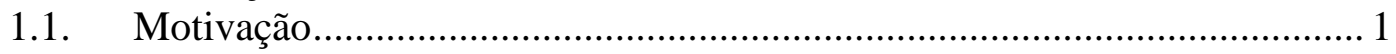

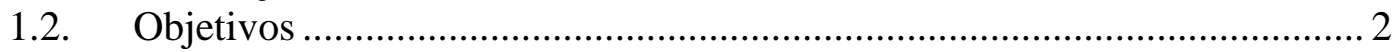

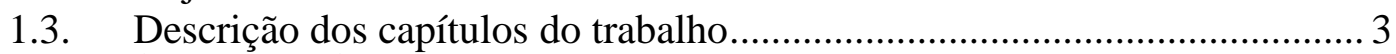

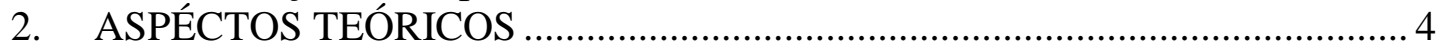

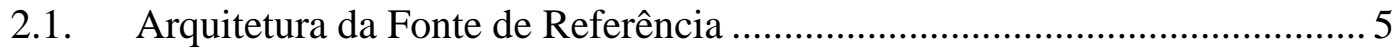

2.2. Divisor de Tensão Passivo/Ativo ................................................................... 5

2.3. Tensão de Referência com Junção p-n Reversamente Polarizada ................ 6

2.4. Referências Bandgap................................................................................ 9

2.5. Polarização Independente da Tensão de Alimentação para Circuito

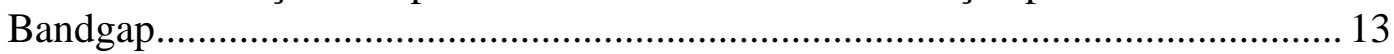

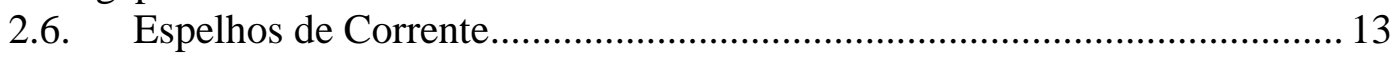

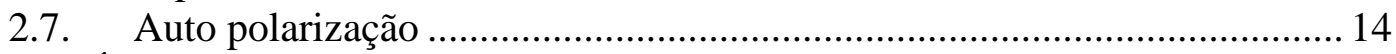

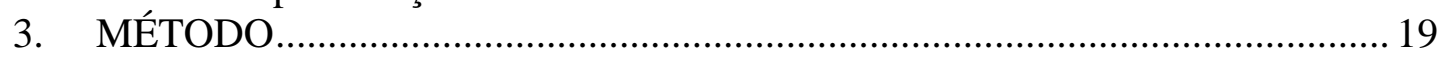

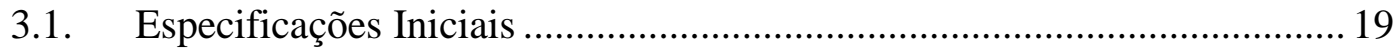

3.2. Funcionamento Básico do Circuito de Tensão de Referência Bandgap .... 20

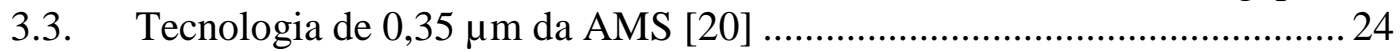

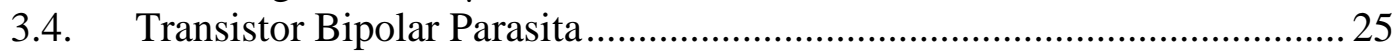

3.5. Simulação do Circuito Integrado ................................................................ 27

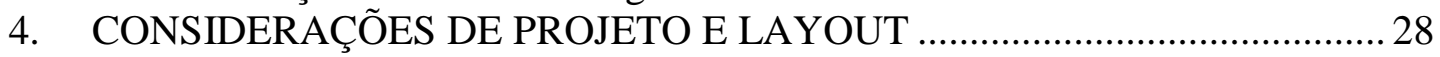

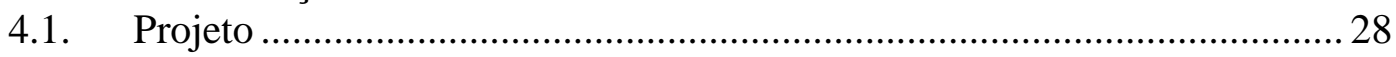

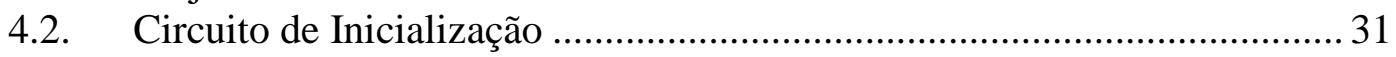

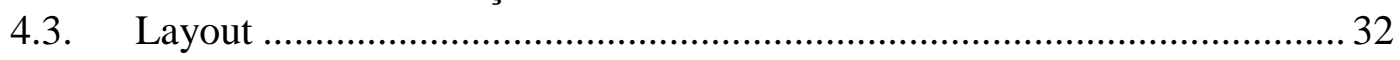

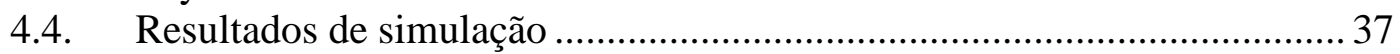

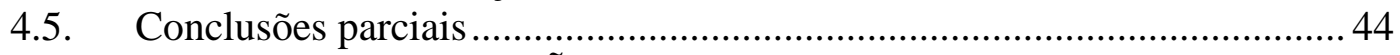

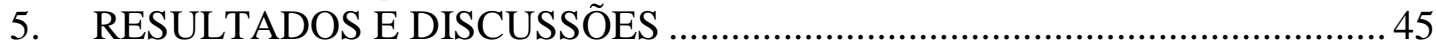

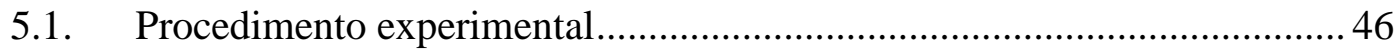

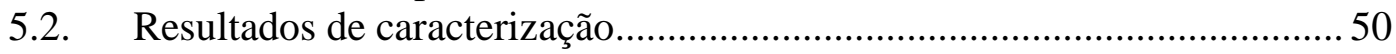

5.2.1. Caracterização com a tensão de alimentação ........................................ 50

5.2.2. Caracterização com a temperatura ....................................................... 53

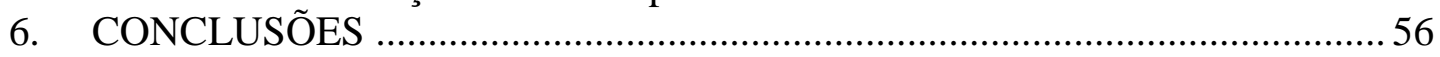

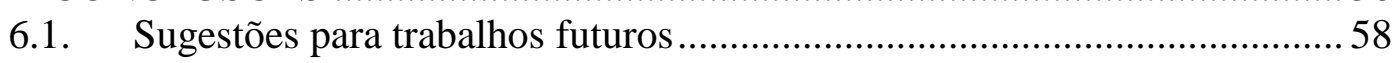

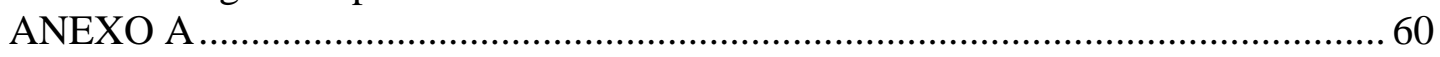

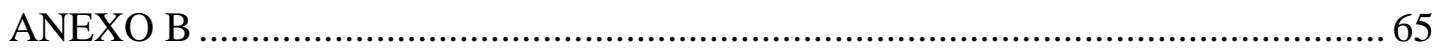

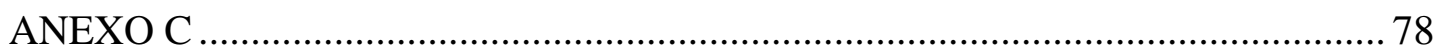

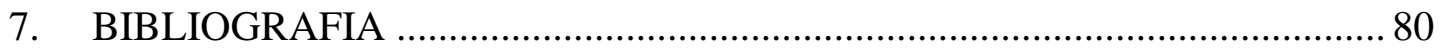




\section{LISTA DE FIGURAS}

Figura 1. Exemplo de um sistema de sinal misto................................................. 4

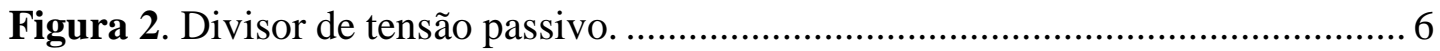

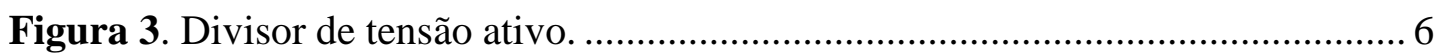

Figura 4. Exemplo de uma fonte de tensão com zener. .......................................... 8

Figura 5. Diagrama de blocos de uma Referência de Tensão Bandgap ................... 10

Figura 6. Circuito Bandgap clássico................................................................. 11

Figura 7. Espelho de corrente MOS simples......................................................... 14

Figura 8. Circuito de referência de corrente CMOS.............................................. 17

Figura 9. Pontos de operação estáveis do circuito de referência de correntes........... 18

Figura 10. Esquemático do circuito bandgap. ........................................................ 21

Figura 11. Vista em corte de um transistor PNP lateral parasitário disponível na

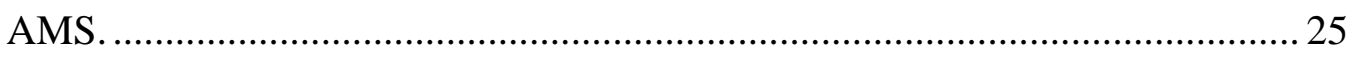

Figura 12. Layout do transistor PNP lateral parasitário disponível na AMS............ 26

Figura 13. Vista em corte do transistor bipolar PNP vertical parasitário disponível

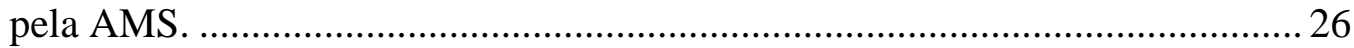

Figura 14. Layout do transistor PNP vertical parasitário disponível na AMS.......... 27

Figura 15. Gráfico de $\log \left(-I_{D S}\right)$ x $V_{G S}$ para os transistores $M_{3}$ e $M_{4}$ com $V D S=3,3$ $V$

Figura 16. Gráfico de $V_{\text {OUT }}$ e $V_{C}$ em função do tempo............................................ 32

Figura 17. (a) Transistor dividido em estruturas paralelas. (b) Layout de um transistor em dedos

Figura 18. (a) Esquemático de um circuito par diferencial. (b) Esboço do Layout do circuito par diferencial utilizando a técnica de centróide comum.

Figura 19. Layout do resistor $R_{l}$ em silício policristalino de alta resistividade (RPOLYH) com dimensões de 286,5 $\mu \mathrm{m}$ x $5 \mu \mathrm{m}$.

Figura 20. Layout do circuito bandgap com resistores de internos (dimensões de 220

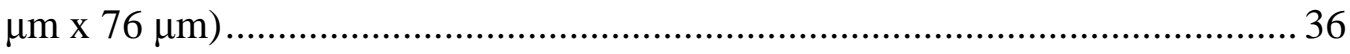

Figura 21. Layout do circuito bandgap sem os resistores (dimensões de $190 \mu \mathrm{m}$ x 36 $\mu \mathrm{m}$, sem $P A D s)$ 
Figura 22. Gráfico de $I_{D} \times V_{D D}$ dos transistores $M_{1}, M_{2}, M_{3}$ e $M_{4}$, utilizando parâmetros típicos da tecnologia e temperatura de $50^{\circ} \mathrm{C}$

Figura 23. Gráfico de $V_{R 1} \times$ Temperatura, utilizando os parâmetros típicos (TM), worst speed (WS) e worst power (WP) da tecnologia e com $V_{D D}$ de 3,3 V.

Figura 24. Gráfico de $I_{D}$ x Temperatura dos transistores $M_{1}, M_{2}, M_{3}$ e $M_{4}$, utilizando parâmetros típicos da tecnologia e com $V_{D D}=3,3 \mathrm{~V}$.

Figura 25. Gráficos de simulação de $V_{O U T} \times V_{D D}$ do circuito de bandgap para diferentes temperaturas $\left(-40^{\circ} \mathrm{C}, 50^{\circ} \mathrm{C}\right.$ e $\left.120^{\circ} \mathrm{C}\right)$, utilizando parâmetros típicos.

Figura 26. Gráfico de $V_{O U T} \times V_{D D}$ do circuito bandgap utilizando os parâmetros típicos (TM), worst speed (WS) e worst power (WP) e temperatura de $50{ }^{\circ} \mathrm{C} .42$

Figura 27. Gráfico de Vout x Temperatura do circuito bandgap utilizando os parâmetros típicos (TM), worst speed (WS) e worst power $(\mathbf{W P})$ e $V_{D D}=3,3 \mathrm{~V}$.

Figura 28. Fotomicrografia do circuito bandgap fabricado (a) com resistores integrados e (b) sem resistores

Figura 29. Diagrama para encapsulamento do circuito integrado. 46

Figura 30. Câmara Climática VT 4004 da Vötsch Industrietechnik usado nas medidas com a temperatura.

Figura 31. Foto da montagem em uma placa de fenolite usada nas medidas. 48

Figura 32. Caracterização da amostra am2.1 com a variação da temperatura utilizando dois procedimentos diferentes $\left(V_{D D}=3,3 \mathrm{~V}\right)$

Figura 33. Medidas da tensão de saída em relação à alimentação dos circuitos com resistores integrados, realizadas à temperatura ambiente de $27^{\circ} \mathrm{C}$.

Figura 34. Medidas da tensão de saída em relação à alimentação dos circuitos com resistores externos, realizadas à temperatura ambiente de $27^{\circ} \mathrm{C}$.

Figura 35. Medidas da tensão de saída em relação à temperatura, dos circuitos com resistores integrados $\left(V_{D D}=3,3 \mathrm{~V}\right)$.

Figura 36. Medidas da tensão de saída em relação à temperatura, dos circuitos sem resistores integrados $\left(V_{D D}=3,3 \mathrm{~V}\right)$. 


\section{LISTA DE TABELAS}

Tabela 1. Vantagens e desvantagens dos circuitos de tensão de referência mais utilizados

Tabela 2. Especificações iniciais de projeto.

Tabela 3. Tamanho dos componentes do circuito bandgap projetado.

Tabela 4. Camadas disponíveis para implementar resistores e respectivas resistividades e coeficientes de temperatura.

Tabela 5. Valores das correntes de dreno nos transistores $M_{1}$ e $M_{2}$ e relação entre elas para algumas tensões de alimentação.

Tabela 6. Valores das correntes de dreno nos transistores $M_{1}$ e $M_{2}$ e relação entre elas para algumas temperaturas de operação.

Tabela 7. Valores de $V_{\text {OUT }}$ para as temperaturas de $-40{ }^{\circ} \mathrm{C}, 50^{\circ} \mathrm{C}$ e $120^{\circ} \mathrm{C}$ do circuito bandgap nas tensões de $2 \mathrm{~V}, 3,3 \mathrm{~V}$ e $4 \mathrm{~V}$.

Tabela 8. Valores máximo e mínimo de $V_{O U T}$ para diferentes parâmetros de simulação, na faixa de temperatura -40 a $120^{\circ} \mathrm{C}$.

Tabela 9. Valores de tensão de saída para tensões de alimentação mínima (1,8 V) e máxima (3,3 V), para o circuito bandgap com resistores integrados.

Tabela 10. Valores de tensão de saída para tensões de alimentação mínima (1,8 V) e máxima $(3,3 \mathrm{~V})$, para o circuito bandgap sem resistores integrados.

Tabela 11: Tabela comparativa entre os resultados de medidas e as especificações iniciais para os circuitos com resistores integrados.

Tabela 12: Tabela comparativa entre os resultados de medidas e as especificações iniciais para os circuitos sem resistores integrados.

Tabela 13. Valores da tensão de saída em função da tensão de alimentação para o circuito bandgap com resistores integrados

Tabela 14. Valores da tensão de saída em função da tensão de alimentação para o circuito bandgap utilizando resistores externos, com $\mathrm{R}_{1}=68,79 \mathrm{~K} \Omega$. 78

Tabela 15. Valores da tensão de saída em função da temperatura de operação para o circuito bandgap com resistores integrados 
Tabela 16. Valores da tensão de saída em função da tensão temperatura de operação para amostras o circuito bandgap utilizando resistores externos, com $\mathrm{R}_{1}=68,79$

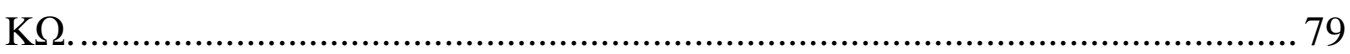




\section{LISTA DE ABREVIATURAS E SIGLAS}

\begin{tabular}{|c|c|}
\hline$A / D$ & Analógico/Digital \\
\hline AMS & Austriamicrosystems \\
\hline BiCMOS & Bipolar-CMOS \\
\hline $\mathrm{Cl}$ & Circuito Integrado \\
\hline CMOS & Complementary Metal-Oxide-Semiconductor \\
\hline CMP & Circuits Multi-Projets \\
\hline CTAT & Complementary to Absolute Temperature \\
\hline $\mathrm{D} / \mathrm{A}$ & Digital/Analógico \\
\hline DC-DC & Direct Current-Direct Current \\
\hline DIL & Dual in Line \\
\hline ESD & Eletro Static Discharge \\
\hline \multirow{2}{*}{ LSI-USP } & Laboratorio de Sistemas Integrados da Universidade de São \\
\hline & Paulo \\
\hline MOS & Metal-Oxide-Semiconductor \\
\hline MOSFET & Metal-Oxide-Semiconductor Field Transistors \\
\hline PTAT & Proportional to Absolute Temperature \\
\hline $\mathrm{RF}$ & Radio Frequencia \\
\hline RDIFFN & Resistor fabricado com camada de difusão N \\
\hline RDIFFP & Resistor fabricado com camada de difusão $P$ \\
\hline RNWELL & Resistor fabricado com poço $\mathrm{N}$ \\
\hline RPOLYH & $\begin{array}{l}\text { Resistor fabricado com camada de silício policristalino de } \\
\text { alta resistividade }\end{array}$ \\
\hline RPOLY & Resistor fabricado com camada de silício policristalino \\
\hline RPOLY2 & Resistor fabricado com camada de silício policristalino \\
\hline TBJ ou BJT & Transistor Bipolar de Junção \\
\hline TC & Temperature Coefficient \\
\hline TCR & Temperature Coefficient Resistence \\
\hline $\mathrm{tm}$ & Typical Mean Condition \\
\hline wp & Worst Case Power Condition \\
\hline ws & Worst Case Speed Condition \\
\hline
\end{tabular}




\section{LISTA DE SIMBOLOS}

\begin{tabular}{|c|c|}
\hline A & Área da junção base emissor \\
\hline$\beta$ & Fator de ganho do transistor MOS \\
\hline $\mathrm{C}$ & Constante para determinar a mobilidade \\
\hline c & $4-\eta$ \\
\hline Cdb & Capacitância parasita entre dreno/substrato \\
\hline Csb & Capacitância parasita entre fonte/substrato \\
\hline $\bar{D}$ & Constante de difusão efetiva dos portadores minoritários na base \\
\hline $\mathrm{D}_{1}$ & Transistor bipolar conectado como diodo \\
\hline $\mathrm{D}_{2}$ & Transistor bipolar conectado como diodo \\
\hline $\mathrm{G}$ & Ganho \\
\hline $\mathrm{I}_{1}$ & Corrente através dos transistores $M_{1}$ e $M_{3}$ \\
\hline $\mathrm{I}_{2}$ & Corrente através dos transistores $\mathrm{M}_{2}$ e $\mathrm{M}_{4}$ \\
\hline $\mathrm{I}_{5}$ & Corrente de dreno do transistor $\mathrm{M}_{5}$ \\
\hline $\mathrm{I}_{\mathrm{C}}$ & Corrente de Coletor \\
\hline $\mathrm{I}_{\mathrm{D}}$ & Corrente de dreno \\
\hline $\mathrm{I}_{\mathrm{DO}}$ & Corrente característica do transistor em inversão fraca \\
\hline $\mathrm{I}_{\mathrm{S}}$ & Corrente de saturação \\
\hline $\mathrm{k}$ & Constante de Boltzmann \\
\hline $\mathrm{L}$ & Comprimento do canal do transistor MOS \\
\hline M & Transistor MOS \\
\hline $\mathrm{M}_{\mathrm{S}}$ & Transistor de start-up do circuito bandgap \\
\hline $\mathrm{n}$ & Fator de slope do transistor MOS \\
\hline$\eta$ & Coeficiente de temperatura para a mobilidade \\
\hline NB & Número Gummel \\
\hline ni & Concentração intrínseca de portadores \\
\hline$q$ & Carga do elétron \\
\hline Q & Transistor Bipolar Vertical Parasitário \\
\hline $\mathrm{R}$ & Resistor \\
\hline S & Relação entre a largura e o comprimento do canal transistor (W/L) \\
\hline $\mathrm{T}$ & Temperatura \\
\hline $\mathrm{T}_{\mathrm{R}}$ & Temperatura de Referência \\
\hline $\mathrm{U}_{\mathrm{T}}$ & Tensão térmica \\
\hline $\mathrm{V}_{\mathrm{BE}}$ & Tensão base-emissor de um transistor Bipolar \\
\hline $\mathrm{V}_{\mathrm{C}}$ & Tensão de controle do circuito \\
\hline $\mathrm{V}_{\mathrm{D}}$ & Tensão sobre o diodo \\
\hline $\mathrm{V}_{\mathrm{DD}}$ & Tensão de alimentação do circuito \\
\hline
\end{tabular}




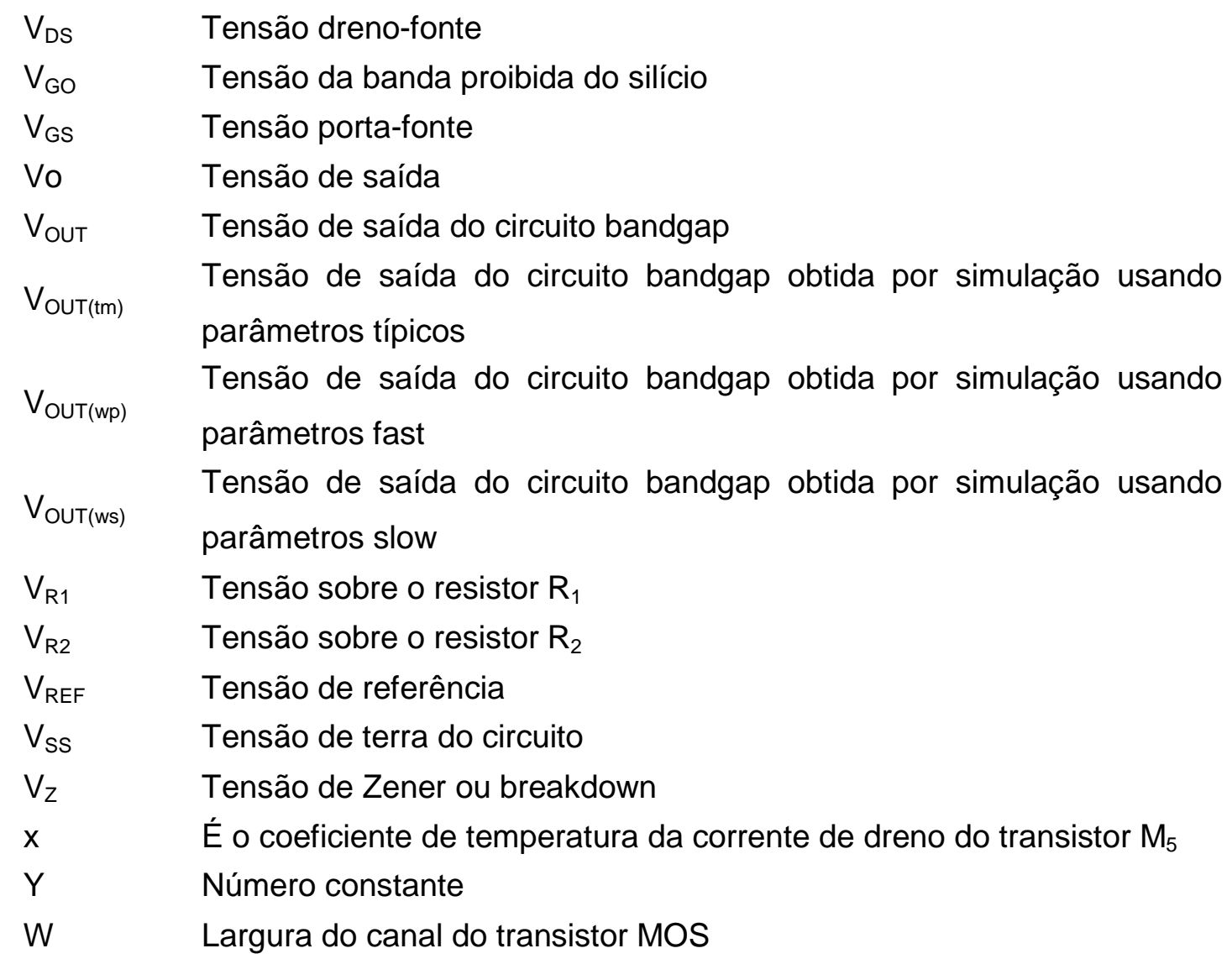




\section{RESUMO}

Este trabalho consiste no projeto de uma Fonte de Tensão de Referência CMOS com coeficiente de temperatura inferior a $50 \mathrm{ppm} /{ }^{\circ} \mathrm{C}$. Esta fonte deve ser aplicada em receptores/transmissores de radio freqüência mas pode também ser utilizada em qualquer sistema analógico. A tecnologia utilizada foi a CMOS 0,35 $\mu \mathrm{m}$ da AMS (Austria Micro Systems) com quatro níveis de metal e dois de silício policristalino.

A fonte de tensão implementada é do tipo Bandgap e utiliza dispositivos MOS em inversão fraca, um transistor bipolar parasitário e resistores de silício policristalino de alta resistividade. No circuito é produzida uma tensão PTAT (Proportional to Absolute Temperature) que somada a tensão base-emissor do transistor bipolar resulta numa tensão de saída independente da temperatura.

O projeto e o desenho do layout desta fonte foram realizados. A partir do layout foram gerados netlists para simulações realizadas utilizando o software ELDO com o modelo MOS BSIM3v3, nas condições de operação típicas, worst speed e worst power. Através destas simulações verificou-se que o circuito atendia as especificações iniciais. O valor da tensão de saída, no entanto, apesar de estar próximo do valor desejado de $1,25 \mathrm{~V}$, variou com as condições de simulação empregadas.

Dois circuitos Bandgap diferentes foram enviados para fabricação: um circuito com resistores integrados (dimensões de $220 \mu \mathrm{m}$ x $76 \mu \mathrm{m}$ ) e outro sem os resistores (dimensões de $190 \mu \mathrm{m}$ x $36 \mu \mathrm{m}$ ). Este último permite, com o ajuste do valor dos resistores colocados externamente, modificar, se necessário, as condições de operação do circuito. Os circuitos foram caracterizados obtendo-se para o circuito com resistores integrados um coeficiente de temperatura inferior à $40 \mathrm{ppm} /{ }^{\circ} \mathrm{C}$, taxa de variação da saída com a tensão de alimentação próxima de $19 \mathrm{mV} / \mathrm{V}$. O valor da tensão de saída a $50{ }^{\circ} \mathrm{C}$ esteve entre $1,1835 \mathrm{~V}$ e $1,2559 \mathrm{~V}(1,25 \mathrm{~V} \pm 67 \mathrm{mV})$. Para o circuito sem os resistores integrados, obteve-se um coeficiente de temperatura que chegou à $90 \mathrm{ppm} /{ }^{\circ} \mathrm{C}$, taxa de variação da saída com a tensão de alimentação inferior à $28 \mathrm{mV} / \mathrm{V}$. $\mathrm{O}$ valor da tensão de saída a $50^{\circ} \mathrm{C}$ esteve entre $1,247 \mathrm{~V}$ e $1,2588 \mathrm{~V}$ 
$(1,25 \mathrm{~V} \pm 9 \mathrm{mV})$. A faixa de temperatura utilizada para as medidas foi de $-30{ }^{\circ} \mathrm{C}$ a $100{ }^{\circ} \mathrm{C}$.

O consumo de corrente dos circuitos é de aproximadamente $14 \mu \mathrm{A}$ e seu funcionamento é garantido para tensões de alimentação tão baixas quanto $1,8 \mathrm{~V}$. 


\section{ABSTRACT}

This work consists in the design of a CMOS Voltage Reference Source with a temperature coefficient inferior to $50 \mathrm{ppm} /{ }^{\circ} \mathrm{C}$. This voltage source should be applied in radio frequency receptor/transmitter but can be also applied in any analog system. The technology employed in the design is the CMOS $0.35 \mu \mathrm{m}$ from the AMS (Austria Micro Systems) with four metal levels and two poly-silicon levels.

The implemented voltage source is of the Bandgap type and uses MOS devices in weak inversion, a parasitic bipolar transistor, and resistors made with high resistive poly-silicon. The circuit produces a PTAT (Proportional to Absolute Temperature) voltage that is added to the bipolar transistor base-emitter voltage to build an output voltage independent of temperature.

The project and the drawing of the layout of the circuit had been carried out. The netlists of the circuit were generated from the layout and they were employed in simulations done with the software ELDO and the BSIM3v3 MOS model, in typical, worst speed, and worst power conditions. Through these simulations it was verified that the circuit reached the initial specifications. The value of the output voltage, however, although being next to the desired value of $1.25 \mathrm{~V}$, varied with the employed simulation conditions.

Two different Bandgap circuits had been sent to the foundry: a circuit with integrated resistors (dimensions of $220 \mu \mathrm{m} \times 76 \mu \mathrm{m}$ ) and another one without the resistors (dimensions of $190 \mu \mathrm{m} \times 36 \mu \mathrm{m}$ ). This last one allows, with the adjustment of external resistor values, modifying, if necessary, the operation conditions of the circuit. The circuits had been characterized and the circuit with integrated resistors has a temperature coefficient inferior to $40 \mathrm{ppm} /{ }^{\circ} \mathrm{C}$, an output variation rate with the power supply close to $19 \mathrm{mV} / \mathrm{V}$. The output voltage value at $50{ }^{\circ} \mathrm{C}$ is between 1.1835 $\mathrm{V}$ and $1.2559 \mathrm{~V}(1.25 \mathrm{~V} \pm 67 \mathrm{mV})$. The circuit without the resistors has a temperature coefficient as high as $90 \mathrm{ppm} /{ }^{\circ} \mathrm{C}$, an output variation rate with the power supply inferior to $28 \mathrm{mV} / \mathrm{V}$. The output voltage value at $50{ }^{\circ} \mathrm{C}$ is between $1.247 \mathrm{~V}$ and $1.2588 \mathrm{~V}(1.25 \mathrm{~V} \pm 9 \mathrm{mV})$. The temperature range used in the measurements was from $-30{ }^{\circ} \mathrm{C}$ to $100{ }^{\circ} \mathrm{C}$. 
The current consumption of the circuits is approximately of $14 \mu \mathrm{A}$, and they operate with power supply voltages as low as $1.8 \mathrm{~V}$. 


\section{INTRODUÇÃO}

\subsection{Motivação}

Nas ultimas décadas a indústria eletrônica tem sido um dos principais propulsores do desenvolvimento tecnológico experimentado. Uma das áreas responsáveis pelo destaque desta indústria é a microeletrônica, que tem possibilitado a fabricação de sistemas complexos com milhões de transistores em um mesmo circuito integrado (C.I.) [1].

Dentro da industria de microeletrônica, a tecnologia CMOS (Complementary Metal-Oxide-Semiconductor) tem sido, nos últimos anos, e continuará a ser, nos próximos, a mais importante [2] devido às diversas vantagens que proporciona, tais como: baixo consumo de potência, elevado nível de integração, simplicidade de projeto e menor custo.

Nas demandas atuais por produtos/circuitos eletrônicos várias tendências são encontradas e entre elas a de redução das dimensões, do custo e do consumo de potência. Uma forma de reduzir dimensões, custos e mesmo consumo é justamente integrar um número maior de dispositivos e funções num mesmo C.I., combinando, se necessários circuitos digitais e analógicos.

Uma das funções quase sempre necessárias para os circuitos analógicos é o gerador de referência, usado na polarização de diversos blocos. Este circuito deve ser capaz de fornecer uma tensão, ou corrente, de saída que apresente pequena sensibilidade às variações na temperatura e na tensão de alimentação. Os circuitos capazes de fornecer tensões estáveis com variações na temperatura e na tensão de alimentação são conhecidos como Fontes de Tensão de Referência [3].

A idéia básica por traz do circuito conhecido como bandgap, largamente utilizado em fontes de tensão de referência, foi introduzido por Widlar em 1971 [4]. Atualmente, existem inúmeras versões deste circuito [5] [6], muitas delas utilizando a tecnologia CMOS. Este tipo de circuito tem como característica gerar uma tensão constante e independente da temperatura e da tensão de alimentação, com um valor de aproximadamente $1,2 \mathrm{~V}$, que é a diferença de potencial da banda proibida do silício extrapolada para $0 \mathrm{~K}$ [7]. 
A estabilidade com a temperatura no circuito bandgap é baseada no fato da tensão base-emissor $\left(\mathrm{V}_{\mathrm{BE}}\right)$ de um transistor Bipolar ser composta por um termo constante e bem definido $\left(\mathrm{V}_{\mathrm{GO}}\right)$, por um termo que decresce de forma linear com a temperatura (Proporcional à Temperatura Absoluta - (Proportional to Absolute Temperature - PTAT) e, por fim, por outros termos de ordem superior [8]. Para obter uma tensão estável com a temperatura adiciona-se a $\mathrm{V}_{\mathrm{BE}}$ uma tensão de correção que possua um termo que cresça de forma linear com a temperatura. Com isso é possível cancelar a componente linear de $\mathrm{V}_{\mathrm{BE}}$; por outro lado os termos de ordem superior, não lineares, restam sem serem canceladas pois isto exigiria um circuito complexo [9]. Esse cancelamento dos termos lineares é, no entanto, suficiente para a maior parte das aplicações.

Para manter a saída estável com a tensão de alimentação são utilizadas técnicas conhecidas como auto polarização (self biasing). Um exemplo de circuito auto polarizado ocorre quando a entrada de um espelho de corrente (porta dos transistores) é ligada à saída de uma fonte de corrente e a entrada dessa fonte de corrente é ligada à saída daquele espelho de corrente. Considerando-se que o loop de realimentação tenha um ponto de operação estável, então, as correntes neste circuito apresentarão uma baixa sensibilidade à tensão de alimentação [6].

\subsection{Objetivos}

O principal objetivo deste trabalho é o estudo e projeto de uma fonte de tensão de referência completamente integrada na tecnologia CMOS de 0,35 $\mu \mathrm{m}$ da AMS (Austria Micro Systems) que apresenta quatro níveis de metal e dois níveis de silício policristalino. A princípio a fonte será utilizada em sistemas receptores/transmissores para comunicação RF (rádio freqüência) desenvolvidos dentro do Laboratório de Sistemas Integrados (LSI-USP), mas pode também ser aplicada em qualquer outro sistema. Deseja-se baixa sensibilidade, menor que $50 \mathrm{ppm} /{ }^{\circ} \mathrm{C}$, na tensão de saída com relação a variações de temperatura entre $-30{ }^{\circ} \mathrm{C}$ e $100{ }^{\circ} \mathrm{C}$ e a variações da tensão de alimentação de $3,3 \mathrm{~V}$.

O trabalho foi realizado passando-se pelas seguintes etapas: 
- Estudo das arquiteturas de circuitos fontes de tensão de referência; escolha da arquitetura adequada; estudo do comportamento elétrico do circuito;

- Projeto e implementação do layout; simulação elétrica do circuito extraído;

- Envio do circuito para fabricação através da foundry (AMS);

- Realização de testes experimentais para verificar os requisitos de precisão da fonte de tensão de referência.

\subsection{Descrição dos capítulos do trabalho}

A dissertação foi divida em seis capítulos. No primeiro capítulo são descritos, de forma geral, a importância do estudo de circuitos geradores de tensão de referência, as motivações e os objetivos do trabalho.

O segundo capítulo apresenta a base teórica deste trabalho e uma revisão bibliográfica. Inicia com os aspectos gerais de circuitos geradores de tensão de referência e de polarização. A seguir, no terceiro capítulo, são definidas as especificações iniciais para o projeto, é explicado o funcionamento básico da arquitetura escolhida e, por fim, é escolhido o tipo de transistor bipolar utilizado.

No capítulo quatro é apresentado o projeto do circuito escolhido e detalhadas algumas partes do seu layout. $\mathrm{O}$ procedimento e o resultado dos testes experimentais do circuito, para variações tanto da temperatura como da tensão de alimentação, estão descritos no capítulo cinco.

As conclusões e as sugestões para trabalhos futuros são apresentadas, por fim, no capítulo seis. 


\section{ASPÉCTOS TEÓRICOS}

Os circuitos de tensão de referência são blocos importantes em sistemas analógicos ou analógicos/digitais. Um exemplo de sua aplicação pode ser visto na Figura 1 que apresenta um sistema com conversores de Analógico/Digital (A/D) e Digital/Analógico (D/A). Neste sistema é utilizada mais de uma fonte de tensão de referência, devido às diferentes necessidades de cada bloco e aos possíveis problemas com crosstalk [10]: há uma fonte utilizada no bloco de gerenciamento de energia (power-management) que inclui conversores DC-DC e que disponibiliza tensões estáveis; uma fonte utilizada pelos conversores $\mathrm{A} / \mathrm{D}$; outra fonte utilizada pelo conversor D/A. As fontes utilizadas pelos conversores servem para fornecer valores de referência e quaisquer variações na saída delas, seja com a temperatura ou com a alimentação, afetam a precisão dos blocos conversores [11].

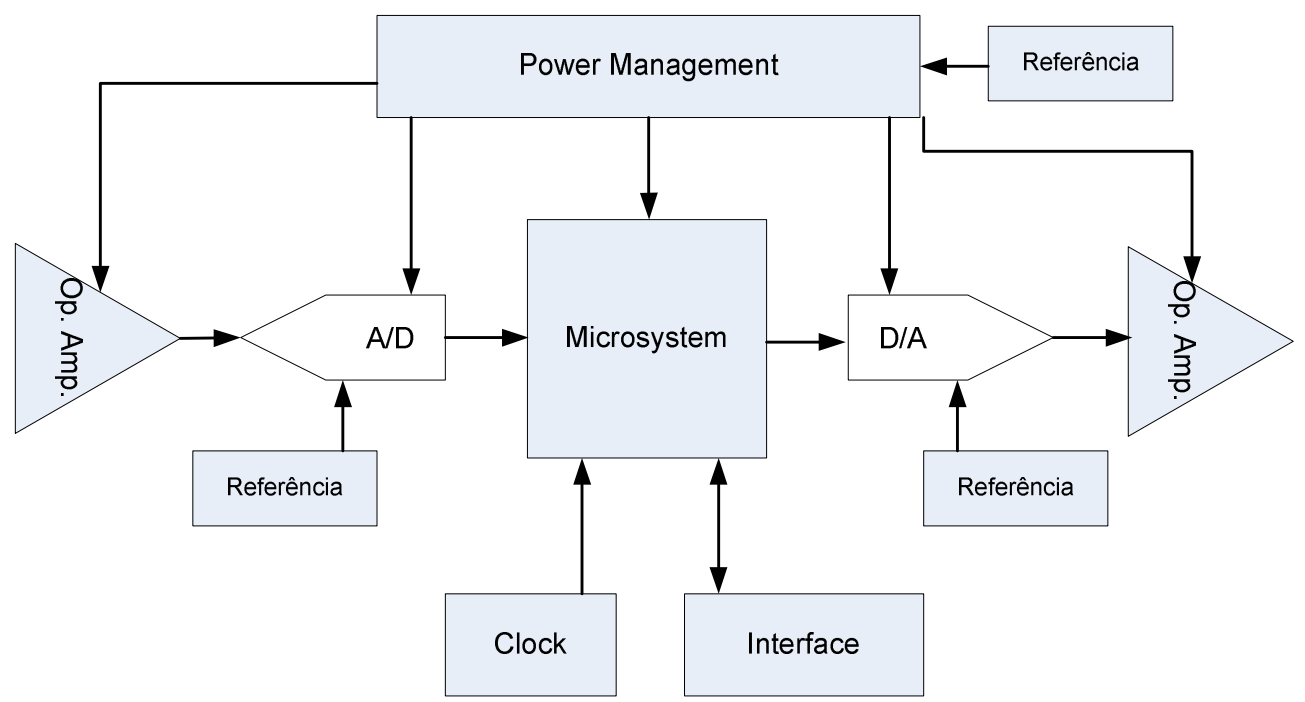

Figura 1. Exemplo de um sistema de sinal misto.

O circuito deste trabalho deverá ser utilizado em receptores RF ou em quaisquer outros sistemas desenvolvidos com a tecnologia empregada aqui.

Para se obter o melhor resultado foram pesquisadas diferentes topologias de circuito e analisadas suas vantagens e desvantagens. Diversos fatores devem ser considerados na escolha do circuito de tensão de referência, dentre eles os que mais se destacam são: 
- como a variação na temperatura e na tensão de alimentação afetam a estabilidade;

- a área utilizada (deve ser a menor possível, para permitir uma maior integração);

- o consumo de potência;

- o excesso de ruído que limita a resolução do sistema.

Observe que a tensão de saída das fontes de referência não varia apenas com a temperatura e com a tensão de alimentação mas, também, com o tempo e com fator ambiental tal como umidade. Por isso a maioria dos conversores A/D e D/A tem referências internas adequadas somente para aplicações com resolução menor ou igual a 12 bits, mesmo que o conversor seja capaz de resoluções maiores [12].

\subsection{Arquitetura da Fonte de Referência}

Existem diversas arquiteturas de fontes de tensão de referência. Neste capítulo serão apresentadas de simples associações de resistores até circuitos complexos com diversos transistores. Dependendo do nível de estabilidade almejado, em relação tanto à temperatura quanto à tensão de alimentação de operação do circuito, uma ou outra arquitetura será mais conveniente.

Não é intuito deste trabalho descrever todas as possibilidades, por isso, nesta seção, foram apresentadas somente algumas arquiteturas, dentre estas a escolhida para o projeto.

\subsection{Divisor de Tensão Passivo/Ativo}

Um divisor de tensão passivo pode ser implementado através de uma simples associação de resistores em série. A queda de tensão nos resistores é utilizada para produzir a tensão desejada; para se obter diferentes níveis de tensão de saída basta conectar $\mathrm{N}$ resistores em série entre $V_{D D}$ e $V_{S S}$ [13] (Figura 2). Em um circuito integrado os resistores podem ser construídos na camada de difusão, de poço ou, preferencialmente, de silício policristalino. 


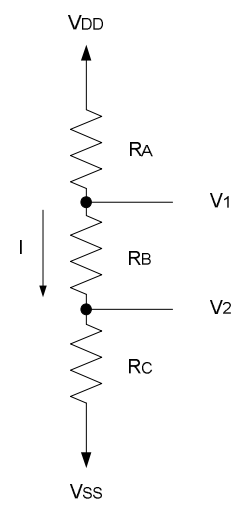

Figura 2. Divisor de tensão passivo.

Um divisor de tensão ativo utiliza resistores ativos no lugar de resistores passivos para produzir uma queda de tensão. Um resistor ativo pode ser obtido conectando-se a porta de um transistor MOS ao seu dreno. Neste caso a tensão $V_{D S}$ passa a controlar a corrente $I_{D}$ e o canal de transcondutância torna-se um canal de condutância [13]. Estes transistores quando agrupados em série, como na Figura 3, são utilizados para se obter um divisor de tensão ativo.

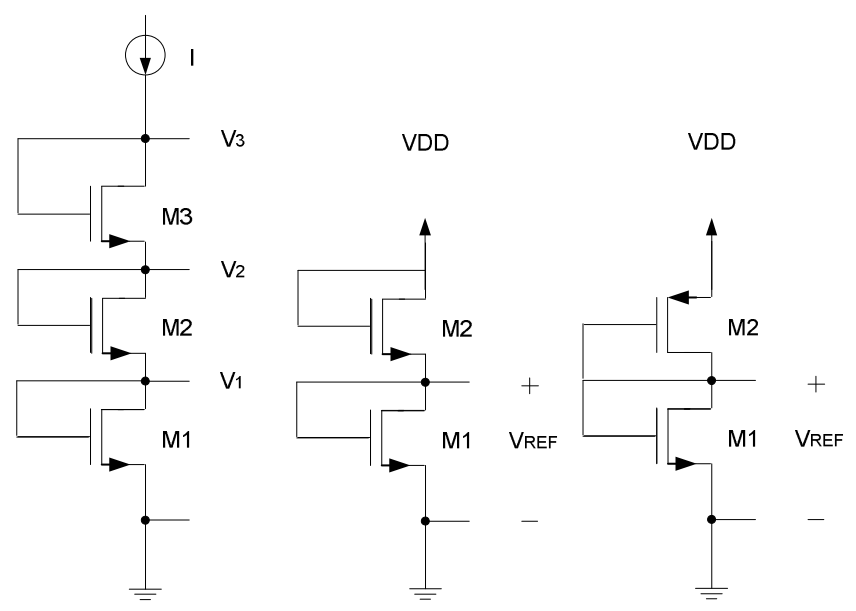

Figura 3. Divisor de tensão ativo.

\subsection{Tensão de Referência com Junção p-n Reversamente Polarizada}

Esta é uma forma simples de se obter uma tensão de referência, com características relativamente boas. Neste circuito utiliza-se um diodo que opera reversamente polarizado. A equação abaixo, que descreve o funcionamento do diodo, mostra que a corrente que passa por ele, $I_{D}$, cresce rapidamente quando o dispositivo está diretamente polarizado, $\left(V_{D}>0\right)$. 
$I_{D}=I_{S}\left[\exp \left(\frac{V_{D}}{n U_{T}}\right)-1\right]$

onde $I_{S}$ é a corrente de saturação, $V_{D}$ é a tensão sobre o diodo, n é um fator de idealidade (constante dependente do processo) e $U_{T}$ é a tensão térmica:

$U_{T}=\frac{k T}{q}$

onde k é a constante de Boltzmann, T é a temperatura absoluta em Kelvin e q é a carga elétrica do elétron.

Por outro lado, quando é polarizado reversamente, $V_{D}<0$, sua corrente será praticamente constante e muito pequena $\left(I_{S}\right)$. Se a tensão $V_{D}$ é continuamente reduzida, ocorrerá o aumento significativo da corrente $I_{D}$ (o que não é modelado pela equação acima) quando $V_{D}$ atinge uma tensão limite $\left(-V_{Z}\right)$ teremos o chamado breakdown.

Dependendo do valor do campo elétrico ao qual uma junção p-n é submetida, quando polarizada reversamente, podem ocorrer dois fenômenos diversos que causam o aumento da corrente: a multiplicação por avalanche e o efeito de tunelamento [14]. A multiplicação por avalanche é devido à colisão dos portadores livres, com alta energia cinética obtida pelo efeito do campo elétrico, com a rede cristalina. Em consequiência, ligações covalentes são quebradas resultando no aparecimento de novos portadores que também ganharão energia, colidirão, e formarão novos portadores. O resultado final é a elevação da corrente. O efeito de tunelamento ocorre quando o campo elétrico na junção é tão intenso que a energia de um elétron situado numa posição x e na banda de valência está próxima da energia de um elétron situado numa posição $x+\Delta x$, com $\Delta x$ pequeno, mas na banda de condução. Como elétrons têm comportamento ondulatório, o elétron que esta na posição $\mathrm{x}$ pode, com probabilidade não nula e proporcional a $1 / \Delta x$, surgir na posição $x+\Delta x$ e aí sua energia será suficiente para que ele passe à banda de condução. Assim se criam pares de portadores elétron-lacuna que causarão o aumento da corrente.

A multiplicação por avalanche ocorre em tensões de polarização reversa de cerca de $7 \mathrm{~V}$ ou mais e possui um coeficiente de temperatura positivo (avalanche diminui com a temperatura). Já o efeito de tunelamento ocorre em tensões de 
polarização reversa de cerca de $5 \mathrm{~V}$ ou menos e possui um coeficiente de temperatura negativo (tunelamento aumenta com a temperatura) .

Observemos que a operação de um diodo na região de breakdown pode ser destrutiva ou alterar algumas características do dispositivo. Em vista disso, é importante limitar a corrente que flui pelo diodo para prevenir danos ou alterações das suas características.

Diodos comerciais com características bem definidas de breakdown são chamados genericamente de diodos zener. Neles podem ocorrer tanto avalanche como o efeito túnel. Alguns dispositivos são construídos de forma que ambos os fenômenos, avalanche e tunelamento, ocorram simultaneamente. Com isso o efeito da temperatura, que é contrário para cada um dos fenômenos, é reduzido. Os zeners têm tensões de breakdown entre $5 \mathrm{~V}$ e $7 \mathrm{~V}$ e baixos coeficientes de temperatura.

Na figura abaixo é mostrado um exemplo de circuito de referência com zener, que é polarizado por meio de uma fonte de corrente [12]. A tensão do zener é dividida entre os resistores $R_{1}$ e $R_{2}$. Esta tensão é aplicada à entrada não inversora de um amplificador operacional, em uma configuração amplificadora, para gerar a tensão de saída. O ganho do amplificador é determinado pelos resistores $R_{3}$ e $R_{4}$ sendo dado por Ganho $=1+R_{4} / R_{3}$. A tensão de saída ficará como:

$V_{\text {OUT }}=\frac{R_{2}}{R_{1}+R_{2}}\left(1+\frac{R_{4}}{R_{3}}\right) V_{Z}$

onde $V_{Z}$ é a tensão no diodo zener.

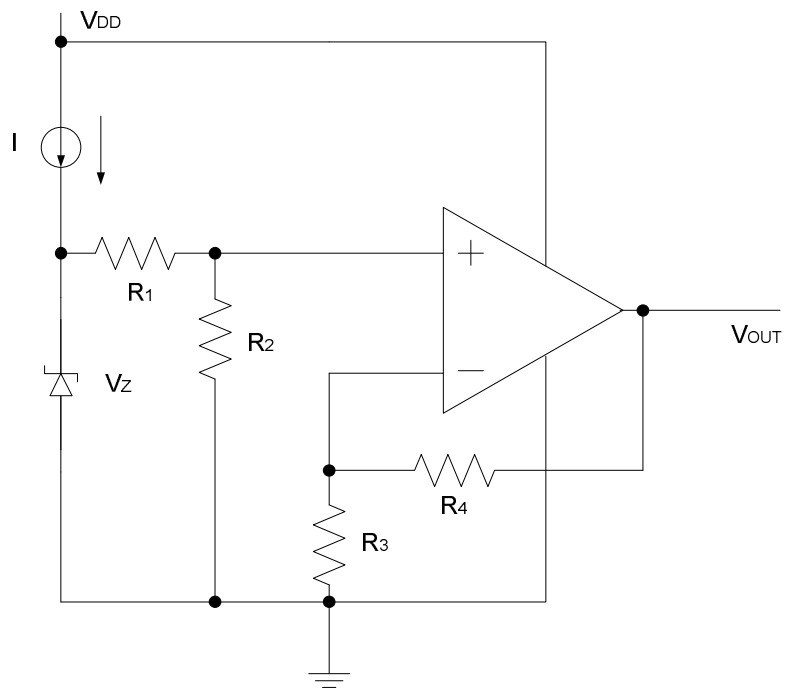

Figura 4. Exemplo de uma fonte de tensão com zener. 
Fontes de tensão de referência com zener possuem baixa sensibilidade ao ruído $(<10 \mu \mathrm{Vpp}$ em 0,1 a $10 \mathrm{~Hz})$ e um bom desempenho em relação à temperatura (1 a $10 \mathrm{ppm} /{ }^{\circ} \mathrm{C}$ ). Por outro lado, como a tensão de breakdown tem valor alto, próximo de $6 \mathrm{~V}$ [15], é também necessária uma tensão de alimentação com valor alto.

Infelizmente diodos zener são raramente disponibilizados em processos CMOS. Em contrapartida, para circuitos de referência externos, não integrados, os diodos zener estão disponíveis, formando fontes ideais para aplicações que precisam de alta resolução como, por exemplo, aplicações com conversores de 14 ou 16 bits.

\subsection{Referências Bandgap}

A fonte de tensão de referência bandgap utiliza a combinação de duas tensões com coeficientes de temperatura próximos, mas de sinais opostos como mostrada na Figura 5. Uma destas é a tensão base-emissor $\left(V_{B E}\right)$ de um transistor bipolar que possui um coeficiente de temperatura de aproximadamente $-2 \mathrm{mV} /{ }^{\circ} \mathrm{C}[5,6]$. A outra é gerada a partir da tensão térmica $U_{T}$, que possui um coeficiente de temperatura positivo, extraída, por exemplo, utilizando a tensão na junção de diodos. Multiplicando-se $U_{T}$ por uma constante $Y$, ajustada para que o produto $U_{T} Y$ tenha um coeficiente de temperatura de aproximadamente $+2 \mathrm{mV} /{ }^{\circ} \mathrm{C}$, e somando-se as tensões $V_{B E}$ e $U_{T} Y$, é possível produzir uma tensão de referência $\left(V_{R E F}\right)$ com um coeficiente de temperatura próximo a $0 \mathrm{mV} /{ }^{\circ} \mathrm{C}[5,6]$. O circuito ganhou o nome "Referência Bandgap" devido ao valor de $V_{R E F}$ ficar próximo à $V_{G O}$, a tensão de bandgap do silício extrapolada para $0 \mathrm{~K}(1,2 \mathrm{~V})[16]$. 


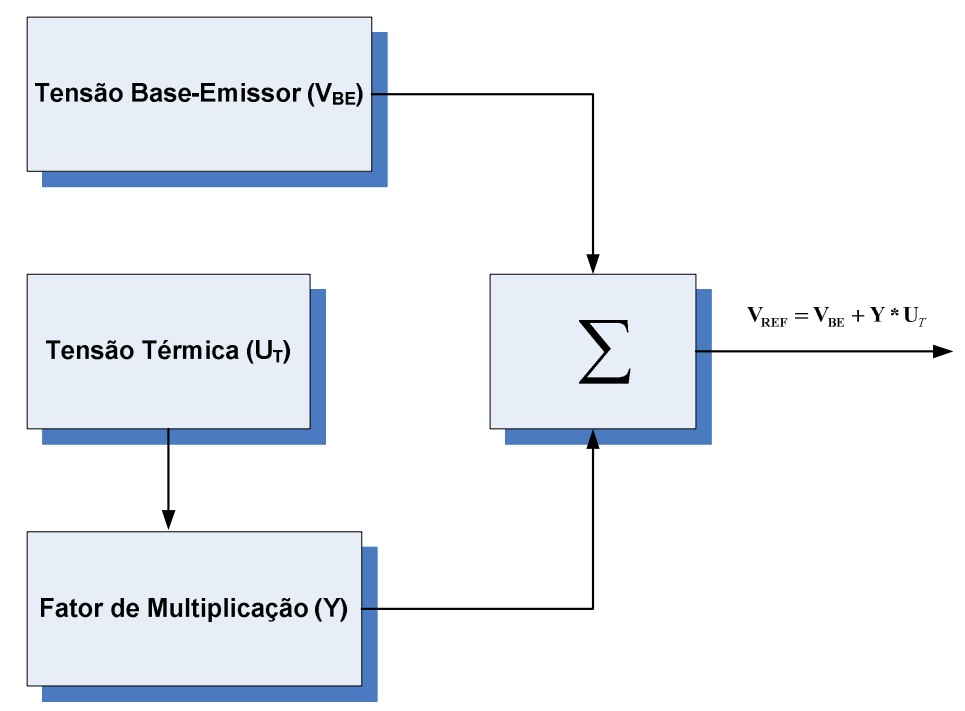

Figura 5. Diagrama de blocos de uma Referência de Tensão Bandgap.

Existem diversas arquiteturas possíveis para o circuito bandgap. Para compreender melhor o funcionamento de uma referência bandgap típica considere o circuito da Figura 6 [17], que utiliza uma arquitetura bem conhecida. Este circuito é composto por dois transistores bipolares conectados como diodo, $D_{1}$ e $D_{2}$, um amplificador operacional e três resistores, $R_{1}, R_{2}$ e $R_{3}$. A tensão de referência é gerada na saída do amplificador. Neste caso a tensão $V_{B E}$ (Figura 5) é fornecida por $D_{1}$ e a tensão $U_{T} Y$, pelo resistor $R_{2}$.

No circuito, considerando que o amplificador seja ideal (ganho diferencial infinito, resistência de entrada infinita, resistência de saída zero) e opere na região linear, teremos que as tensões nos pontos 1 e 2 são praticamente iguais. Podemos então escrever:

$I_{2} R_{2}=I_{1} R_{1}$

Como os transistores $D_{1}$ e $D_{2}$ estão conectados como diodo, suas correntes são iguais a:

$$
\begin{aligned}
& I_{1}=I_{S 1}\left[\exp \left(\frac{V_{B E 1}}{U_{T}}\right)-1\right] \\
& I_{2}=I_{S 2}\left[\exp \left(\frac{V_{B E 2}}{U_{T}}\right)-1\right]
\end{aligned}
$$

onde $V_{B E}$ é a tensão base-emissor e $I_{S}$ é a corrente de saturação do transistor bipolar. Os índices são relativos aos transistores $D_{1}$ e $D_{2}$. 
Substituindo (5) e (6) em (4) resulta em:

$\frac{R_{2}}{R_{1}}=\frac{I_{S 1}}{I_{S 2}} \exp \left(\frac{V_{B E 1}-V_{B E 2}}{U_{T}}\right)$ e, portanto, $\Delta V_{B E}=V_{B E 1}-V_{B E 2}=U_{T} \ln \left(\frac{I_{S 2} R_{2}}{I_{S 1} R_{1}}\right)$

Observe $\Delta V_{B E}$ é a tensão sobre o resistor $R_{3}$ e esta tensão é proporcional a $U_{T}$.

A tensão de saída $V_{O}$ é a soma da tensão $V_{B E l}$ com a tensão sobre $R_{2}$; como a corrente em $R_{2}$ é igual à corrente em $R_{3}$ (considerando o amplificador ideal), podemos escrever que:

$V_{O}=V_{B E 1}+R_{2} \frac{U_{T}}{R_{3}} \ln \left(\frac{R_{2} I_{S 2}}{R_{1} I_{S 1}}\right)$

Supondo que $V_{B E 1}$ é linear com a temperatura, podemos escrever que $V_{B E I}=$ $V_{G O}+C T$, onde $\mathrm{C}$ é uma constante com valor aproximado de $-2 \mathrm{mV} /{ }^{\circ} \mathrm{C}$ (uma expressão mais completa para $V_{B E}$ está no anexo A). Por fim, temos que a tensão na saída é:

$V_{O}=V_{G 0}+\left(C+R_{2} \frac{K}{q R_{3}} \ln \left(\frac{R_{2} I_{S 2}}{R_{1} I_{S 1}}\right)\right) T$

Com o adequado ajuste dos valores dos resistores podemos obter um coeficiente de temperatura para $V_{O}$ próximo de zero e, neste caso, a tensão de saída estará próxima de $V_{G 0}=1,205 \mathrm{~V}$. Esta tensão caracteriza, portanto, uma fonte de referência bem ajustada.

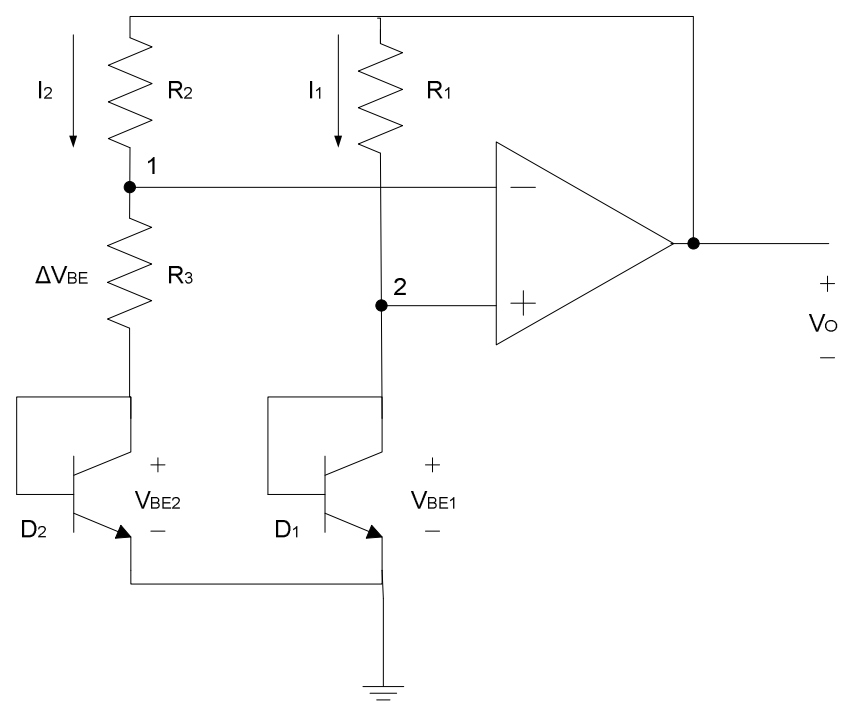

Figura 6. Circuito Bandgap clássico. 
Os circuitos de tensão de referência mais utilizados pela indústria são justamente os circuitos com diodos zener discretos e os circuitos bandgap. A tabela a seguir [15] ilustra algumas características destes dois tipos de circuitos e serve, ainda, para esclarecer suas vantagens e desvantagens na aplicação como fontes de precisão.

Tabela 1. Vantagens e desvantagens dos circuitos de tensão de referência mais utilizados.

\begin{tabular}{|c|c|}
\hline \multicolumn{2}{|c|}{ Referência Zener } \\
\hline Vantagens & Desvantagens \\
\hline Baixo ruído & Necessita de tensões de alimentação \\
acima de 5 V \\
Desvio de temperatura pequeno \\
Consumo de potência alto \\
$\begin{array}{c}\text { Excelente estabilidade a longo prazo } \\
\text { Alta Precisão }\end{array}$ & $\begin{array}{c}\text { Projeto caro pois utiliza, normalmente, } \\
\text { um componente discreto }\end{array}$ \\
\hline $\begin{array}{c}\text { Baixo consumo de potência } \\
\text { Boa precisão, que pode ser aumentada } \\
\text { por ajuste }\end{array}$ & Ruído Moderado \\
$\begin{array}{c}\text { Opera com tensões de alimentação } \\
\text { abaixo de 1 V }\end{array}$ & Dande temperatura limitado \\
\hline
\end{tabular}

$\mathrm{O}$ fato de blocos analógicos muitas vezes operarem com tensões de $3,3 \mathrm{~V}$ ou 5 V limita o emprego de fontes de tensão de referência com zener. Para sistemas com precisão máxima de 10 bits, a escolha natural para uma fonte de tensão de referência é o bandgap, que além de trabalhar com tensões mais baixas pode ser integrado em tecnologias Bipolares, BiCMOS ou mesmo CMOS típico sem a necessidade da utilização de componentes externos. Coeficientes de temperatura entre 25 - 50 $\mathrm{ppm} /{ }^{\circ} \mathrm{C}$ são obtidos com bandgaps sem dificuldades. 


\subsection{Polarização Independente da Tensão de Alimentação para Circuito} Bandgap

\subsection{Espelhos de Corrente}

Espelhos de corrente são estruturas freqüentemente usadas na polarização de circuitos analógicos. Um exemplo simples deste circuito está indicado na Figura 7. Nele o transistor $M_{1}$ está conectado como diodo (dreno e porta conectados); o transistor $M_{2}$ tem sua fonte e porta ligadas a fonte e porta do transistor $M_{l}$. Assumindo que os dois transistores estejam operando na saturação e que a modulação de canal seja desprezível, podemos escrever que a corrente de dreno nos transistores $M_{1}$ e $M_{2}$ é:

$I_{D 1}=I_{I N}=\frac{k^{\prime}}{2} \frac{W_{1}}{L_{1}}\left(V_{G S_{1}}-V_{t}\right)^{2}$ e $I_{D 2}=I_{O U T}=\frac{k^{\prime}}{2} \frac{W_{2}}{L_{2}}\left(V_{G S_{2}}-V_{t}\right)^{2}$

onde k' é um parâmetro de transcondutância que é proporcional a mobilidade e a capacitância de porta do transistor, $W$ é a largura do canal do transistor, $L$ é o comprimento do canal do transistor, $V_{G S}$ a tensão porta-fonte e $V t$ a tensão de limiar do transistor. Os índices são relativos aos transistores $M_{1}$ e $M_{2}$.

Dada a configuração do espelho de corrente temos que $V_{G S I}=V_{G S 2}$ e, portanto:

$I_{\text {OUT }}=I_{D 2}=\frac{(W / L)_{2}}{(W / L)_{1}} I_{D 1}=\frac{(W / L)_{2}}{(W / L)_{1}} I_{I N}$

Esta expressão mostra que a corrente de saída do espelho de corrente, $I_{O U T}$, está relacionada com a corrente de entrada, $I_{I N}$, por um fator igual razão entre a relação geométrica $(W / L)$ dos transistores que compõe o espelho. Espelhos de corrente têm, numa estrutura para polarização, a função geral de replicar e distribuir correntes. 


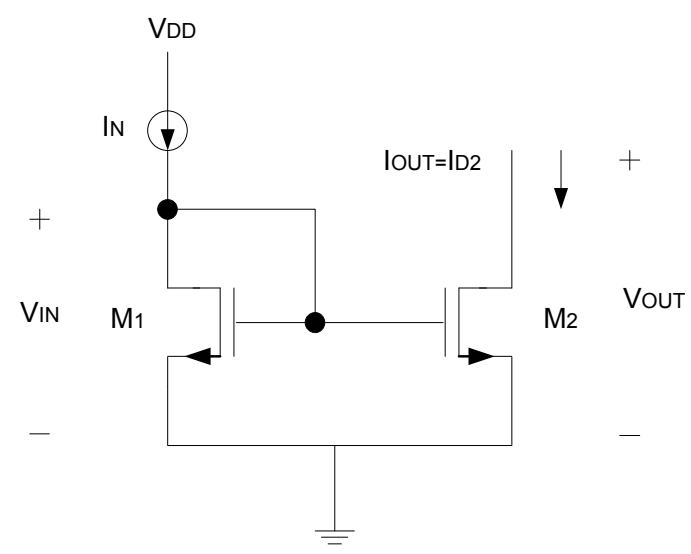

Figura 7. Espelho de corrente MOS simples.

\subsection{Auto polarização}

A sensibilidade, nas fontes de tensão, em relação à tensão de alimentação depende em boa parte da sensibilidade do seu circuito de polarização. Para reduzir esta dependência pode-se utilizar a técnica de auto-polarização. A Figura 8 ilustra esta técnica através do circuito de referência de corrente proposto por Vittoz [7].

Este circuito de referência consiste de quatro transistores e um resistor (o transistor PMOS $M_{5}$, serve apenas espelhar correntes para saída). Os dois transistores PMOS $\left(M_{1}\right.$ e $\left.M_{2}\right)$ formam um espelho de corrente que força correntes iguais a um par de transistores NMOS $\left(M_{3}\right.$ e $\left.M_{4}\right)$. Estes transistores NMOS e o resistor formam um circuito equivalente a fonte de corrente de Widlar [4] que força, por sua vez, outro valor de corrente aos transistores PMOS, formando uma realimentação. Este circuito realimentado estabiliza para certo valor de corrente que depende das relações geométricas dos transistores $M_{1}, M_{2}, M_{3}$, e $M_{4}$ e do valor da resistência. O ponto de estabilização do circuito não depende, a princípio, da tensão de alimentação $V_{D D}$.

Observemos que para o correto funcionamento do circuito os transistores NMOS da fonte equivalente de Widlar devem operar na região chamada de inversão fraca.

Costuma-se separar a operação do transistor MOS em três regiões, de acordo com a densidade de portadores presentes no canal formado sob o terminal de porta. São elas: 
- Região de Inversão Forte - ocorre quando a tensão porta-dreno, $V_{G S}$, é suficiente para formar um canal com concentração de portadores maior ou igual à concentração inicial de portadores do substrato;

- Região de Inversão Fraca - o transistor é polarizado no limiar da condução $\left(V_{G S} \approx V_{T}\right)$. Nesta situação o canal tem concentração de portadores inferior à concentração de portadores inicial do substrato;

- Região de Inversão Moderada - é uma região de transição entre a inversão forte e a inversão fraca. Esta região é mal definida e por isso de difícil modelamento.

Para determinar qual a região de operação do transistor será utilizada a relação [18] abaixo:

$$
0,125>\quad \frac{I_{D}}{\beta 2 n\left(U_{T}\right)^{2}} \quad>10
$$

Inversão fraca

Inversão forte

onde $\beta=\frac{W}{L} \mu C_{O X}$ é o fator de ganho do transistor MOS, $\mu$ é a mobilidade dos portadores no canal, $C_{O X}$ é a capacitância por área na estrutura porta-óxido-substrato, $W$ e $L$ são o comprimento e a largura do canal do transistor $(W / L), n$ é o fator slope e $U_{T}$ é tensão térmica.

Esta relação nos mostra que a região de operação depende dos valores da corrente de dreno, dos parâmetros geométricos $(W / L)$, da mobilidade, etc. Apenas corrente e os parâmetros geométricos do transistor podem ser modificados pelo projetista, mas são suficientes para controlar o seu estado [18]. Os outros parâmetros são dependentes do processo e fixos.

Utilizaremos a equação abaixo para descrever a curva $I-V$ de um transistor canal $\mathrm{N}$ na inversão fraca:

$$
I_{D}=S I_{D O} e^{V_{G} / n U_{T}}\left(e^{-V_{S} / U_{T}}-e^{-V_{D} / U_{T}}\right)
$$

onde $I_{D}$ é a corrente de dreno, $I_{D O}$ é uma corrente característica da tecnologia; $n$ é o fator slope; $S$ é a relação entre a largura e o comprimento do canal do transistor $(W / L) ; V_{G}, V_{D}, V_{S}$ e $U_{T}$ são respectivamente as tensões de porta-substrato, drenosubstrato, fonte-substrato e térmica. 
Este modelo de inversão fraca é válido quando as seguintes condições forem obedecidas [6]:

- O canal é longo o suficiente, de modo que a aproximação gradual de canal possa ser utilizada e os efeitos de modulação do comprimento de canal possam ser desprezados;

- As correntes geradas nas regiões de carga espacial associadas às regiões de fonte, dreno e porta são desprezíveis;

- A densidade dos estados de superfície rápidos e as flutuações do potencial de superfície são desprezíveis.

- A tensão porta-fonte é suficiente para formar um canal mas a concentração de portadores nele é inferior à concentração inicial de portadores do substrato.

Normalmente o valor de $\mathrm{V}_{\mathrm{D}}$ é muito maior que $\mathrm{U}_{\mathrm{T}}$, o que fará com que a expressão acima seja reduzida a

$I_{D}=S I_{D O} e^{V_{G} / n U_{T}}\left(e^{-V_{S} / U_{T}}\right)$.

Vamos determinar o valor da corrente $I_{D 1}$ estável no circuito da Figura 8 e que é espelhada para a saída $I_{\text {OUT }}$. Para isso primeiro achemos a tensão no resistor $R$. Para os transistores NMOS, que devem estar em inversão fraca, utilizamos a equação (13) para corrente. Assim podemos escrever que:

$I_{D 1}=I_{D 3}=I_{D O}\left(\frac{W_{3}}{L_{3}}\right) e^{\left(\frac{V_{G 3}}{n U_{T}}-\frac{V_{S 3}}{U_{T}}\right)}=I_{D O} S_{3} e^{\left(\frac{V_{G 3}}{n U_{T}}-\frac{V_{S 3}}{U_{T}}\right)}$

$\mathrm{e}$

$$
I_{D 2}=I_{D 4}=I_{D O}\left(\frac{W_{4}}{L_{4}}\right) e^{\left(\frac{V_{G 4}}{n U_{T}}\right)}=I_{D O} S_{4} e^{\left(\frac{V_{G 4}}{n U_{T}}\right)}
$$

onde, $I_{D 1}, I_{D 2}, I_{D 3}$ e $I_{D 4}$ são as correntes de dreno dos transistores $M_{1}, M_{2}, M_{3}$ e $M_{4}$ respectivamente, $V_{G 3}$ e $V_{G 4}$ são as tensões de porta dos transistores $M_{3}$ e $M_{4}, V_{S 3}$ é a tensão fonte-substrato do transistor $M_{3}$ e $S_{3}$ e $S_{4}$ é a relação (W/L) dos transistores $M_{3}$ e $M_{4}$.

Pela Figura 8 podemos ver que as tensões de porta dos transistores $M_{3}$ e $M_{4}$ são iguais, ou seja $V_{G 3}=V_{G 4}$, e que a tensão fonte-substrato do transistor $M_{3}$ é igual à queda de tensão sobre o resistor $R$, ou seja $V_{S 3}=V_{R}$. Assim teremos 
$\frac{I_{D 2}}{I_{D 1}}=\frac{I_{D 4}}{I_{D 3}}=\frac{S_{4} I_{D O} e^{\left(\frac{V_{G 4}}{n U_{T}}\right)}}{S_{3} I_{D O} e^{\left(\frac{V_{G 3}}{n U_{T}}-\frac{V_{R}}{U_{T}}\right)}}=\frac{S_{4}}{S_{3}} e^{\left(\frac{V_{G 4}}{n U_{T}}-\frac{V_{G 3}}{n U_{T}}+\frac{V_{R}}{U_{T}}\right)}=\frac{S_{4}}{S_{3}} e^{\left(\frac{V_{R}}{U_{T}}\right)}$

Lembrando que as correntes de dreno dos transistores $M_{1}$ e $M_{2}$ são iguais devido aos transistores PMOS iguais, temos que:

$\frac{S_{4}}{S_{3}} e^{\left(\frac{V_{R}}{U_{T}}\right)}=1$

Isolando $V_{R}$ obtemos a equação desejada:

$V_{R}=U_{T}\left[\ln \left(\frac{S_{3}}{S_{4}}\right)\right]$

Veja que esta tensão é proporcional a $U_{T}$, fato que será utilizado no circuito de referência implementado [6], e independente da tensão de alimentação. A corrente $I_{D I}$ por fim tem seu valor dado por:

$I_{D 1}=\frac{V_{R}}{R}=\frac{U_{T} \ln \left(\frac{S_{3}}{S_{4}}\right)}{R}$

Assim as correntes que passam no circuito e que serviriam para polarização de outros blocos ficam independentes, ou praticamente independentes, da tensão de alimentação e são proporcionais a tensão térmica $U_{T}$.

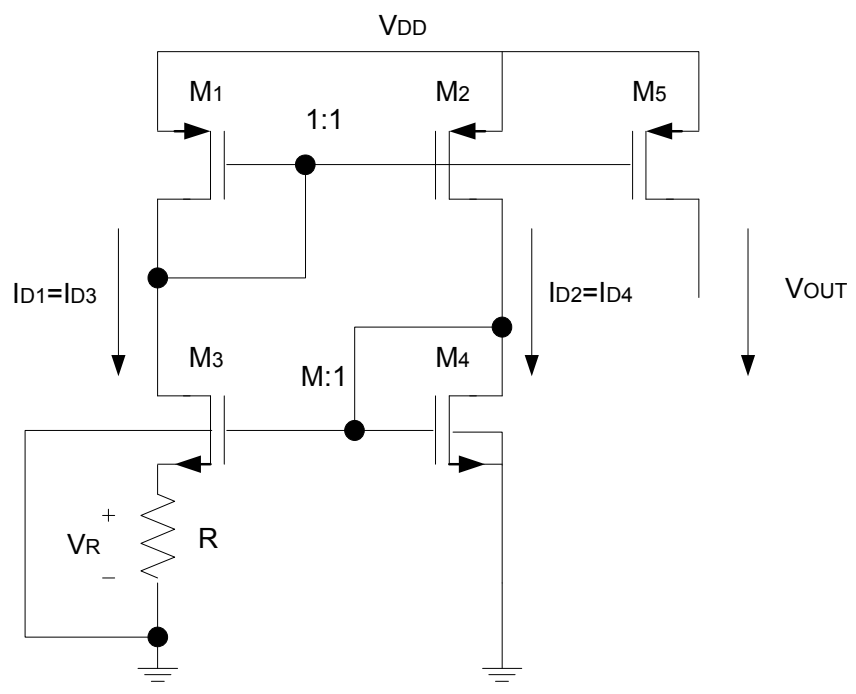

Figura 8. Circuito de referência de corrente CMOS.

É importante ressaltar que o circuito de referência operando nesta configuração possui tipicamente dois estados estáveis de corrente [19]. Através da Figura 9, que 
mostra a relação entre correntes imposta pelos pares de transistores $M_{1}-M_{2}$ e $M_{3}-M_{4}$, é possível identificar estes dois estados nos pontos A e B. No ponto B as correntes nos transistores são nulas e ele deve ser evitado.

A condição de operação desejada é indicada no ponto A da figura, onde as correntes $I_{D 3}$ e $I_{D 4}$ são iguais e diferentes de zero. Para garantir que este estado seja o real do circuito é necessário incluir uma estrutura junto aos espelhos de corrente, cuja função é forçar a circulação de correntes nos transistores durante a fase de acionamento do circuito. Esta estrutura é conhecida como circuito de start-up ou circuito de inicialização [6].

Uma característica essencial do circuito de start-up é que ele não interfira com a operação normal do circuito auto-polarizado uma vez que se tenha alcançado o ponto de operação desejado.

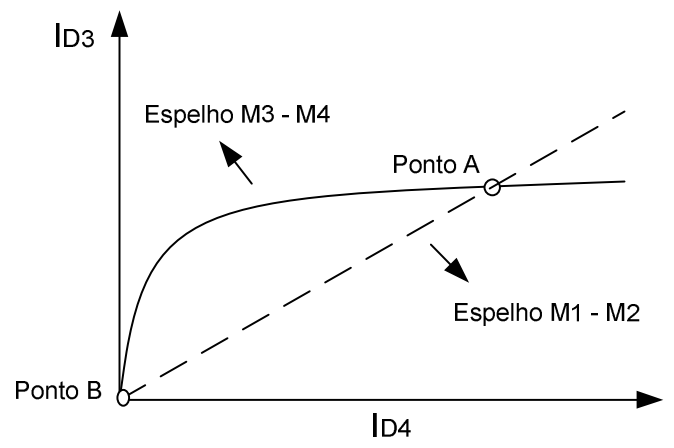

Figura 9. Pontos de operação estáveis do circuito de referência de correntes. 


\section{MÉTODO}

O objetivo principal deste trabalho é projetar um circuito de tensão de referência com pequena sensibilidade à temperatura $\left(<50 \mathrm{ppm} /{ }^{\circ} \mathrm{C}\right)$ para ser implementada numa tecnologia CMOS de $0,35 \mu \mathrm{m}$ com tensão típica para operação de $3,3 \mathrm{~V}[20]$.

\subsection{Especificações Iniciais}

Como dito anteriormente, as duas arquiteturas mais usadas na indústria são aquelas que usam diodos zener ou que usam a técnica bandgap. Comparamos estas arquiteturas e apontamos as vantagens e desvantagens de cada uma delas. Para este projeto optou-se pela arquitetura com a técnica bandgap devido à baixa tensão de alimentação utilizada, 3,3 V, e ao desejo de ter um circuito totalmente integrado.

Foi feito um levantamento dos tipos de circuitos bandgap apresentados na literatura, para se definir especificações possíveis para o circuito. De acordo com o levantamento feito e baseado no projeto do qual este trabalho faz parte foram estabelecidas as especificações iniciais dadas na Tabela 2. A temperatura de operação ou temperatura de referência $T_{R}$ será $50^{\circ} \mathrm{C}$.

Tabela 2. Especificações iniciais de projeto.

\begin{tabular}{|l|c|c|c|c|}
\hline & Min. & Tip. & Max. & Unidades \\
\hline Tensão de saída $\left(\boldsymbol{T}_{\boldsymbol{R}}=\mathbf{5 0} \mathbf{0} \mathbf{C}\right)$ & 1,10 & 1,25 & 1,40 & $\mathrm{~V}$ \\
\hline Coeficiente de Temperatura Máximo & 24 & 37 & 50 & $\mathrm{ppm} / \stackrel{\circ}{ } \mathrm{C}$ \\
\hline Tensão de alimentação & - & 3,3 & - & $\mathrm{V}$ \\
\hline Faixa de temperatura de Operação & -30 & 50 & 100 & $\stackrel{\circ}{ } \mathrm{C}$ \\
\hline
\end{tabular}

A faixa de temperatura utilizada em circuitos de referência varia muito de acordo com a aplicação, sendo, por exemplo, de $0{ }^{\circ} \mathrm{C}$ a $70{ }^{\circ} \mathrm{C}$ para circuitos comerciais e de $-55{ }^{\circ} \mathrm{C}$ a $125{ }^{\circ} \mathrm{C}$ para aplicações militares [21]. A principio desejávamos trabalhar com a especificação militar, mas optamos por uma faixa menor, Tabela 2, pois: 
- A Câmara Climática utilizada durante as medidas (Seção 5.1) pode operar com a temperatura mínima de $-40{ }^{\circ} \mathrm{C}$ até $130{ }^{\circ} \mathrm{C}$. Entretanto medidas utilizando os extremos de temperatura do equipamento são em geral menos confiáveis, além de exigir mais do equipamento;

- Testes realizados a temperaturas maiores do que $100{ }^{\circ} \mathrm{C}$ exigem cabos e placas especiais que não estão disponíveis.

\subsection{Funcionamento Básico do Circuito de Tensão de Referência Bandgap}

A topologia utilizada como base para este projeto foi aquela proposta por Tsividis [22]. Ela foi escolhida pois atende as condições iniciais de projeto e é simples, condição importante para se obter uma implementação funcional. Algumas características desta topologia são: não utiliza amplificadores operacionais; utiliza apenas um transistor bipolar (interessante para tecnologias onde há apenas transistores bipolares parasitas); e trabalha com baixas correntes (importante para aplicação em sistemas de baixa potência).

A Figura 10 apresenta o circuito esquemático do bandgap projetado. $\mathrm{O}$ circuito é formado por seis transistores MOS, dois resistores e um transistor bipolar. Os quatro transistores $M_{1}, M_{2}, M_{3}$ e $M_{4}$ mais o resistor $R_{1}$ formam o circuito de referência de corrente auto polarizado como vimos. O circuito de corrente é realimentado e estabiliza para um valor de corrente que dependerá da relação geométrica dos transistores e do valor da resistência de $R_{l}$.

A corrente que passa por $R_{1}$, que é proporcional a temperatura, é espelhada pelo par de transistores $M_{1}-M_{5}$ e, como resultado, teremos no resistor $R_{2}$ uma tensão também proporcional a temperatura. Por fim, a tensão sobre $R_{2}$ é somada à tensão $V_{B E}$ do transistor bipolar $Q_{6}$ (inversamente proporcional à temperatura) produzindo uma tensão de referência com um baixo coeficiente de temperatura se o circuito for devidamente projetado. 


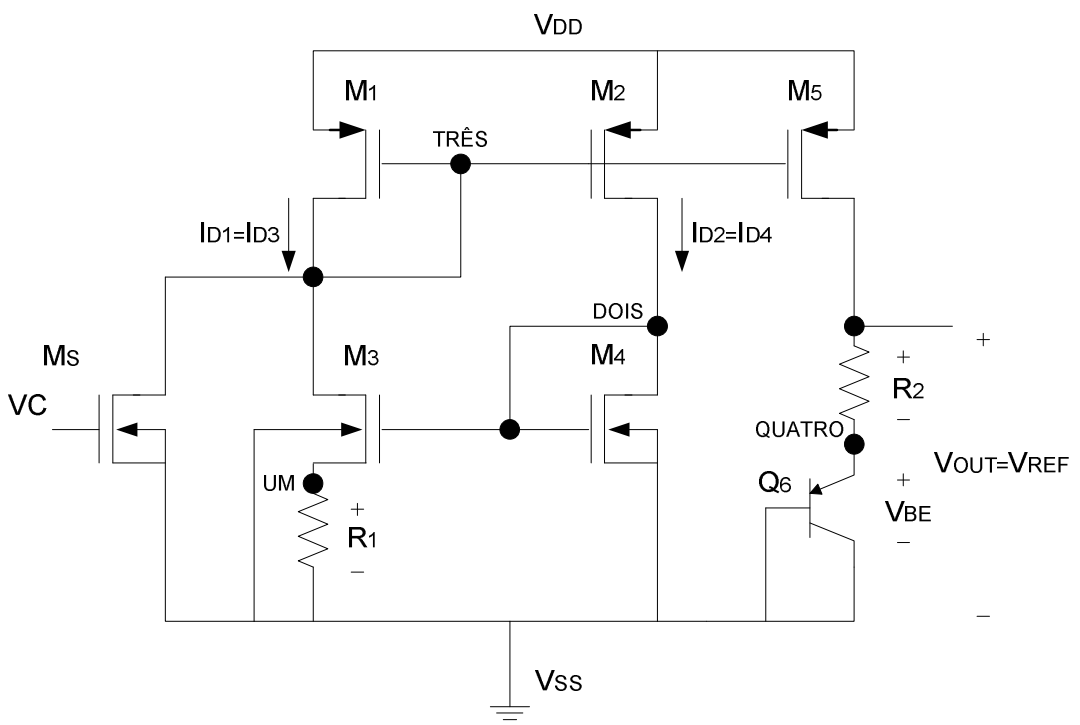

Figura 10. Esquemático do circuito bandgap.

No circuito os transistores $M_{3}$ e $M_{4}$, que formam o espelho NMOS, devem operar na inversão fraca. Os transistores $M_{l}, M_{2}$ e $M_{5}$, que formam os espelhos PMOS, podem operar em qualquer região mas, para melhorar o casamento entre eles, optamos por polarizá-los em forte inversão. Uma consequiência dessa opção é que a tensão mínima de alimentação do circuito deve aumentar [23].

Vamos determinar o valor da tensão de saída $V_{O U T}=V_{R E F}$. Iniciamos com a relação (16) encontrada acima, ou seja:

$\frac{I_{D 2}}{I_{D 1}}=\frac{I_{D 4}}{I_{D 3}}=\frac{S_{4} I_{D O} e^{\left(\frac{V_{G 4}}{n U_{T}}\right)}}{S_{3} I_{D O} e^{\left(\frac{V_{G 3}}{n U_{T}}-\frac{V_{R 1}}{U_{T}}\right)}}=\frac{S_{4}}{S_{3}} e^{\left(\frac{V_{G 4}}{n U_{T}}-\frac{V_{G 3}}{n U_{T}}+\frac{V_{R 1}}{U_{T}}\right)}=\frac{S_{4}}{S_{3}} e^{\left(\frac{V_{R 1}}{U_{T}}\right)}$

Isolando $V_{R I}$ obtemos a equação

$V_{R 1}=U_{T}\left[\ln \left(\frac{I_{D 2}}{I_{D 1}} \frac{S_{3}}{S_{4}}\right)\right]$

Esta relação pode ser um pouco mais desenvolvida. Lembrando que os transistores $M_{1}$ e $M_{2}$ operam como espelho de corrente, a seguinte relação é possível:

$V_{G 1}=V_{G 2} \Rightarrow \frac{I_{D 2}}{I_{D 1}}=\frac{(W / L)_{2}}{(W / L)_{1}}=\frac{S_{2}}{S_{1}}$

onde $S$ é a relação entre a largura e o comprimento do canal do transistor.

Chegamos a: 
$V_{R 1}=U_{T}\left[\ln \left(\frac{S_{2}}{S_{1}} \frac{S_{3}}{S_{4}}\right)\right]$

Usando a Lei de Ohm para encontrar a expressão de corrente sobre $R_{l}$ obtemos $I_{R 1}=\frac{U_{T}}{R_{1}}\left[\ln \left(\frac{S_{2}}{S_{1}} \frac{S_{3}}{S_{4}}\right)\right]$

Como dito anteriormente esta corrente é espelhada pelo transistor $M_{5}$ e será usada para obter a tensão sobre $R_{2}$, que será

$V_{R 2}=U_{T} \frac{R_{2}}{R_{1}}\left(\frac{S_{5}}{S_{1}}\right)\left[\ln \left(\frac{S_{2}}{S_{1}} \frac{S_{3}}{S_{4}}\right)\right]$

onde $S_{5}$ é a relação $(W / L)$ no transistor $M_{5}$.

Por esta equação vemos que a tensão $V_{R 2}$ depende da tensão térmica e, portanto, é diretamente da temperatura $T$. Esta tensão $V_{R 2}$ será somada a $V_{B E}$ do transistor bipolar para produzir a tensão de referência $V_{R E F}$ :

$V_{R E F}=V_{R 2}+V_{B E}$

Uma expressão mais completa para a tensão de saída será obtida ao aplicar a expressão de $V_{B E}$ descrita no Anexo A, expressão (a13), na equação (26). Podemos escrever então que a tensão na saída do circuito na temperatura $T$ é

$$
\begin{aligned}
& V_{R E F(T)}=U_{T} \frac{R_{2}}{R_{1}}\left(\frac{S_{5}}{S_{1}}\right)\left[\ln \left(\frac{S_{2}}{S_{1}} \frac{S_{3}}{S_{4}}\right)\right]+V_{G O(T)}-\left(\frac{T}{T_{R}}\right) V_{G O\left(T_{R}\right)} \\
& +\left(\frac{T}{T_{R}}\right) V_{B E\left(T_{R}\right)}-c\left(\frac{k T}{q}\right)\left[\ln \left(\frac{T}{T_{R}}\right)\right]+\frac{k T}{q}\left[\ln \left(\frac{I_{C(T)}}{I_{C(T R)}}\right)\right]
\end{aligned}
$$

onde $V_{G O(T)}$ é a tensão de bandgap do silício na temperatura $T, V_{B E(T R)}$ é a tensão baseemissor do transistor na temperatura de referência $T_{R}, c$ é uma constante que depende do processo de fabricação do transistor ( $c=4-\eta$, Anexo A) e $I_{C}$ é a corrente do transistor $Q_{6}$.

A corrente $I_{C}$ é igual a corrente de dreno do transistor $M_{5}$ dada por:

$$
I_{D 5}=\frac{S_{5}}{S_{1}} I_{R 1}=\frac{S_{5}}{S_{1}} \frac{U_{T}}{R_{1}}\left[\ln \left(\frac{S_{2}}{S_{1}} \frac{S_{3}}{S_{4}}\right)\right]
$$

Podemos considerar que $I_{C}=I_{D 5} \approx D T^{x}$, onde $x$ é o coeficiente de temperatura da corrente (veremos mais a frente que seu valor está próximo de um). Utilizando esta expressão em (26) obtemos: 


$$
\begin{aligned}
& V_{R E F(T)}=U_{T} \frac{R_{2}}{R_{1}}\left(\frac{S_{5}}{S_{1}}\right)\left[\ln \left(\frac{S_{2}}{S_{1}} \frac{S_{3}}{S_{4}}\right)\right]+V_{G O(T)}-\left(\frac{T}{T_{R}}\right) V_{G O\left(T_{R}\right)} \\
& +\left(\frac{T}{T_{R}}\right) V_{B E\left(T_{R}\right)}-(c-x)\left(\frac{k T}{q}\right)\left[\ln \left(\frac{T}{T_{R}}\right)\right]
\end{aligned}
$$

O objetivo principal do circuito é gerar uma tensão com um baixo coeficiente de temperatura. Para alcançá-lo o circuito é projetado de forma que a derivada da expressão acima, em relação a temperatura, é anulada ao menos na temperatura de referência $T_{R}$. Determinemos quando isto acontece. A expressão para esta derivada é

$$
\begin{aligned}
& \left.\frac{\partial V_{R E F}}{\partial T}\right|_{T=T_{R}}=\frac{k}{q}\left(\frac{R_{2}}{R_{1}}\right)\left(\frac{S_{5}}{S_{1}}\right)\left[\ln \left(\frac{S_{2}}{S_{1}} \frac{S_{3}}{S_{4}}\right)\right]-\frac{V_{G O\left(T_{R}\right)}}{T_{R}} \\
& +\frac{V_{B E\left(T_{R}\right)}}{T_{R}}-\frac{(c-x) k}{q}=0
\end{aligned}
$$

A condição para anulá-la será

$$
\left(\frac{R_{2}}{R_{1}}\right)\left(\frac{S_{5}}{S_{1}}\right)\left[\ln \left(\frac{S_{2}}{S_{1}} \frac{S_{3}}{S_{4}}\right)\right]=\left(\frac{q}{k T_{R}}\right)\left(V_{G O_{\left(T_{R}\right)}}-V_{B E\left(T_{R}\right)}\right)+(c-x)
$$

Observemos nesta expressão que a condição desejada pode ser obtida pela escolha conveniente das dimensões dos transistores e dos valores dos resistores. Observemos ainda que foi negligenciada na dedução acima a variação do valor dos resistores com a temperatura. Como $V_{R E F}$ depende apenas da relação $\left(R_{1} / R_{2}\right)$ e o valor desta relação permanece constante com a temperatura se os dois resistores são implementados com o mesmo material, o que é desejável, tal negligencia não causa erros.

Substituindo a equação (28) em (27) obtemos a expressão para a tensão de referência, quando o projeto esta ajustado para ter mínima variação de $V_{R E F}$ com a temperatura:

$$
V_{R E F(T)}=V_{G O}+\frac{(c-x) k T}{q}\left(1+\left[\ln \left(\frac{T_{R}}{T}\right)\right]\right)
$$

No caso de $T=T_{R}$ a equação fica reduzida a:

$$
V_{R E F(T R)}=V_{G O}+\frac{(c-x) k T_{R}}{q}
$$

Desta forma vemos que é possível ajustar o circuito de tensão de referência para operar com um coeficiente de temperatura próximo à zero, ao menos para uma 
temperatura de referência. Neste caso, a tensão de saída será igual a 1,205 V mais c vezes a tensão térmica $U_{T}$ na temperatura $T_{R}$.

O transistor $M_{S}$, apresentado na Figura 10, tem a função de dar o start-up do circuito. Quando acionado, forçará a tensão $V_{S S}$ na porta dos transistores $M_{1}$ e $M_{2}$ fazendo-os conduzir e evitando que o circuito fique num estado estável onde todos os transistores estão cortados. A operação deste transistor será vista no próximo capítulo.

Para implementar o transistor bipolar foi utilizada uma célula da AMS com um transistor bipolar vertical conforme será visto adiante.

\subsection{Tecnologia de 0,35 um da AMS [20]}

Antes de fazer o layout de um circuito é preciso escolher o processo de fabricação em que este será produzido. Definido isto basta utilizar o conjunto de regras disponíveis para o projeto. Estas regras incluem informações como comprimento mínimo de porta do transistor, distâncias mínimas entre linhas, número de camadas de silício policristalino e de metal disponíveis, etc.

A foundry escolhida neste projeto foi a Áustria Micro Systems (AMS), e o processo CMOS de 0,35 $\mu \mathrm{m}$ que disponibiliza duas camadas de silício policristalino e quatro camadas de metal. A razão para tal escolha é que o processo tem sido utilizado em outros blocos dos sistemas de RF desenvolvidos. Como circuitos de tensão de referência não necessitam de tecnologias de ponta para sua implementação, trabalham com tensões DC, nosso circuito pode ser fabricado sem maiores dificuldades nesta tecnologia.

O processo CMOS da AMS foi utilizado na fabricação do circuito que foi realizada através da Circuits Multi-Projets (CMP) [24]. Como esta foundry utiliza lâminas de silício tipo p e não dispõe de nenhuma camada especial para construir transistores bipolares, a possibilidade de se obter tais transistores é através de PNP parasitas. 
Na tecnologia da AMS é sugerido que, caso o projeto seja analógico, o comprimento mínimo de canal de um MOS seja de 0,6 $\mu \mathrm{m}$. Para projetos digitais, o comprimento mínimo de canal de $0,35 \mu \mathrm{m}$ é aplicável sem maiores restrições.

\subsection{Transistor Bipolar Parasita}

Uma vez definidos o processo e o tipo de fonte de referência devemos saber como implementar os transistores bipolares necessários. Há duas possibilidades para construir esses dispositivos: transistores bipolares laterais e transistores bipolares verticais parasitas.

O transistor bipolar lateral parasita é um dispositivo de cinco terminais (emissor, base, coletor, porta e substrato) como mostrado na Figura 11. Polarizandose corretamente o substrato e a porta os demais terminais atuam como os terminais de um transistor bipolar normal. Os transistores laterais possuem um fator de ganho de corrente entre 30 a 380 , dependendo da polarização da porta. Geralmente este fator de ganho é pequeno devido à largura da base grande e a perda de correntes para o substrato.

Este é o dispositivo necessário para circuitos onde o transistor bipolar tem o terminal de coletor conectado a tensões diferentes de $V_{S S}$. Na literatura são apresentados alguns exemplos de seu uso, inclusive em fontes de referência [25] [26] [27].

A AMS disponibiliza transistores bipolares laterais como células de sua biblioteca, Figura 12, junto com modelos para sua simulação. Como dito anteriormente, nesta tecnologia apenas transistores PNP podem ser fabricados.

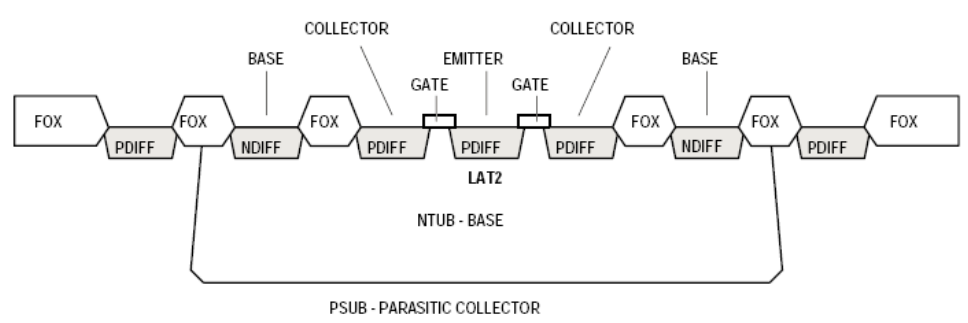

Figura 11. Vista em corte de um transistor PNP lateral parasitário disponível na AMS. 


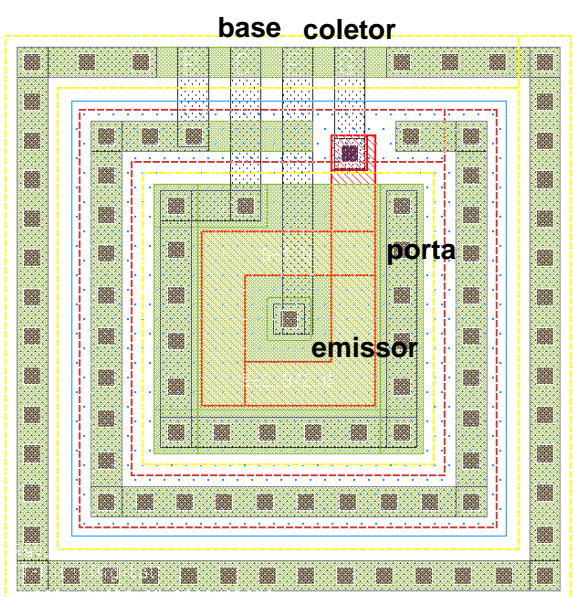

Figura 12. Layout do transistor PNP lateral parasitário disponível na AMS.

O transistor bipolar vertical é um dispositivo de três terminais como mostrado na Figura 13. Nele a difusão de fonte-dreno p+ serve como emissor, o n-well como base e o substrato como coletor. O transistor PNP vertical só pode ser aplicado em configurações onde o coletor esta ligado à tensão do substrato, ou seja, a $V_{S S}$. Felizmente há vários circuitos que satisfazem esta condição [28] [22] [5]. Também a fonte de tensão proposta pode ser construída com tal dispositivo já que o transistor é ligado como diodo com um dos lados ligado ao $V_{S S}$.

A AMS disponibiliza transistores verticais como células de biblioteca, Figura 14, junto com modelos para sua simulação. Foi escolhido este tipo de transistor para nossa aplicação. Como este transistor bipolar é um dispositivo fornecido pelo fabricante, não deve ser modificado e, deste modo, o projeto fica com sua flexibilidade reduzida. Por outro lado, ele já foi devidamente caracterizado, o que facilita sua aplicação e reduz riscos.

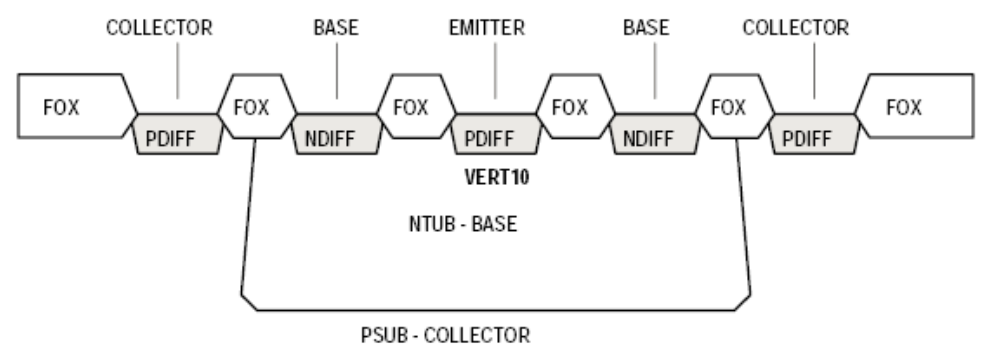

Figura 13. Vista em corte do transistor bipolar PNP vertical parasitário disponível pela AMS. 


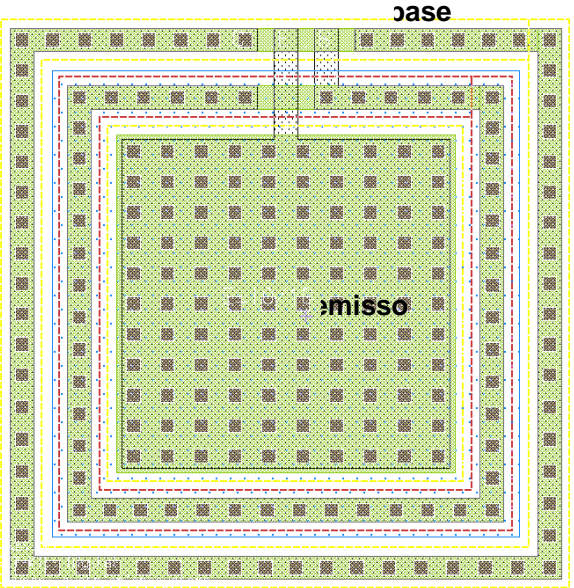

Figura 14. Layout do transistor PNP vertical parasitário disponível na AMS.

\subsection{Simulação do Circuito Integrado}

A finalidade de simular um circuito é verificar se o mesmo funciona da maneira desejada, utilizando modelos extraídos pela foundry. Para as simulações do projeto foi utilizada como ferramenta o software ELDO da Mentor Graphics [29]. O Anexo B apresenta os modelos para os transistores MOS, modelo BSIM3v3, para os transistores bipolares verticais e para os resistores fornecidos pela AMS e utilizados aqui.

Como o comportamento do circuito com a temperatura depende essencialmente do comportamento do transistor bipolar, procuramos verificar como este dispositivo é modelado no simulador para os parâmetros fornecidos pela foundry e, assim, saber se podemos ou não esperar resultados experimentais próximos dos simulados. Observamos que no modelo usado do transistor o valor da tensão de banda proibida $\left(V_{G}\right)$ é considerado constante e igual a $1,15 \mathrm{~V}$ (Anexo A). Em modelos mais sofisticados $V_{G}$ é dependente também da temperatura 


\section{CONSIDERAÇÕES DE PROJETO E LAYOUT}

\subsection{Projeto}

Neste projeto foi necessário certo cuidado com o dimensionamento de cada transistor, uma vez que estes operam em diferentes regiões como descrito na seção 2.1.4.2. O primeiro passo para determinar as dimensões dos transistores foi adotar um valor inicial de corrente de dreno para o transistor $M_{1}\left(I_{D 1}\right)$, Figura 10. Neste projeto foi adotada a corrente de $1 \mu \mathrm{A}$; o valor baixo assegura que não serão necessárias dimensões irreais para fazer com que os transistores NMOS estejam em inversão fraca. Por outro lado, correntes muito pequenas obrigam que se aumente o valor dos resistores ou da relação geométrica dos transistores, conforme indica (23).

De acordo com a equação (22) para que passe corrente no resistor $R_{1}$ e o circuito funcione corretamente é necessário que a razão entre as relações geométricas dos transistores, $\left(\frac{S_{2}}{S_{1}} \frac{S_{3}}{S_{4}}\right)$, seja maior que um. É importante salientar que quanto maior esta razão entre os transistores menos sensível fica a tensão de saída com a tensão de alimentação. A área ocupada pelo circuito, entretanto, também aumenta. Foi escolhida a seguinte razão para o projeto, $\frac{S_{2}}{S_{1}}=\frac{S_{3}}{S_{4}}=3$.

Uma vez definidas as correntes no circuito e as razões entre os transistores, calculamos os valores de $S$ por meio da relação (12). Ela nos dirá o valor mínimo para a relação $W / L$ do canal dos transistores $N$, para garantir que fiquem em inversão fraca, e o valor máximo para a relação $W / L$ do canal dos transistores $\mathrm{P}$, para garantir que fiquem em inversão forte. Lembrando que o transistor $M_{4}$ deve estar em fraca inversão com $3 \mu \mathrm{A}$ de corrente e utilizando $n=1,2$, obtemos que $S_{4}$ deve ser maior ou igual a 50; como o transistor $M_{3}$ deve ter $S_{3}=3 S_{4}$, obtemos $S_{3}$ maior ou igual a 150 o que, com certeza, garante que ele esteja em fraca inversão com $1 \mu \mathrm{A}$. Por sua vez, o transistor $M_{1}$ deve estar em forte inversão com $1 \mu \mathrm{A}$ de corrente. Para isso é necessário usar $S_{1}$ menor ou igual a 0,2 ; como o transistor $M_{2}$ deve ter $S_{2}=3 S_{1}$, obtemos $S_{2}$ menor ou igual a 0,6 o que também garante a sua operação em forte inversão. 
Achados os valores de $S$, para determinar as dimensões dos transistores iniciamos com a escolha dos valores do comprimento de canal $(L)$. Para escolher estes valores é necessário levar em consideração a influência do $L$ no casamento e na modulação de canal dos transistores. No geral o casamento é melhorado e a modulação é reduzida quando utilizamos comprimento de canal grande. Para os transistores NMOS, que possuem um valor de $S$ muito elevado, foi utilizado o valor de $L=3 \mu \mathrm{m}$ ( $L$ 's maiores tornariam os transistores NMOS muito grandes). No caso dos transistores PMOS, que possuem um valor de $S$ pequeno, foi utilizado $L=5 \mu \mathrm{m}$ para reduzir bem a modulação de canal neles.

Utilizando os valores de $S$ e de $L$ anteriormente calculados, obtivemos os seguintes valores de $W / L$ para os transistores: $M_{l}=1 \mu \mathrm{m} / 5 \mu \mathrm{m}, M_{2}=3 \mu \mathrm{m} / 5 \mu \mathrm{m}, M_{3}$ $=450 \mu \mathrm{m} / 3 \mu \mathrm{m}, M_{4}=150 \mu \mathrm{m} / 3 \mu \mathrm{m}$.

Pela Figura 15, obtida simulando $M_{3}$ e $M_{4}$ com as dimensões dadas acima para várias tensões de porta-fonte $\left(V_{G S}\right)$, confirmamos que estes transistores operam em fraca inversão, relação exponencial entre $I_{D}$ e $V_{G S}$, para correntes de dreno de $1 \mu \mathrm{A}$ e $3 \mu \mathrm{A}$, respectivamente.

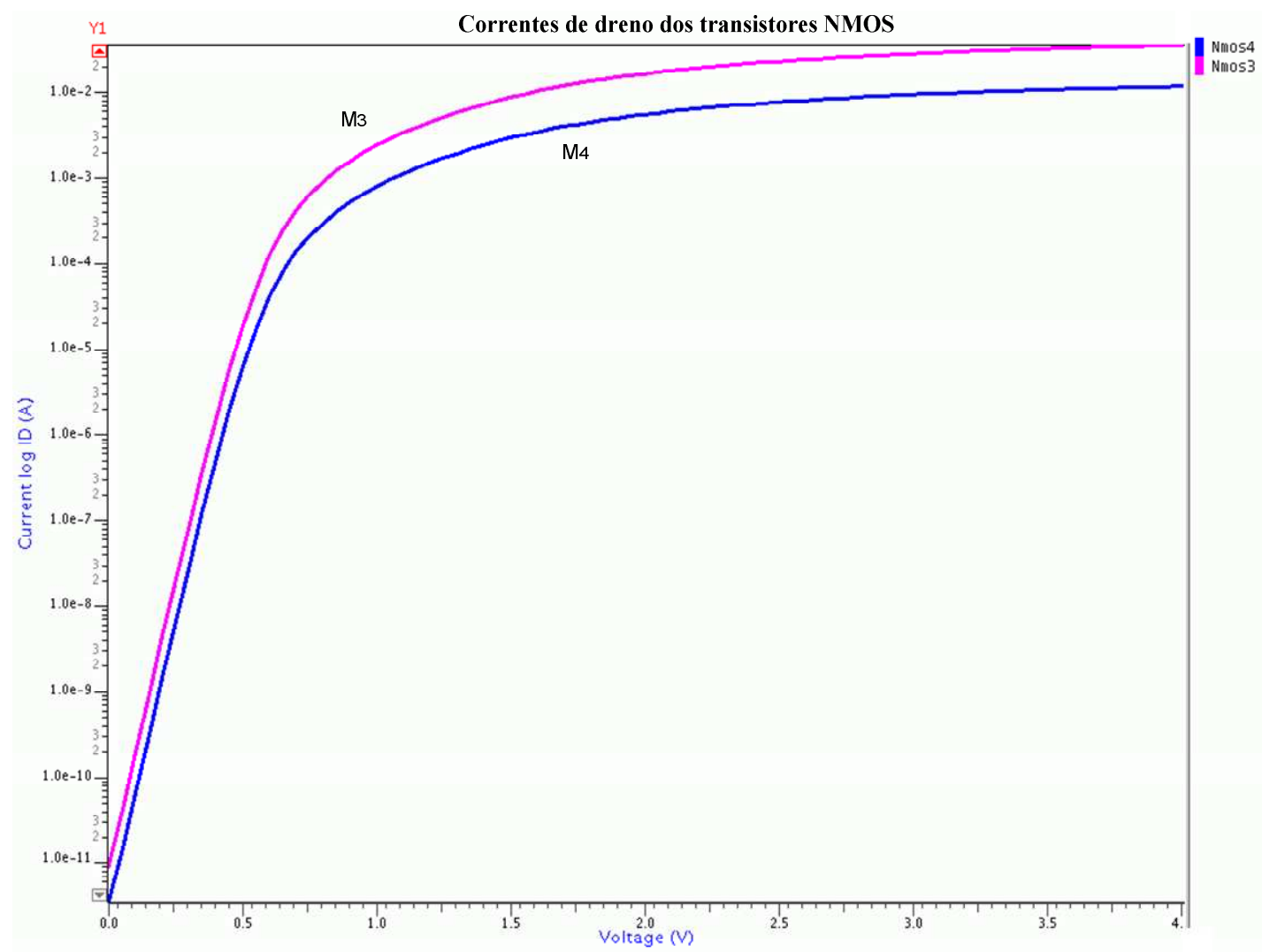

Figura 15. Gráfico de $\log \left(-I_{D S}\right)$ x $V_{G S}$ para os transistores $M_{3}$ e $M_{4} \operatorname{com} V D S=3,3 V$. 
Uma vez escolhida à corrente no transistor $M_{l}$ e determinadas as relações $S_{l}$, $S_{2}, S_{3}$ e $S_{4}$ podemos calcular o valor de $R_{1}$, equação (23), e será igual $61,2 \mathrm{~K} \Omega$

Os transistores $M_{1}$ e $M_{5}$ formam um espelho de corrente que influencia no valor do resistor $R_{2}$. O transistor $M_{5}$ foi dimensionado para ter uma corrente dez vezes maior que a corrente em $M_{1}$. Com isto o valor do resistor $R_{2}$, calculado através da relação (28), não ficará muito maior do que o valor de $R_{l}$. Utilizando $c=5.53$ (ver Anexos A e B), $V_{B E}=0.680 \mathrm{~V}$ (valor típico fornecidos pela foundry), $V_{G O(T R)}$ $=1,1088 \mathrm{~V}$, e $T_{R}=50{ }^{\circ} \mathrm{C}$ obtivemos $R_{2}=58,3 \mathrm{~K} \Omega$. O valor de $V_{G O(T R)}$ foi obtido utilizando-se a relação abaixo que fornece como a tensão de bandgap do silício varia com a temperatura [8]:

$V_{G O\left(T_{R}\right)}=V_{G}-7,02\left(\frac{T_{R}{ }^{2}}{T_{R}+1108}\right) 10^{-4}$

onde $V_{G}=1.1557 \mathrm{~V}$

A Tabela 3 mostra os valores e as dimensões dos componentes obtidos por cálculo.

Foi simulado um circuito com estas dimensões e houve a necessidade de alterar os valores de $R_{l}$, para ajustar a corrente que passa neste resistor para $1 \mu \mathrm{m}$, e de $R_{2}$, para ajustar o ponto onde a derivada da tensão de saída com a temperatura é zerada (desejamos que seja em $50^{\circ} \mathrm{C}$ ). A Tabela 3 mostra também os valores e as dimensões do circuito final com estes ajustes obtidos por simulação e que foi o circuito implementado e caracterizado.

Tabela 3. Tamanho dos componentes do circuito bandgap projetado.

\begin{tabular}{|c|c|c|c|}
\hline Componente & Calculado & Simulado/Implementado & Unidade \\
\hline $\mathbf{M}_{\mathbf{1}}$ & $1 / 5$ & $1 / 5$ & $\mu \mathrm{m} / \mu \mathrm{m}$ \\
\cline { 1 - 2 } $\mathbf{M}_{\mathbf{2}}$ & $3 / 5$ & $3 / 5$ & $\mu \mathrm{m} / \mu \mathrm{m}$ \\
\cline { 1 - 2 } $\mathbf{M}_{\mathbf{3}}$ & $450 / 3$ & $450 / 3$ & $\mu \mathrm{m} / \mu \mathrm{m}$ \\
\hline $\mathbf{M}_{\mathbf{4}}$ & $150 / 3$ & $150 / 3$ & $\mu \mathrm{m} / \mu \mathrm{m}$ \\
\hline $\mathbf{M}_{\mathbf{5}}$ & $10 / 5$ & $10 / 5$ & $\mathrm{~mm} / \mu \mathrm{m}$ \\
\hline $\mathbf{R}_{\mathbf{1}}$ & 61,2 & 68,8 & $\mathrm{k} \Omega$ \\
\hline $\mathbf{R}_{\mathbf{2}}$ & 58,3 & 62,8 & $\mathrm{k} \Omega$ \\
\hline
\end{tabular}




\subsection{Circuito de Inicialização}

Devido à utilização da técnica de auto polarizados é importante incluir nesta referência bandgap um circuito de inicialização, conforme descrito na seção 2.1.4.2. Observou-se, por meio de simulação, que numa situação onde as tensões de porta dos transistores $\mathrm{P}$ estão em $V_{D D}$ e as tensões de porta dos transistores $\mathrm{N}$ estão em $V_{S S}$, o circuito auto polarizado não se inicia. Neste estado os quatro transistores $M_{1}, M_{2}, M_{3}$ e $M_{4}$ estão e permanecem cortados.

Por tratar-se de uma primeira versão do circuito, o start-up foi projetado para ser o mais simples possível e consta apenas do transistor $M_{S}$, Figura 10. Este transistor deve ser suficientemente grande para forçar para baixo a tensão na porta dos transistores PMOS, fazendo-os conduzir. Utilizaram-se aqui as dimensões de $W$ $=1 \mu \mathrm{m}$ e $L=2,5 \mu \mathrm{m}$. Observemos que há na tecnologia empregada uma mínima relação entre a área lateral total dos metais conectados a porta de um transistor e a área de canal deste transistor. Caso esta relação não seja obedecida, cargas formadas durante a etapa de ion etch dos metais, e capturadas pelos mesmos, podem causar a ruptura no óxido de porta do transistor. Como a porta do transistor $M_{5}$ é ligada a um $P A D$ de entrada, o que implica numa área lateral de metais grande, foi empregado um comprimento de canal maior para aumentar a área do canal.

A Figura 16, obtida por simulação de transiente, mostra as tensões de saída ( $\left.V_{\text {OUT }}\right)$ e de controle $\left(V_{C}\right)$ do transistor $M_{S}$ ao longo do tempo. Foram ainda forçadas condições iniciais de forma que o circuito bandgap não se inicie, o que pode ser reconhecido observando a tensão de saída zerada nos primeiros instantes da simulação. Quando aplicado o sinal de controle, a tensão de porta dos transistores PMOS é forcada para baixo e a tensão de saída se eleva aproximando-se de $3 \mathrm{~V}$, ficando neste valor. Apenas após a desativação do sinal de controle é que a tensão de saída assume o valor desejado (leva cerca de 270 ns para isto). 


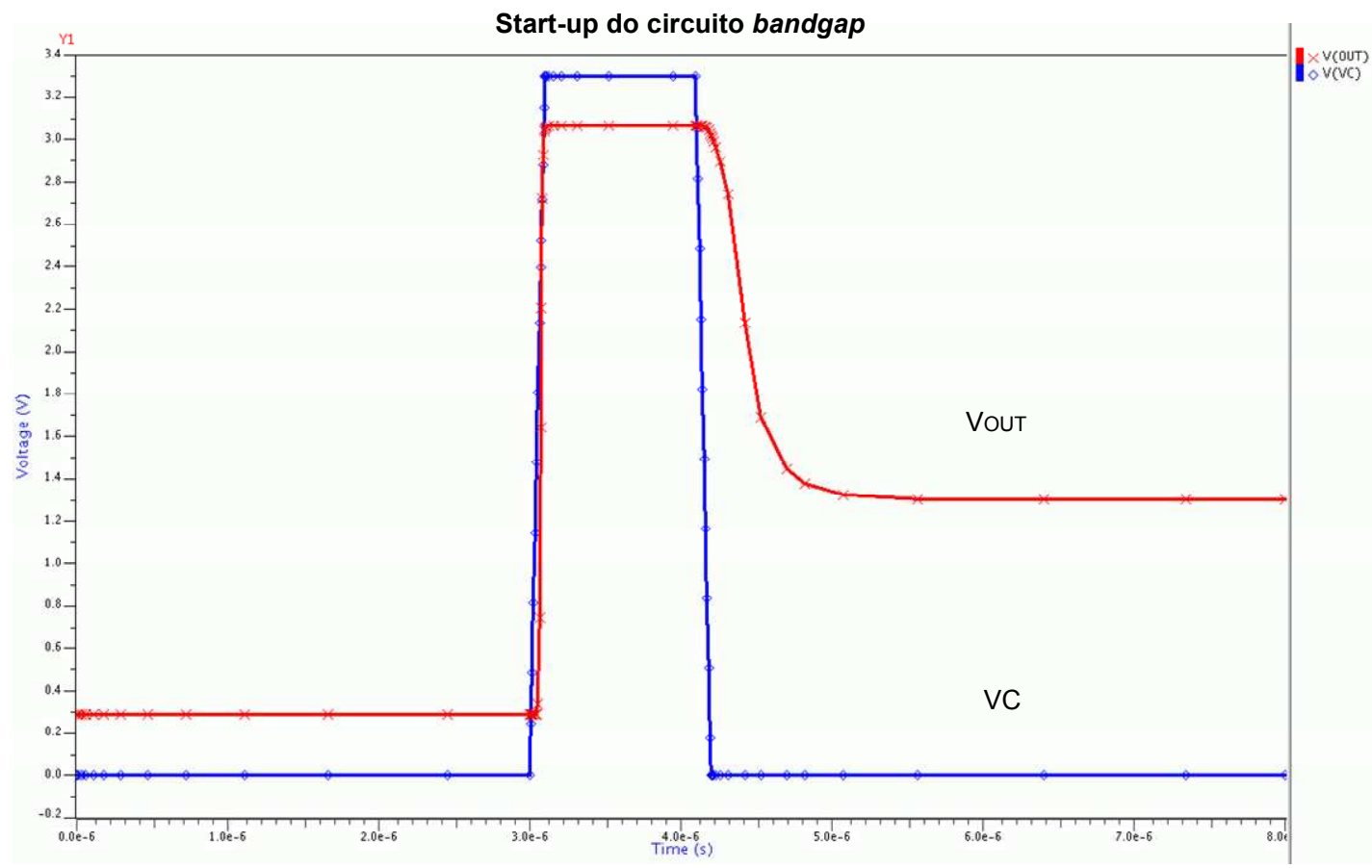

Figura 16. Gráfico de $V_{O U T}$ e $V_{C}$ em função do tempo.

\subsection{Layout}

Para realizar o layout de um circuito analógico são necessários diversos cuidados. Isto torna o projeto mais complexo quando comparado ao de um circuito digital, pois o layout, neste segundo caso, é composto por blocos simples e a maior dificuldade está na distribuição, placement, e interconexão, routing, das células. Em geral, em um circuito digital, as restrições primárias são minimizar área e atrasos dos sinais, e uma maior atenção é voltada aos blocos lógicos e não aos transistores individualmente [30].

Um dos cuidados tomados aqui foi a utilização de anéis de guarda. Mesmo não havendo a integração de blocos digitais junto à fonte de referência, teve-se a preocupação de que o ruído gerado por tais blocos influenciaria no desempenho do circuito analógico. Para minimizar tal influência, os nós críticos do circuito foram protegidos por anéis de difusões $\mathrm{P}+\mathrm{e} \mathrm{N}+$ conectados a $V_{S S}$ e $V_{D D}$, respectivamente [30].

Outro cuidado tomado foi a utilização da estrutura de "dedos" na implementação de alguns transistores. Como descrito anteriormente os transistores $M_{3}$ e $M_{4}$ foram polarizados para operar na região de inversão fraca, o que resulta em 
um $W$ bastante grande, como mostra a Tabela 3. Devido ao seu tamanho esses transistores, se desenhados sem atenção, ocupariam uma região desproporcional a aquela ocupada pelos outros componentes do circuito. Para reduzir esta desproporcionalidade, estes transistores foram divididos em transistores menores colocados em paralelo, utilizando a estrutura de layout conhecida como estrutura de “dedos", mostrada na Figura 17. Este tipo de estrutura paralela não modifica o desempenho elétrico do transistor, pois a soma da largura de canal dos transistores em paralelo é igual à largura de canal de transistor original.

Para melhorar o casamento entre os transistores $M_{3}$ e $M_{4}$, o que é crucial para o circuito, ambos foram formados a partir de transistores com largura de canal de 15 $\mu \mathrm{m}$ colocados muito próximos. $\mathrm{O}$ transistor $M_{3}$ foi implementado como 30 transistores em paralelo e $M_{4}$, como 10 transistores. O valor de $15 \mu \mathrm{m}$ foi escolhido para se ter números inteiros de transistores para $M_{3}$ e para $M_{4}$.

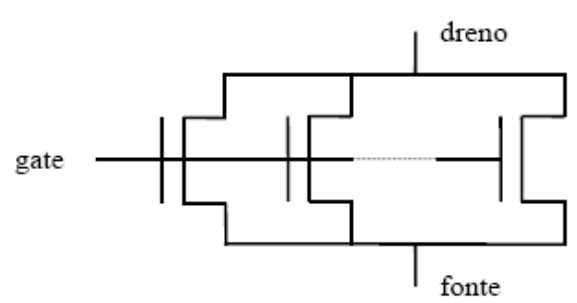

(a)

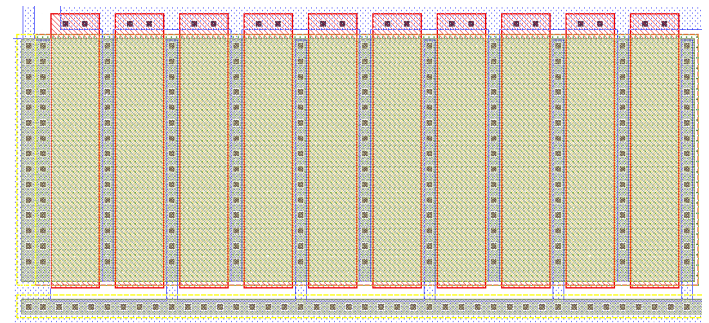

(b)

Figura 17. (a) Transistor dividido em estruturas paralelas. (b) Layout de um transistor em dedos

Devido a grande área ocupada pelos transistores, gradientes que aparecem durante o processo de fabricação, na dopagem, na espessura de óxido, etc., podem ter modificar as características elétricas dos dispositivos. Isto pode fazer que a relação da corrente que passa nos transistores deixe de ser proporcional a razão geométrica deles, como é o esperado em espelhos de corrente, equação (11), pares diferenciais, etc. [6]. Para minimizar a influência destes gradientes, comuns aos processos de fabricação, existe a técnica de layout chamada de centróide comum. Nesta técnica os transistores, normalmente de dimensões iguais, são divididos e suas partes são posicionadas de modo diagonal entre si. Deste modo, a influência dos gradientes é reduzida tanto horizontalmente quanto verticalmente. A Figura 18 (a) mostra o esquemático de um circuito par diferencial e a Figura 18 (b) apresenta o esboço do layout deste mesmo circuito, utilizando a técnica de centróide comum. 
Neste trabalho a técnica de centróide comum foi descartada pois os transistores, no qual ela poderia ser aplicada, têm dimensões diferentes entre si e, neste caso, a sua aplicação tornaria o layout complexo, resultando, possivelmente, em melhoras pouco expressivas.

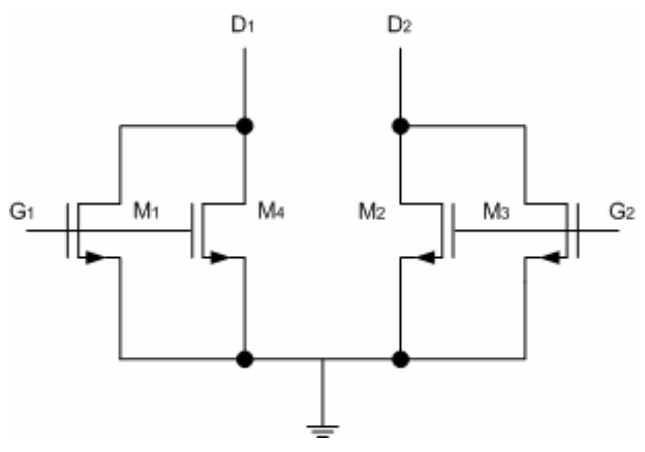

(a)

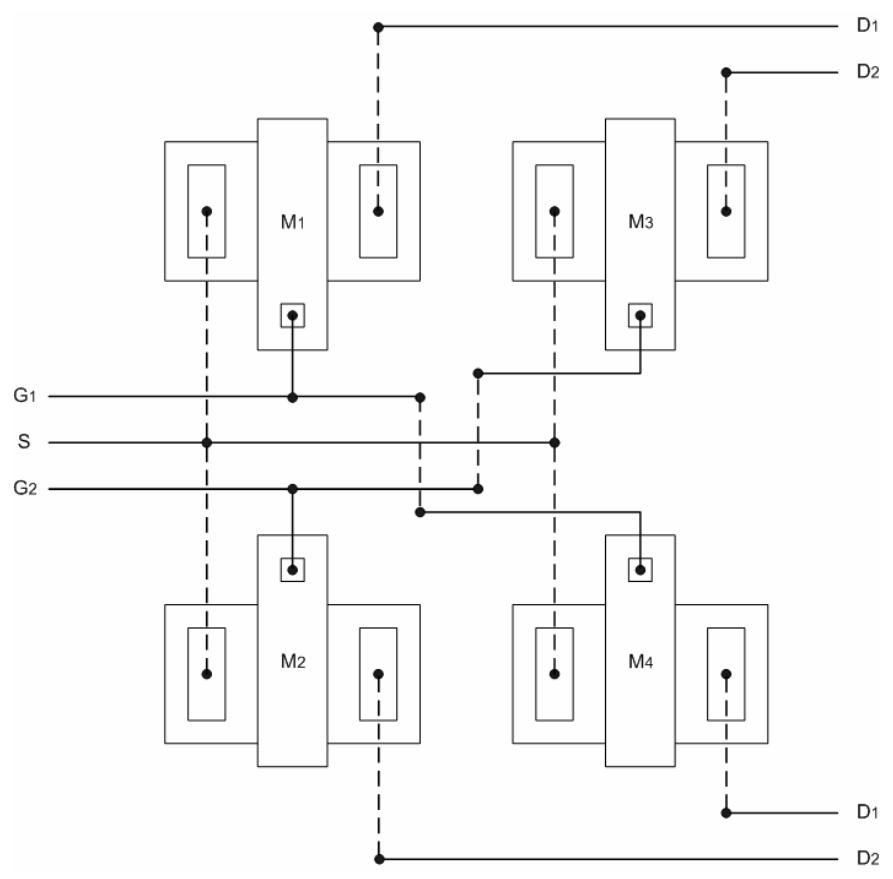

(b)

Figura 18. (a) Esquemático de um circuito par diferencial. (b) Esboço do Layout do circuito par diferencial utilizando a técnica de centróide comum.

Os resistores $R_{1}$ e $R_{2}$, Tabela 3, têm valores altos e por isso precisam de materiais com alta resistência de folha na sua construção [20]. A Tabela 4 fornece as resistividades e coeficientes de temperatura das camadas que a foundry disponibiliza para implementar resistores. São elas: camada de silício policristalino de alta resistividade, RPOLYH, de silício policristalino de porta, RPOLY, de silício policristalino usado para capacitores, RPOLY2, de difusão P, RDIFFP, de difusão N, RDIFFN, e do poço tipo N, RNWELL.

$\mathrm{Na}$ tecnologia utilizada apenas as camadas RNWELL e RPOLYH têm alta resistência de folha. Os resistores de nosso circuito foram implementados com o silício policristalino RPOLYH pois esta camada tem, além da alta resistência de folha, o coeficiente de temperatura baixo. Adicionalmente, resistores implementados no silício policristalino não sofrem o efeito de regiões de depleção como acontece no poço. 
Observemos que pode haver variações de até $25 \%$ no valor da resistência de folha das camadas devido ao processo de fabricação, Tabela 4. Para melhorar o casamento entre os resistores $R_{l}$ e $R_{2}$, minimizando os efeitos destas variações, os resistores foram desenhados, Figura 19, com as dimensões de largura iguais e bem superiores à mínima permitida na tecnologia.

Tabela 4. Camadas disponíveis para implementar resistores e respectivas resistividades e coeficientes de temperatura.

\begin{tabular}{|l|c|c|c|c|c|}
\hline \multicolumn{1}{|c|}{ Tipo } & Mínimo & Típico & Máximo & Unidade & Coef. De Temp. \\
\hline RPOLYH & 0,9 & 1,2 & 1,5 & $\mathrm{~K} \Omega / \square$ & $-0,410^{-3} / \mathrm{K}$ \\
\hline RPOLY2 & 40 & 50 & 60 & $\Omega / \square$ & $0,710^{-3} / \mathrm{K}$ \\
\hline RDIFFN & 55 & 70 & 85 & $\Omega / \square$ & $1,510^{-3} / \mathrm{K}$ \\
\hline RDIFFP & 100 & 130 & 160 & $\Omega / \square$ & $1,510^{-3} / \mathrm{K}$ \\
\hline RNWELL & 0,8 & 1,0 & 1,2 & $\mathrm{~K} \Omega / \square$ & $6,210^{-3} / \mathrm{K}$ \\
\hline RPOLY & 1 & 8 & 15 & $\Omega / \square$ & $0,910^{-3} / \mathrm{K}$ \\
\hline
\end{tabular}

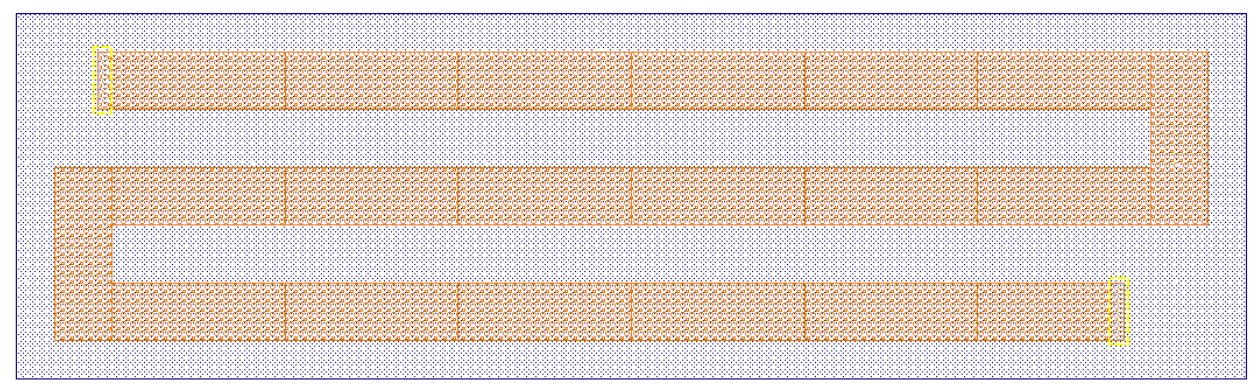

Figura 19. Layout do resistor $R_{l}$ em silício policristalino de alta resistividade (RPOLYH) com dimensões de $286,5 \mu \mathrm{m}$ x $5 \mu \mathrm{m}$.

Devido à importância dos resistores para zerar o coeficiente de temperatura na tensão de saída, foram fabricadas duas estruturas distintas do bandgap: uma estrutura com os resistores $R_{1}$ e $R_{2}$ implementados de fato no circuito integrado e usando silicio policristalino de alta resistividade; outra estrutura sem estes resistores, o que implica que eles devem ser colocados externamente. Com um circuito com resistores externos poderemos: ajustar a relação entre os valores de $R_{1}$ e $R_{2}$ para verificar se a relação determinada no projeto é a correta; ajustar o valor da tensão de saída caso ele esteja muito diferente do desejado; reduzir, se necessário, o valor das correntes para garantir que os transistores NMOS estejam mesmo na inversão fraca.

A Figura 20 apresenta o circuito com resistores internos. Nela podemos ver os resistores $R_{1}$ e $R_{2}$ implementados em polisilicio RPOLYH, o transistor bipolar, BJT, 
e quatro PADs: dois de alimentação, VDD e VSS, o da tensão de saída, VOUT, e um utilizado para o start-up do circuito, VC. As dimensões do circuito são de aproximadamente $220 \mu \mathrm{m} \times 76 \mu \mathrm{m}$, sem as estruturas de $P A D$.

A Figura 21 apresenta o circuito sem os resistores. São utilizados aqui seis PADs: quatro com as mesmas funções do circuito anterior, VDD, VSS, VOUT e VC, e UM e QUATRO que são utilizados para conectar externamente $R_{1}$ e $R_{2}$ respectivamente (estes dois pontos estão identificados na Figura 10). As dimensões deste circuito são de aproximadamente $190 \mu \mathrm{m}$ x $36 \mu \mathrm{m}$, sem as estruturas de PAD.

Observemos que foram utilizados $P A D s$ sem proteção para descargas estáticas nos protótipos. A razão para isto foi que os $P A D s$, com proteção, fornecidos pela foundry têm dimensões muito grandes. A utilização de tais $P A D s$ implicaria em uma área de circuito de quatro a cinco vezes maior do que a dos circuitos das Figuras 20 e 21.

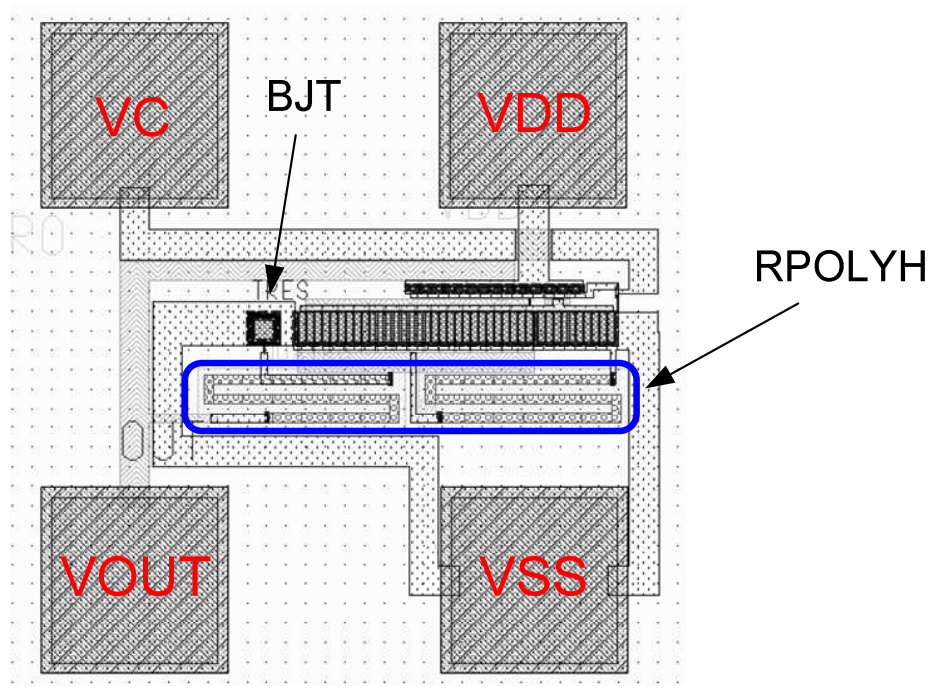

Figura 20. Layout do circuito bandgap com resistores de internos (dimensões de $220 \mu \mathrm{m}$ x $76 \mu \mathrm{m}$ ) 


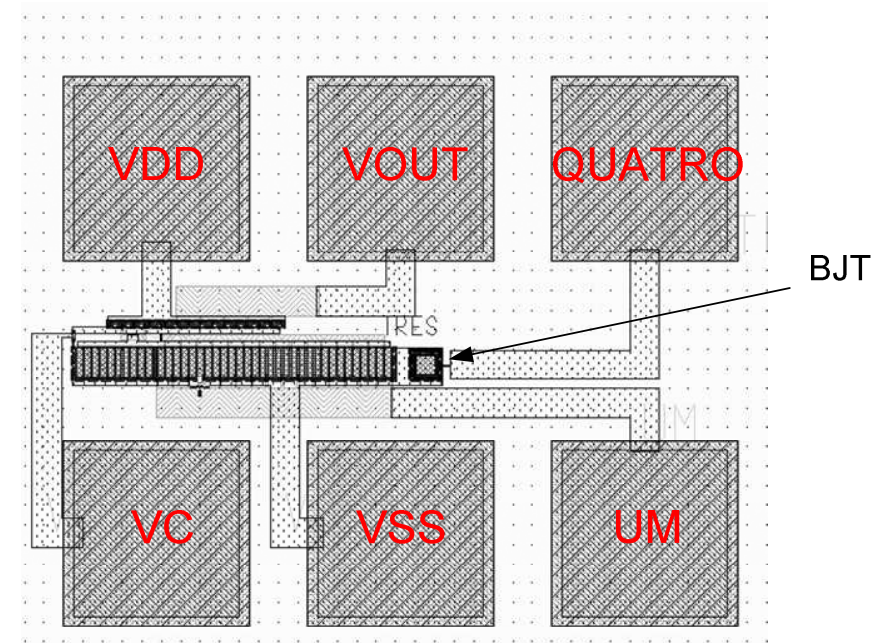

Figura 21. Layout do circuito bandgap sem os resistores (dimensões de $190 \mu \mathrm{m}$ x $36 \mu \mathrm{m}$, sem PADs)

\subsection{Resultados de simulação}

O circuito proposto foi projetado para fornecer uma tensão de referência $V_{R E F}$ de aproximadamente $1,25 \mathrm{~V}$ em uma temperatura de referência de $50{ }^{\circ} \mathrm{C}$. Os resultados da simulação foram obtidos com o netlist extraído do layout e os modelos com os parâmetros típicos (TM), os parâmetros worst speed (WS) e os parâmetros worst power (WP) (Anexo B).

Foram feitas análises DC para determinar a variação da tensão de saída em função da tensão de alimentação e da temperatura. Para todas as simulações de temperatura foi utilizada a faixa de operação especificada pela foundry, de $-40{ }^{\circ} \mathrm{C}$ a $120^{\circ} \mathrm{C}$. Esta faixa de simulação foi utilizada para avaliar o comportamento do circuito em condições mais agressivas de operação.

As simulações do circuito foram separadas, de acordo com seu objetivo, em dois grupos: no primeiro grupo estão as simulações realizadas para avaliar os espelhos de corrente; no segundo, as simulações realizadas para analisar o comportamento do circuito completo. Separando as simulações desta forma torna-se mais fácil a identificação de possíveis problemas no bandgap.

As três primeiras simulações, Figuras 22, 23 e 24, visam à avaliação do comportamento dos espelhos de corrente com relação à alimentação e a temperatura.

Na Figura 22 são mostradas as correntes DC de dreno dos transistores $M_{1}, M_{2}$, negativas devido à convenção de correntes adotada, $M_{3}$ e $M_{4}$ em função do valor da 
tensão de alimentação $V_{D D}$ (faixa de simulação de $1,0 \mathrm{~V}$ a 4,0 V). O objetivo aqui é verificar se os espelhos de corrente mantêm a relação de correntes de 3:1 para valores diferentes de tensão de alimentação. A Tabela 5 fornece os valores das correntes em $M_{1}$ e $M_{2}$ para alguns valores particulares de tensão.

Pelos resultados destas simulações podemos ver que a relação de correntes esta bem próxima de 3:1; a corrente que passa por $M_{1}$ e $M_{3}$ está bem próxima de $1 \mu \mathrm{A}$; o espelho de corrente funciona convenientemente para tensões tão baixas quanto 1,4 V.

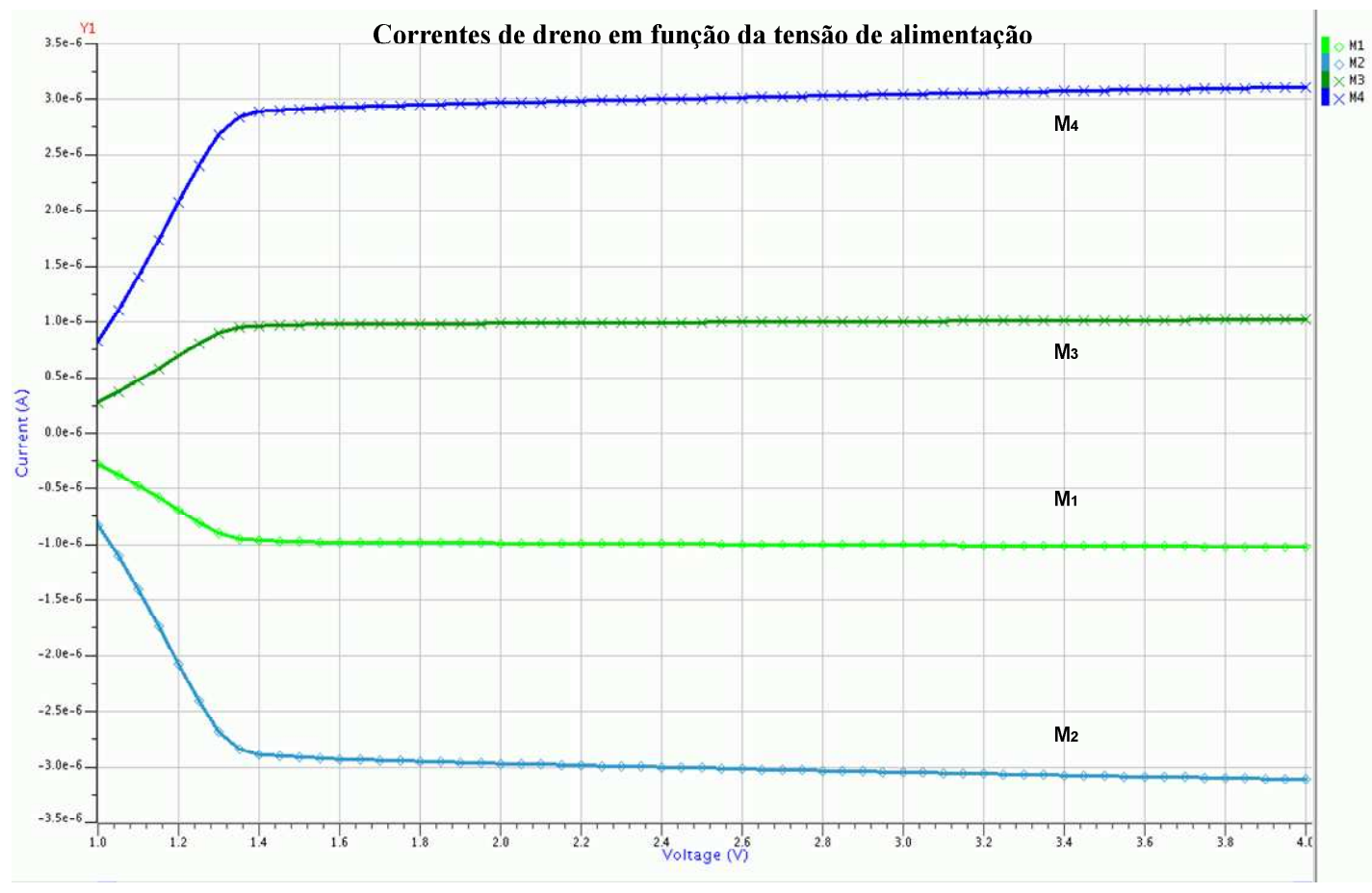

Figura 22. Gráfico de $I_{D} \times V_{D D}$ dos transistores $M_{1}, M_{2}, M_{3}$ e $M_{4}$, utilizando parâmetros típicos da tecnologia e temperatura de $50^{\circ} \mathrm{C}$.

Tabela 5. Valores das correntes de dreno nos transistores $M_{1}$ e $M_{2}$ e relação entre elas para algumas tensões de alimentação.

\begin{tabular}{|c|c|c|c|}
\hline $\begin{array}{c}\text { Tensão de } \\
\text { alimentação }\end{array}$ & $\mathbf{2 ~ V}$ & $\mathbf{3 , 3} \mathbf{~ V}$ & $\mathbf{4 ~ V}$ \\
\hline $\boldsymbol{I}_{\boldsymbol{D} \mathbf{1}}\left(\mathbf{M}_{\mathbf{1}}\right)$ & $0,986 \mu \mathrm{A}$ & $1,010 \mu \mathrm{A}$ & $1,022 \mu \mathrm{A}$ \\
\hline $\boldsymbol{I}_{\boldsymbol{D} \mathbf{2}}\left(\mathbf{M}_{\mathbf{2}}\right)$ & $2,969 \mu \mathrm{A}$ & $3,066 \mu \mathrm{A}$ & $3,112 \mu \mathrm{A}$ \\
\hline $\boldsymbol{I}_{\boldsymbol{D} 2} / \boldsymbol{I}_{\boldsymbol{D} \mathbf{1}}$ & 3,011 & 3,036 & 3,045 \\
\hline
\end{tabular}

A Figura 23 mostra as curvas das tensões sobre o resistor $R_{l}$ em função da temperatura de operação. A finalidade da figura é verificar se as curvas da tensão sobre o resistor são lineares como aponta a expressão (20). Ainda, podemos determinar a inclinação da curva teórica e compará-la com a simulada. A partir da 
expressão de $V_{R l}$, equação (22), obtemos por simulação que $\frac{\partial V_{R 1}}{\partial t}=189 \mu \mathrm{V} /{ }^{\circ} \mathrm{C}$; para os valores de $S_{1}, S_{2}, S_{3}$ e $S_{4}$ utilizados no projeto, utilizando parâmetros típicos, obtemos $\frac{\partial V_{R 1}}{\partial t}=194 \mu \mathrm{V} /{ }^{\circ} \mathrm{C}$, valor próximo do teórico.

Na Figura 24 são mostradas as correntes DC de dreno dos transistores $M_{1}, M_{2}$, $M_{3}$ e $M_{4}$ em função da temperatura de operação. O objetivo aqui é verificar se os espelhos de corrente mantêm a relação de correntes com a temperatura (faixa de simulação de $-40^{\circ} \mathrm{C}$ a $120^{\circ} \mathrm{C}$ ). A Tabela 6 fornece os valores das correntes em $M_{l}$ e $M_{2}$ para alguns valores particulares de temperatura.

Pelos resultados destas simulações podemos ver que: a relação de correntes praticamente não depende da temperatura; as correntes que passam por $M_{1}$ e $M_{2}$ têm variação linear com a temperatura (coeficiente $x$ igual a um). Este comportamento linear é devido à pequena influência do coeficiente de temperatura do resistor $R_{l}$ (Anexo B).

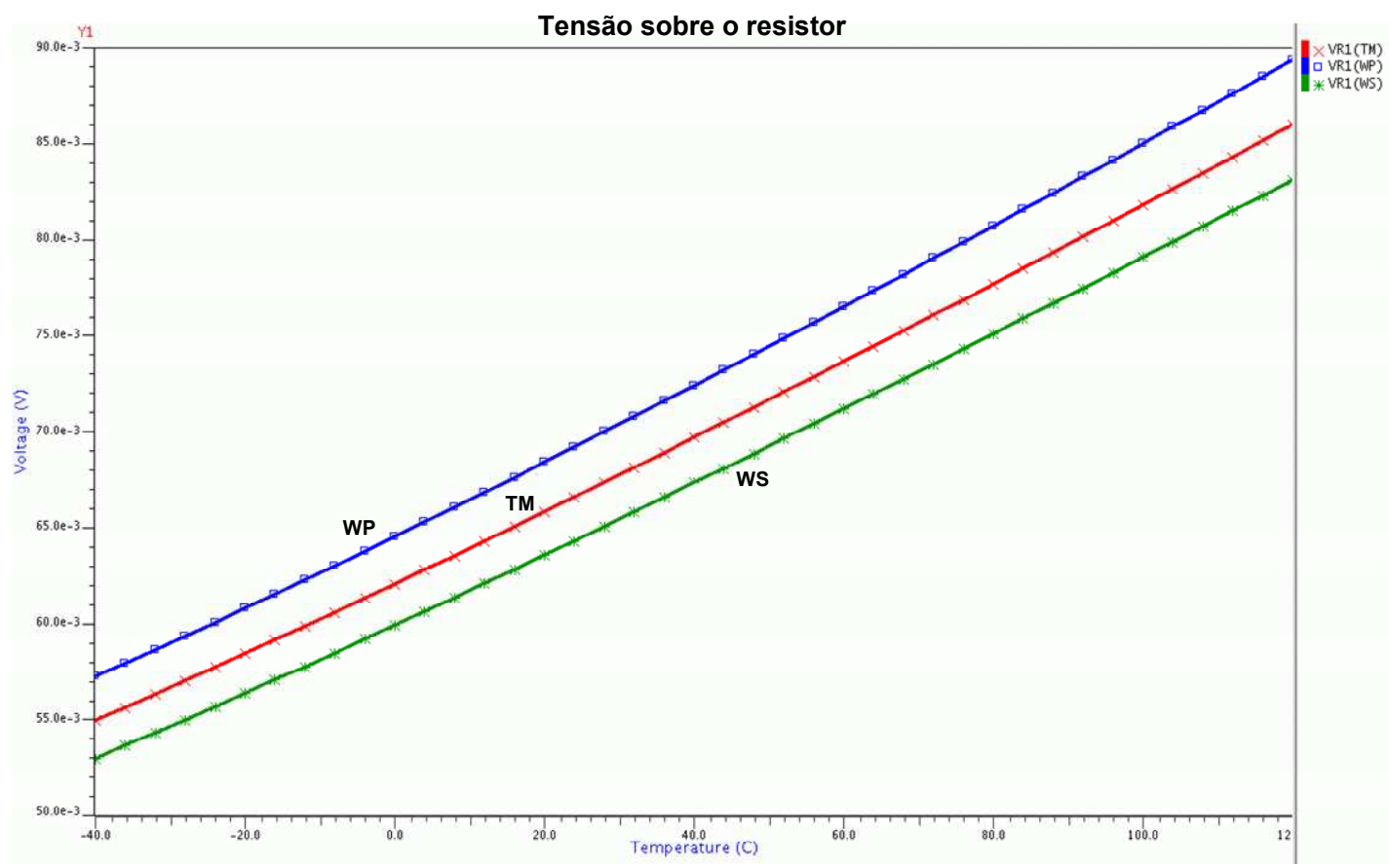

Figura 23. Gráfico de $V_{R I}$ x Temperatura, utilizando os parâmetros típicos (TM), worst speed (WS) e worst power (WP) da tecnologia e com $V_{D D}$ de $3,3 \mathrm{~V}$. 


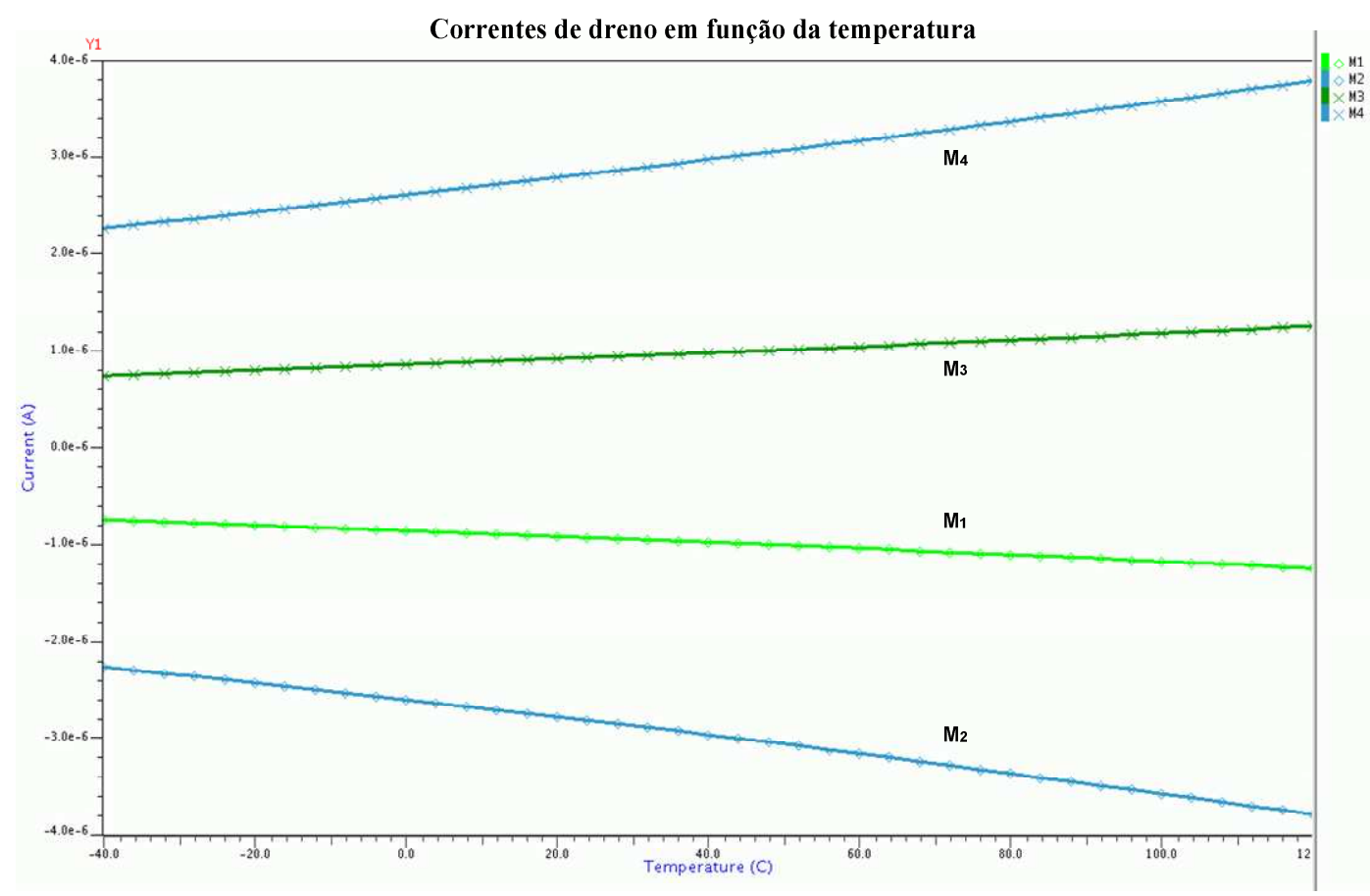

Figura 24. Gráfico de $I_{D}$ x Temperatura dos transistores $M_{1}, M_{2}, M_{3}$ e $M_{4}$, utilizando parâmetros típicos da tecnologia e com $V_{D D}=3,3 \mathrm{~V}$.

Tabela 6. Valores das correntes de dreno nos transistores $M_{1}$ e $M_{2}$ e relação entre elas para algumas temperaturas de operação.

\begin{tabular}{|c|c|c|}
\hline $\begin{array}{c}\text { Temperatura de } \\
\text { simulação }\end{array}$ & $\mathbf{- 4 0}^{\mathbf{0}} \mathbf{C}$ & $\mathbf{1 2 0}^{\mathbf{}} \mathbf{C}$ \\
\hline $\boldsymbol{I}_{\boldsymbol{D} 1}\left(\mathbf{M}_{1}\right)$ & $0,747 \mu \mathrm{A}$ & $1,248 \mu \mathrm{A}$ \\
\hline $\boldsymbol{I}_{\boldsymbol{D} 2}\left(\mathbf{M}_{\mathbf{2}}\right)$ & $2,268 \mu \mathrm{A}$ & $3,788 \mu \mathrm{A}$ \\
\hline $\boldsymbol{I}_{\boldsymbol{D} 2} / \boldsymbol{I}_{\boldsymbol{D} 1}$ & 3,036 & 3,035 \\
\hline
\end{tabular}

As próximas simulações, Figuras 25, 26 e 27, incluem os demais componentes do circuito bandgap (o transistor $M_{5}$, o resistor $R_{2}$ e o transistor bipolar $Q_{6}$ ). Nelas observaremos o comportamento da tensão de saída do bandgap para diferentes valores de tensão de alimentação e de temperatura. Neste caso utilizaram-se nas simulações tanto os parâmetros típicos como o worst speed e o worst power.

Na Figura 25 são mostradas as tensões de saída do circuito em três temperaturas diferentes, $-40{ }^{\circ} \mathrm{C}, 50{ }^{\circ} \mathrm{C}$ e $120{ }^{\circ} \mathrm{C}$, como função da tensão de alimentação que varia de $1 \mathrm{~V}$ a $4 \mathrm{~V}$, utilizando parâmetros típicos.

Na Figura 26 é mostrada a tensão de saída, para simulações com parâmetros típico, worst speed e worst power, em função da tensão de alimentação que varia de $1 \mathrm{~V}$ a $4 \mathrm{~V}$. Neste gráfico a temperatura é de $50{ }^{\circ} \mathrm{C}$. As curvas para os diferentes 
parâmetros são praticamente paralelas e a distância entre as curvas WP e WS é de 55 $\mathrm{mV}$ quando a tensão de alimentação é de 3,3 V.

A Tabela 7 fornece os valores das tensões de saída para alguns valores particulares de tensão de alimentação e temperatura, para os parâmetros típicos $\left(V_{\text {OUT }}(\boldsymbol{T M})\right)$, worst speed $\left(V_{\text {OUT }}(\boldsymbol{W S})\right)$ e worst power $\left(V_{\text {OUT }}(\boldsymbol{W P})\right)$. A tensão de saída na temperatura de referência, $50^{\circ} \mathrm{C}$, para alimentação de $3,3 \mathrm{~V}$ é de $(1,3 \pm 0,028) \mathrm{V}$; para alimentação de $2 \mathrm{~V}$ esta tensão será de $(1,274 \pm 0,026) \mathrm{V}$; para alimentação de 4 $\mathrm{V}$, está tensão será de $(1,311 \pm 0,028) \mathrm{V}$.

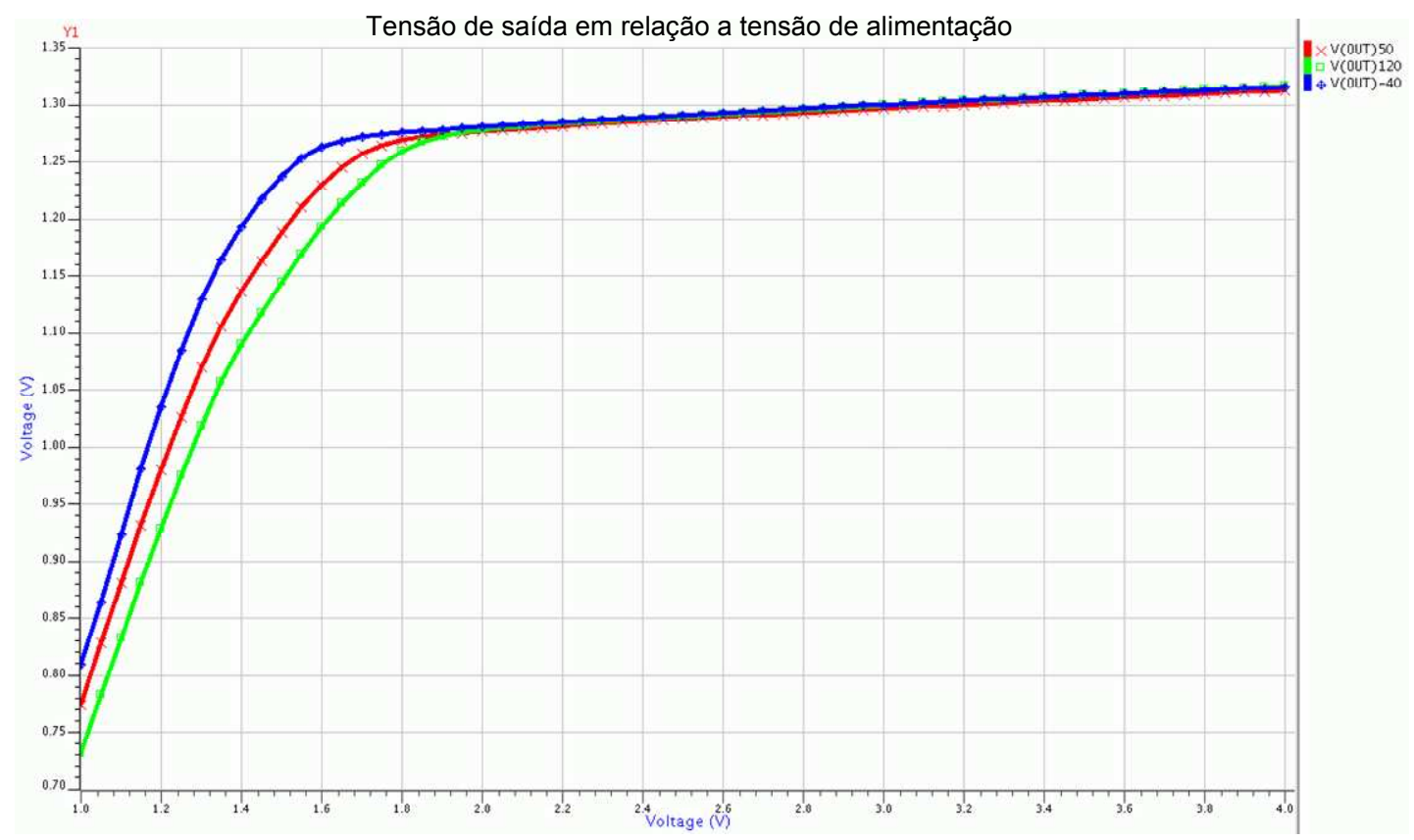

Figura 25. Gráficos de simulação de $V_{O U T} \times V_{D D}$ do circuito de bandgap para diferentes temperaturas $\left(-40^{\circ} \mathrm{C}, 50^{\circ} \mathrm{C}\right.$ e $\left.120^{\circ} \mathrm{C}\right)$, utilizando parâmetros típicos.

Pelos resultados destas simulações podemos ver que a tensão obtida na saída depende da tensão de alimentação e das características do transistor. Observemos que para se conseguir um valor preciso de tensão na saída deste bandgap serão necessários ajustes no valor dos resistores para compensar as variações nos transistores. 
Tabela 7. Valores de $V_{\text {OUT }}$ para as temperaturas de $-40{ }^{\circ} \mathrm{C}, 50^{\circ} \mathrm{C}$ e $120^{\circ} \mathrm{C}$ do circuito bandgap nas tensões de $2 \mathrm{~V}, 3,3 \mathrm{~V}$ e $4 \mathrm{~V}$.

\begin{tabular}{|c|c|c|c|c|}
\hline & $\mathbf{T}\left({ }^{\circ} \mathbf{C}\right)$ & $2 \mathrm{~V}$ & $3,3 \mathrm{~V}$ & $4 V$ \\
\hline \multirow{3}{*}{ V $_{\text {OUT(TM) }}(\mathbf{V})$} & 120 & 1,2777 & 1,3048 & 1,3157 \\
\hline & 50 & 1,2765 & 1,3014 & 1,3125 \\
\hline & -40 & 1,2806 & 1,3048 & 1,3163 \\
\hline \multirow{3}{*}{ V $_{\text {OUT(WS) }}(\mathbf{V})$} & 120 & 1,2445 & 1,2689 & 1,2796 \\
\hline & 50 & 1,2488 & 1,2719 & 1,2823 \\
\hline & -40 & 1,2593 & 1,2822 & 1,2925 \\
\hline \multirow{3}{*}{$\mathbf{V}_{\text {OUT(WP) }}(\mathbf{V})$} & 120 & 1,3041 & 1,3351 & 1,3479 \\
\hline & 50 & 1,3001 & 1,3271 & 1,3392 \\
\hline & -40 & 1,3013 & 1,3270 & 1,3386 \\
\hline
\end{tabular}

Tensão de saída para os três parâmetros de simulação

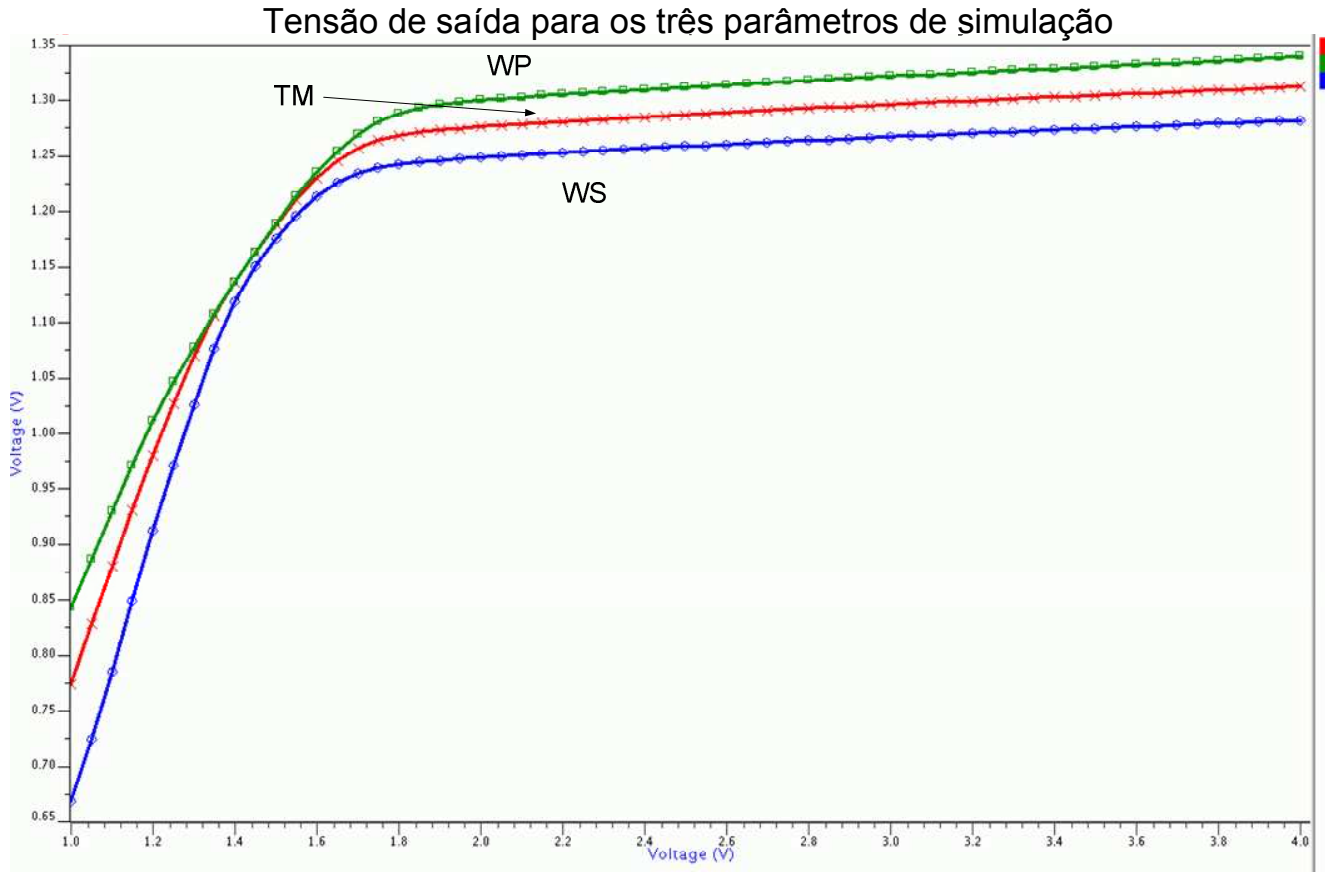

Figura 26. Gráfico de $V_{O U T} \times V_{D D}$ do circuito bandgap utilizando os parâmetros típicos (TM), worst speed (WS) e worst power (WP) e temperatura de $50^{\circ} \mathrm{C}$.

Na Figura 27 é mostrada a tensão de saída do circuito, para simulações com parâmetros típicos, worst speed e worst power, em função da temperatura que varia de $-40{ }^{\circ} \mathrm{C}$ a $120{ }^{\circ} \mathrm{C}$. A tensão de alimentação é mantida aqui em 3,3 V. É possível visualizar que há, para cada uma das três curvas, uma diferente temperatura onde a derivada é zero (coeficiente de temperatura local igual a zero). Para os parâmetros de simulação típicos, worst speed e worst power a temperatura onde a derivada é zero está em $27{ }^{\circ} \mathrm{C}, 115{ }^{\circ} \mathrm{C}$ e $0{ }^{\circ} \mathrm{C}$ respectivamente. Estas diferenças são devidas, 
principalmente, às variações nas correntes encontradas no circuito para as simulações com os três parâmetros.

Como foi dito na seção 4.1 por meio de simulações pré-layout o circuito foi ajustado para ter o coeficiente de temperatura local igual a zero na temperatura de referência de $50{ }^{\circ} \mathrm{C}$. Vemos que isso não está ocorrendo nem para os parâmetros típicos (utilizados no ajuste pré-layout). A diferença se deve ao valor dos resistores extraído a partir do layout. Dado a grande variação que acontece entre os resultados das simulações com os vários parâmetros, não se achou necessário fazer novos ajustes no valor do resistor $R_{2}$.

A Tabela 8 sumariza as principais informações da Figura 27 e mostra que o coeficiente de temperatura varia de $17 \mathrm{ppm} /{ }^{\circ} \mathrm{C}$, para os parâmetros típicos, à 65 $\mathrm{ppm} /{ }^{\circ} \mathrm{C}$ para os parâmetros worst speed. Para o cálculo dos coeficientes de temperatura do circuito bandgap foi utilizada a seguinte relação

$c t=\frac{V_{\text {OUT (máx) }}-V_{\text {OUT (min) }}}{V_{\text {OUT }(\text { nominal })}\left(T_{(\max )}-T_{(\min )}\right)} 10^{6}$

onde $V_{\text {OUT }}(\max )$ e $V_{\text {OUT }}(\min )$ são a máxima e mínima tensões da saída, $T(\max )$ e $T\left(\right.$ min) são a máxima é mínima temperaturas consideradas em ${ }^{\circ} \mathrm{C}, V_{\text {OUT }}$ (nominal) é a tensão esperada na saída e o resultado é dado em $\mathrm{ppm} /{ }^{\circ} \mathrm{C}$.

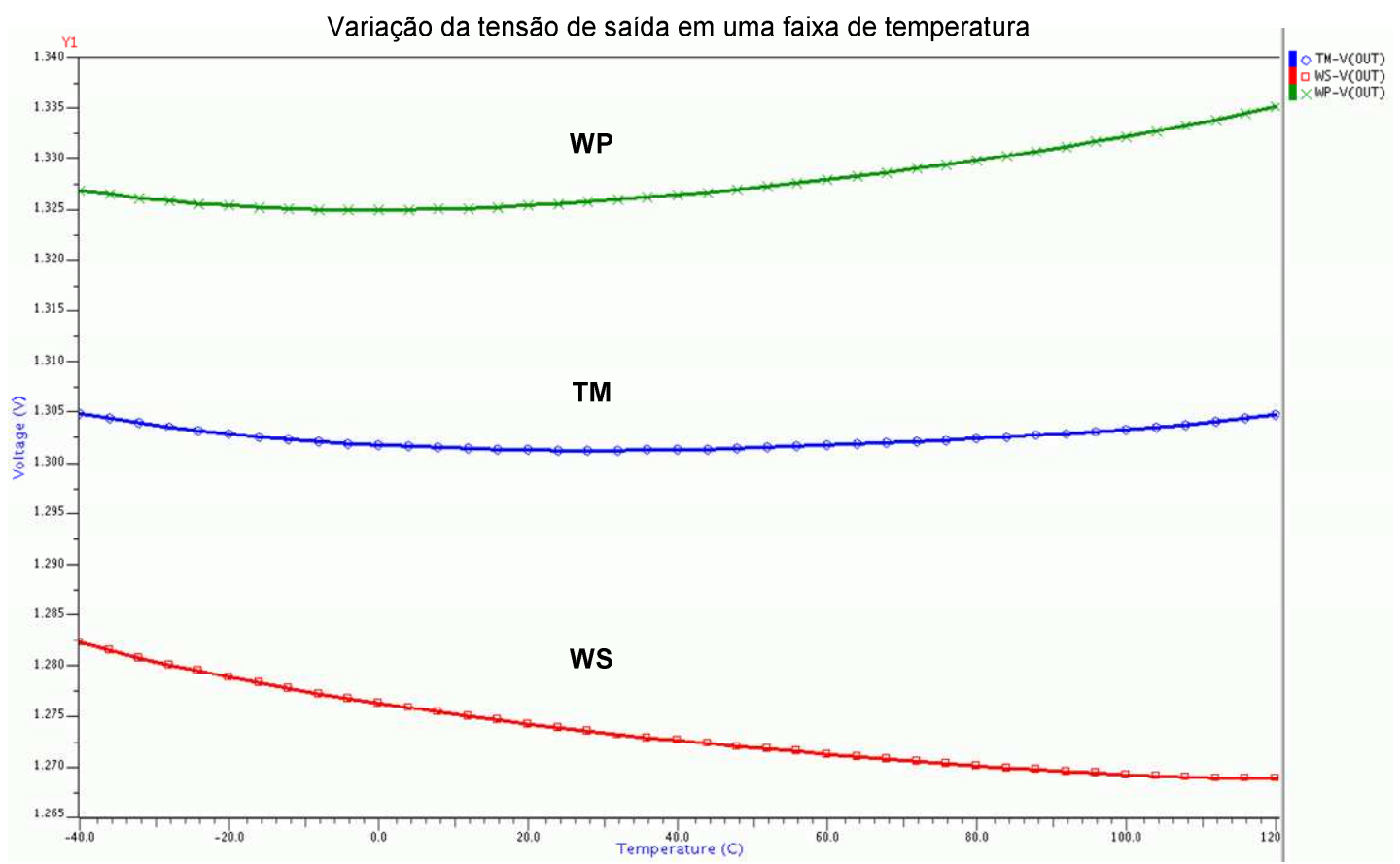

Figura 27. Gráfico de Vout x Temperatura do circuito bandgap utilizando os parâmetros típicos (TM), worst speed (WS) e worst power (WP) e $V_{D D}=3,3 \mathrm{~V}$. 
Tabela 8. Valores máximo e mínimo de $V_{\text {OUT }}$ para diferentes parâmetros de simulação, na faixa de temperatura -40 a $120^{\circ} \mathrm{C}$.

\begin{tabular}{|l|c|c|c|c|}
\hline & $\begin{array}{c}\text { Vmin } \\
(\mathbf{V})\end{array}$ & $\begin{array}{c}\text { Vmáx } \\
(\mathbf{V})\end{array}$ & $\begin{array}{c}\text { Coeficiente de } \\
\text { temperatura zerado }\left({ }^{\circ} \mathbf{C}\right)\end{array}$ & $\begin{array}{c}\text { Coeficiente de } \\
\text { temperatura } \\
\left(\mathbf{p p m} / \mathbf{}^{\circ} \mathbf{C}\right)\end{array}$ \\
\hline V OUT(TM) $_{\text {OTM }}$ & 1,3012 & 1,3048 & 27 & 17 \\
\hline$V_{\text {OUT(WP) }}$ & 1,3249 & 1,3351 & 0 & 48 \\
\hline$V_{\text {OUT(WS) }}$ & 1,2689 & 1,2822 & 115 & 65 \\
\hline
\end{tabular}

\subsection{Conclusões parciais}

Os resultados obtidos por simulação do circuito bandgap em relação à alimentação e a temperatura encaixam-se nas especificações iniciais de projeto. $\mathrm{O}$ coeficiente de temperatura do circuito na faixa extrapolada de $-40{ }^{\circ} \mathrm{C}$ a $120{ }^{\circ} \mathrm{C}$ ficou em aproximadamente $17 \mathrm{ppm} /{ }^{\circ} \mathrm{C}, 65 \mathrm{ppm} /{ }^{\circ} \mathrm{C}$ e $48 \mathrm{ppm} /{ }^{\circ} \mathrm{C}$ para os parâmetros típicos, worst speed e worst power respectivamente. O valor da tensão de saída esta próxima de 1,3 V, acima do valor típico desejado de 1,25 V.

A taxa de variação de $V_{O U T}$ em relação à alimentação, para tensões acima de 2 $\mathrm{V}$, foi de $18 \mathrm{mV} / \mathrm{V}, 17 \mathrm{mV} / \mathrm{V}$ e $20 \mathrm{mV} / \mathrm{V}$ para os parâmetros típicos, worst speed e worst power respectivamente. É interessante observar que esta variação é causada principalmente pela dependência das correntes nos espelhos de corrente com a tensão de alimentação. Esta dependência pode ser reduzida aumentando-se o comprimento de canal dos transistores e considerando-se alguns efeitos de segunda ordem. Uma alternativa é a utilização de espelhos de corrente mais sofisticados, espelho de Wilson, por exemplo, principalmente para os transistores NMOS onde a relação $(W / L)$ é muito alta.

A temperatura em que o coeficiente de temperatura é igual a zero é diferente do valor ajustado no projeto de $50{ }^{\circ} \mathrm{C}$ e varia bastante com os parâmetros usados na simulação. 


\section{RESULTADOS E DISCUSSÕES}

Neste capítulo serão descritos os métodos utilizados para testar os dois circuitos bandgap e os resultados obtidos, além de serem apresentadas discussões. O circuito integrado fabricado na foundry AMS tem dimensões totais, os dois bandgaps juntamente com os PADs, de $771 \mu \mathrm{m}$ x $327 \mu \mathrm{m}$. A Figura 28 apresenta as fotos dos circuitos: o circuito com resistores integrados esta na Figura 28(a); o circuito sem resistores está na Figura 28(b). O número de amostras disponíveis para testes é de cinco para o circuito com resistor, nomeadas am1.1 até am5.1, e cinco para o circuito sem resistor, nomeadas am1.2 até am5.2.

Como o circuito bandgap é um circuito analógico de baixa freqüência os testes puderam ser realizados com ele encapsulado. As duas versões do circuito contidas em um chip foram encapsuladas em um DIL14 (Dual in Line de 14 pinos) e o esquema para encapsulamento está apresentado na Figura 29. Observemos que o par de amostras am1.1 e am1.2 estão no mesmo encapsulamento; o mesmo acontece com os pares am2.1 - am2.2, am3.1 - am3.2, am4.1 - am4.2 e am5.1 - am5.2.

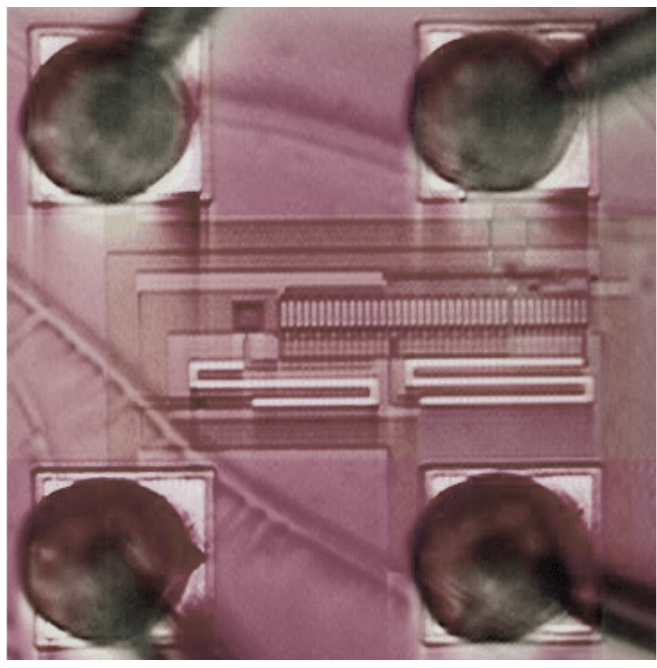

(a)

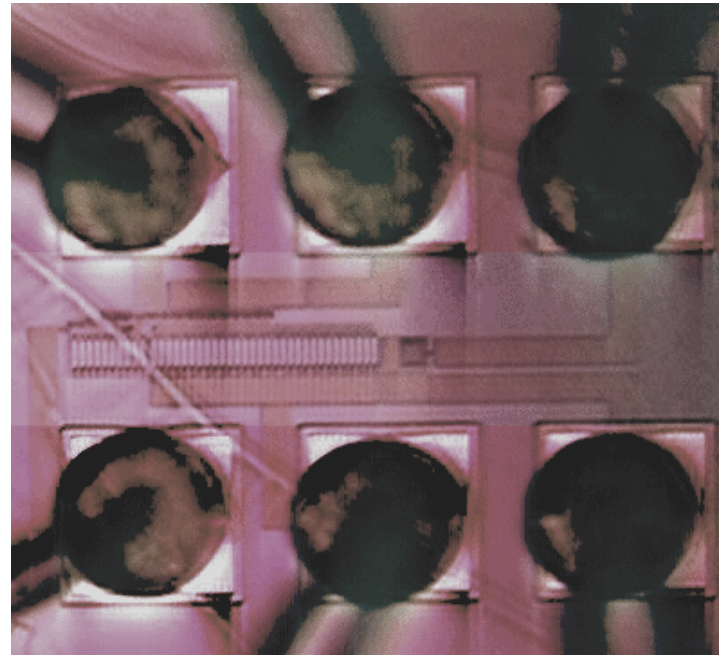

(b)

Figura 28. Fotomicrografia do circuito bandgap fabricado (a) com resistores integrados e (b) sem resistores. 


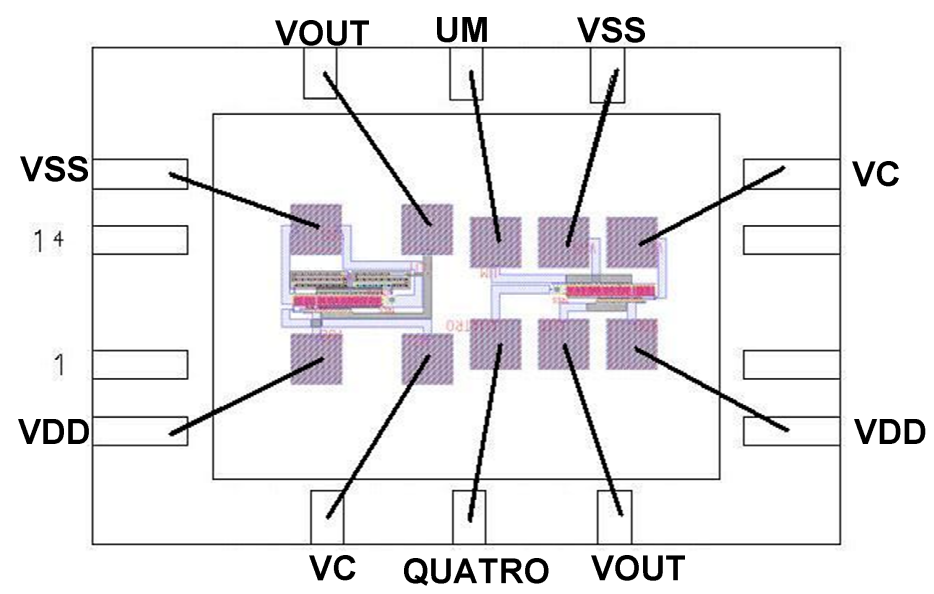

Figura 29. Diagrama para encapsulamento do circuito integrado.

\subsection{Procedimento experimental}

Os testes dos circuitos foram divididos em duas categorias. $\mathrm{Na}$ primeira categoria os testes foram realizados para analisar a variação da tensão de saída com a tensão de alimentação; na segunda, foram realizados para analisar a variação da tensão de saída com a temperatura externa ao circuito.

Observemos inicialmente que, não obstante o cuidado no manuseio dos chips, com a utilização constante de pulseira e superfícies anti-estáticas, as amostras am1.1, am2.1 e am5.1 do circuito com resistores e as amostras am1.2 e am2.2 do circuito sem resistores apresentaram problemas durante os testes: as amostras am1.1, am1.2 e am2.2 "queimaram" no início das medidas; a amostra am2.1, que foi submetida a temperatura de $120^{\circ} \mathrm{C}$, teve seu comportamento degradado; a amostra am5.1 foi danificada durante os testes com a temperatura. Foram feitos alguns testes com as amostras "queimadas" am1.1, am1.2 e am2.2 e verificou-se que estas possuíam fuga de corrente pela porta do transistor $M_{S}$, sugerindo ter havido o rompimento no óxido de porta, dano que normalmente ocorre devido a cargas eletrostática (ESD). Como não se utilizou circuitos de proteção nos $P A D s$, este tipo de problema é bastante provável.

Em consequiência disso, as medidas finais apresentadas se referem às amostras am2.1, am3.1, am4.1 e, em alguns casos, a amostra am5.1 para o circuito com resistor, e as amostras am3.2, am4.2 e am5.2 para o circuito sem resistor. 
Em relação ao transistor de start-up adicionado ao circuito, seu uso não foi necessário em nenhum dos testes.

Os equipamentos que foram usados durante os testes são apresentados a seguir:

1. Uma fonte de alimentação DC da HP-6614C

- Tensão de saída de 0 a 100 V;

- Corrente de saída de 0 a 0,5 A;

- Precisão de $0,03 \%$

2. Multímetro Digital da Agilent-33401A

- Faixa de tensão para medidas de tensão DC de $100 \mathrm{mV}, 1 \mathrm{~V}, 10 \mathrm{~V}, 100 \mathrm{~V}$ e $1000 \mathrm{~V}(750 \mathrm{Vac})$;

- Faixa de Corrente de 10 mA (somente DC), $100 \mathrm{~mA}$ (somente DC), $1 \mathrm{~A} \mathrm{e}$ $3 \mathrm{~A}$;

- Resolução máxima de 100 nV (na faixa de 100 mV);

- Opera com precisão na faixa de temperatura de $0{ }^{\circ} \mathrm{C}$ a $55^{\circ} \mathrm{C}$.

3. Câmara Climática VT 4004 da Vötsch Industrietechnik (Figura 30)

- Opera na faixa de temperatura de $-40{ }^{\circ} \mathrm{C}$ a $130{ }^{\circ} \mathrm{C}$;

- Volume interno de $35 \mathrm{~L}$.

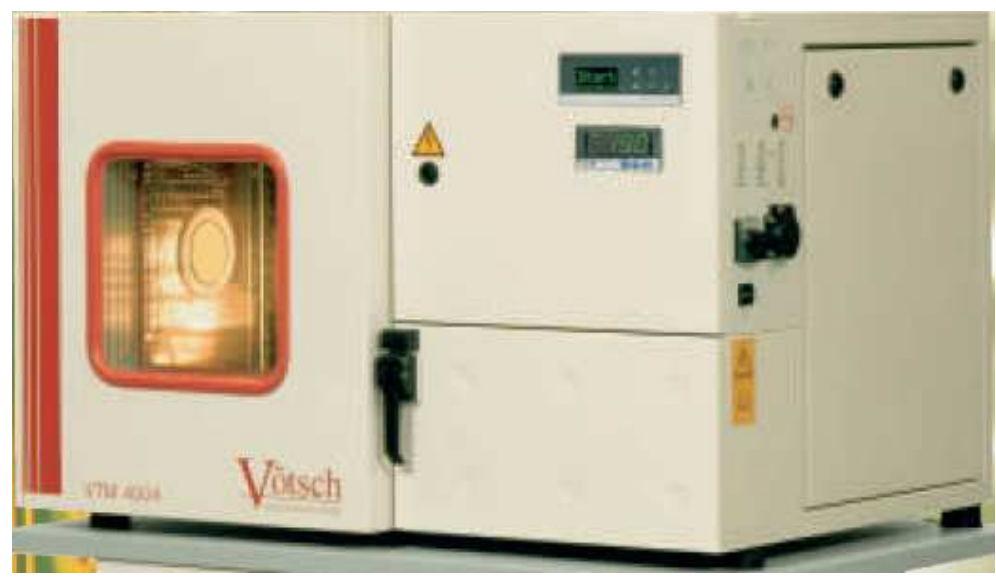

Figura 30. Câmara Climática VT 4004 da Vötsch Industrietechnik usado nas medidas com a temperatura.

Além destes equipamentos, foi utilizada uma placa de fenolite (Figura 31) para montagem do circuito. Foi evitado o uso de protoboards para reduzir influências de maus contatos e evitar problemas com o aquecimento no forno. Na realidade, em testes iniciais com a amostra am2.1 foi feito o uso de protoboard mas este sofreu 
deformações quando submetido à temperatura de $120^{\circ} \mathrm{C}$. Em vista disto optou-se por limitar a temperatura máxima de testes a $100{ }^{\circ} \mathrm{C}$ e utilizar apenas a placa de fenolite.

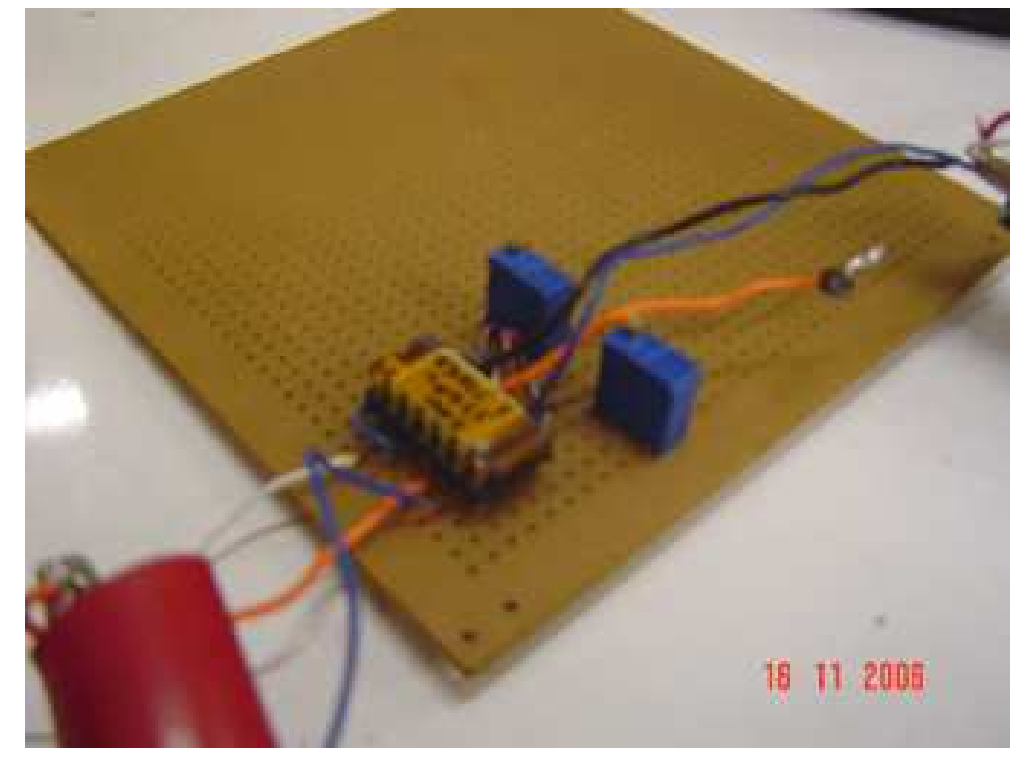

Figura 31. Foto da montagem em uma placa de fenolite usada nas medidas.

Nos circuitos sem os resistores integrados foram acrescentados externamente trimpot's de $100 \mathrm{~K} \Omega$ que foram ajustados através do seguinte procedimento: inicialmente o trimpot que substituiria $R_{l}$, Figura 10, foi ajustado para ter um valor de aproximadamente $68,8 \mathrm{~K} \Omega$ e o trimpot que substituiria $R_{2}$, para ter um valor de aproximadamente $62,8 \mathrm{~K} \Omega$. Em seguida o circuito foi alimentado com $3,3 \mathrm{~V}$ e a tensão de saída foi acertada para 1,25 V através da variação do valor de $R_{2}$ (espera-se que quando a saída do circuito estiver próxima de $V_{G 0}$ o valor derivada do coeficiente de temperatura esteja próximo de zero). Ressaltamos que este ajuste foi feito à temperatura ambiente o que indica, a principio, que estamos zerando a derivada do coeficiente de temperatura não a $50{ }^{\circ} \mathrm{C}$.

Os valores da resistência $R_{2}$ após ajustes ficaram em 65,01 $\mathrm{K} \Omega$, para a amostra am3.2, 61,38 K $\Omega$, para am4.2, e 59,55 K $\Omega$, para am5.2.

Observemos que foram utilizados trimpot's multivoltas de $100 \mathrm{~K} \Omega$, devido ao menor coeficiente de temperatura $\left(100 \mathrm{ppm} /{ }^{\circ} \mathrm{C}\right)$ e a maior faixa de temperatura de operação $\left(-55^{\circ} \mathrm{C}\right.$ a $\left.150{ }^{\circ} \mathrm{C}\right)$ destes componentes [31].

Para os testes feitos em relação à variação da tensão de alimentação, que são simples, foi adotado o seguinte procedimento: a fonte DC da HP foi utilizada como alimentação individual dos circuitos e se aplicaram tensões entre $1,2 \mathrm{~V}$ e 3,0 V, com 
passos de $200 \mathrm{mV}$. A tensão de saída então foi lida diretamente no Multímetro Digital. Todas as medidas aqui foram realizadas a temperatura ambiente de $27^{\circ} \mathrm{C}$.

Nos circuitos com resistores externos houve problemas de instabilidade na sua caracterização em relação à tensão de alimentação: após cada ajuste na tensão de alimentação do circuito a tensão na saída oscilou por cerca de três minutos antes de estabilizar. A amostra onde se teve maior instabilidade foi a am5.2, principalmente para baixas tensões.

Para os testes feitos em relação à variação da temperatura, foi adotado o seguinte procedimento: a câmara climática foi utilizada para fixar a temperatura ambiente entre as temperaturas de $-30{ }^{\circ} \mathrm{C}$ e $100^{\circ} \mathrm{C}$, com passos de $10^{\circ} \mathrm{C}$. A tensão de alimentação é mantida em 3,3 V.

As medidas poderiam ter sido realizadas, a princípio, tanto partindo da temperatura mais baixa e avançando até a mais alta como na direção contrária. $\mathrm{O}$ comportamento do circuito, no entanto, varia de acordo com o procedimento de medida adotado, conforme mostra a Figura 32. Nesta figura estão apresentadas as medidas da tensão de saída da amostra am2.1 em função da temperatura que varia de $-30^{\circ} \mathrm{C}$ a $100^{\circ} \mathrm{C}$. A curva $\mathrm{Medl}$ foi obtida iniciando as medidas em $-30^{\circ} \mathrm{C}$ e elevando a temperatura, em passos de $10^{\circ} \mathrm{C}$, até atingir $100^{\circ} \mathrm{C}$; a curva $\mathbf{M e d} 2$, por sua vez, foi obtida iniciando em $100{ }^{\circ} \mathrm{C}$ e reduzindo a temperatura, em passos de $10{ }^{\circ} \mathrm{C}$, até -30 ${ }^{\circ} \mathrm{C}$. A curva Med1 fornece um coeficiente de temperatura de $189 \mathrm{ppm} /{ }^{\circ} \mathrm{C}$ (equação (32)), enquanto a curva $\boldsymbol{M e d} 2$, de $140 \mathrm{ppm} /{ }^{\circ} \mathrm{C}$. A distância entre elas é de $16 \mathrm{mV}$ a temperatura de $20{ }^{\circ} \mathrm{C}$. Fica claro que os procedimentos de medida influenciam os resultados.

A direção adotada para as medidas foi da temperatura mais alta para a mais baixa. Com isso se reduz possíveis problemas com a umidade do ambiente que em baixas temperaturas pode vir a causar desvios nos resultados ou mesmo danificar o circuito.

Observemos que nas medidas com a temperatura, alguns cuidados foram tomados para garantir que a estabilidade térmica no circuito fosse alcançada. Assim, após o mostrador da câmara climática indicar que esta atingiu a temperatura desejada, se aguardou mais 20 minutos, em média, para permitir que a temperatura 
interna do CI entrasse em equilíbrio com a temperatura da câmara. Só então foram tomadas as medidas.

Todos os valores medidos podem ser encontrados no Anexo C.

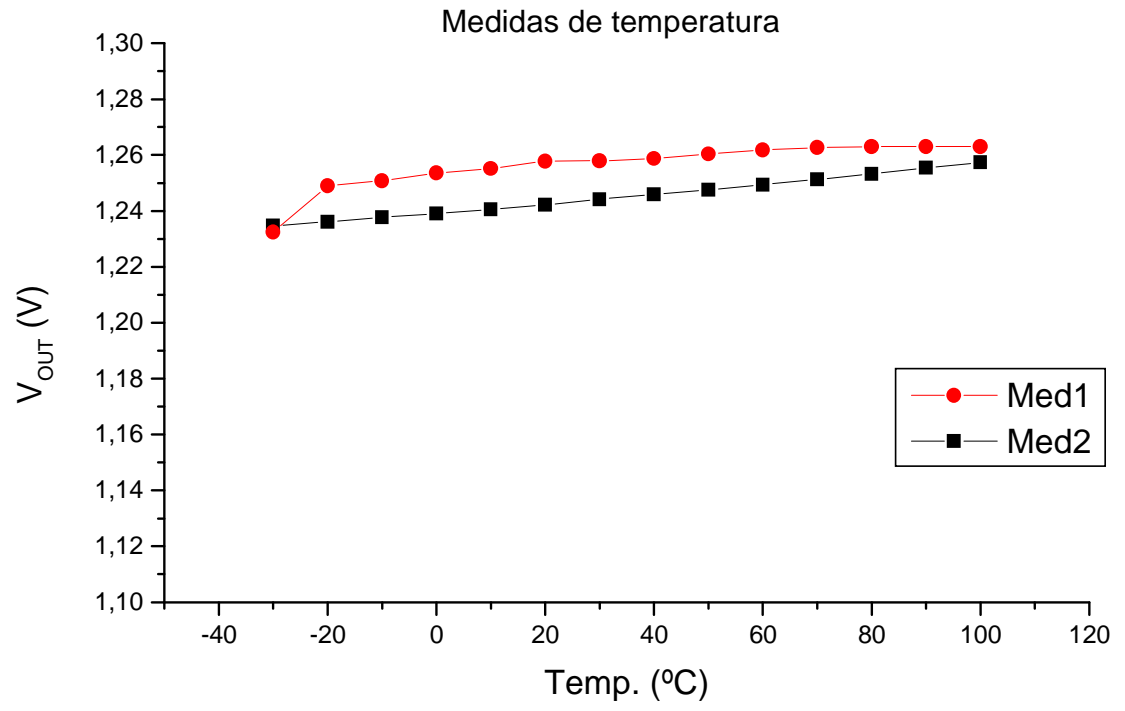

Figura 32. Caracterização da amostra am2.1 com a variação da temperatura utilizando dois procedimentos diferentes $\left(V_{D D}=3,3 \mathrm{~V}\right)$.

\subsection{Resultados de caracterização}

A apresentação dos resultados da caracterização dos circuitos será dividida em duas seções. Na primeira serão mostrados os resultados relacionados à variação da tensão de alimentação e na segunda, os resultados relacionados à variação da temperatura.

\subsubsection{Caracterização com a tensão de alimentação}

Na Figura 33 estão as tensões de saída das quatro amostras testadas para o circuito com resistores integrados em função da tensão de alimentação, estas medidas foram realizadas a temperatura ambiente de $27{ }^{\circ} \mathrm{C}$. Podemos observar que para tensões de alimentação superiores a $1,8 \mathrm{~V}$ o comportamento da tensão de saída é praticamente constante. Fazendo uma rápida comparação entre as Figuras 33 e 25, resultados simulados, é possível perceber que as curvas nestes gráficos tem comportamento similar. 
Tomando 1,8 V como tensão mínima de operação e 3,3 V como tensão máxima, obtêm-se os resultados da Tabela 9.

Tabela 9. Valores de tensão de saída para tensões de alimentação mínima (1,8 V) e máxima (3,3 V), para o circuito bandgap com resistores integrados.

\begin{tabular}{|c|c|c|}
\hline Amostras & $\begin{array}{c}\text { Min. } \\
(\mathbf{V})\end{array}$ & $\begin{array}{c}\text { Máx. } \\
(\mathbf{V})\end{array}$ \\
\hline $\boldsymbol{a m - 2 . 1}$ & 1,207 & 1,238 \\
\hline $\boldsymbol{a m}-\mathbf{3 . 1}$ & 1,223 & 1,257 \\
\hline $\boldsymbol{a m}-\mathbf{4 . 1}$ & 1,147 & 1,178 \\
\hline $\mathbf{a m}-\mathbf{5 . 1}$ & 1,195 & 1,229 \\
\hline
\end{tabular}

É possível fazer duas considerações a partir dos resultados da tabela acima. A primeira é que todos os circuitos apresentam tensões de saída dentro da faixa de especificações iniciais de projeto $(1,1 \mathrm{~V}$ a 1,3 V) para a tensão de alimentação de 3,3 V. Em relação à tensão de saída desejada, 1,25 V para tensão de alimentação de 3,3 $\mathrm{V}$, a amostra $\boldsymbol{a m} \mathbf{- 3 . 1}$ apresentou o menor desvio, $7 \mathrm{mV}$, e a amostra $\boldsymbol{a m} \mathbf{- 4 . 1}$ o maior, $72 \mathrm{mV}$.

Uma segunda consideração é que em todas as amostras a taxa de variação na tensão de saída com a tensão de alimentação está próxima de $20 \mathrm{mV} / \mathrm{V}$ (tensão de alimentação variando entre $1,8 \mathrm{~V}$ e $3,3 \mathrm{~V}$ )

As amostras medidas apresentaram curvas com comportamento e valores de tensão de saída próximos aos obtidos por simulação utilizando o parâmetro worst power. 
Medidas para diferentes tensões de alimentação

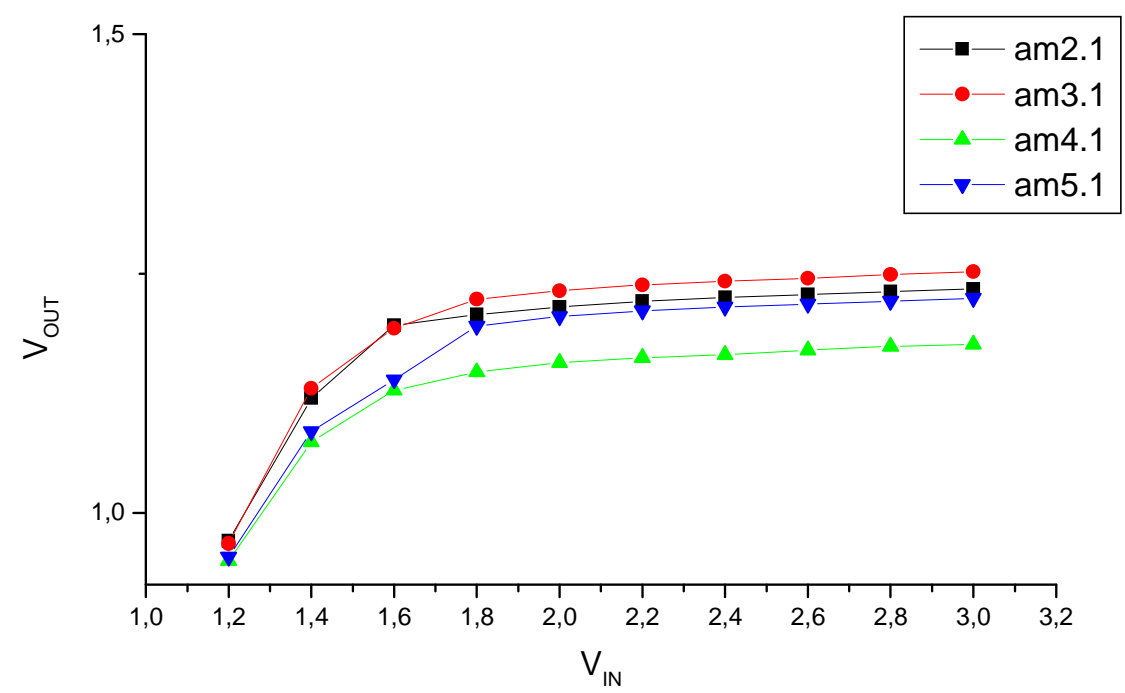

Figura 33. Medidas da tensão de saída em relação à alimentação dos circuitos com resistores integrados, realizadas à temperatura ambiente de $27^{\circ} \mathrm{C}$.

Após as medidas de caracterização das amostras dos circuitos com resistor integrado, foram testadas as amostras do circuito sem resistor.

Na Figura 34 são apresentadas as tensões de saída das três amostras para o circuito sem resistores em função da tensão de alimentação. Os circuitos sem os resistores mostram um comportamento similar aos circuitos com resistores, estando, naquele caso, as curvas mais próximas. Podemos observar que para tensões de alimentação acima de $1,8 \mathrm{~V}$ o comportamento da tensão de saída é praticamente constante.

Como antes, tomando 1,8 V como tensão mínima de operação e 3,3 V como tensão máxima, obtém-se os resultados da Tabela 10.

Tabela 10. Valores de tensão de saída para tensões de alimentação mínima (1,8 V) e máxima (3,3 V), para o circuito bandgap sem resistores integrados.

\begin{tabular}{|c|c|c|}
\hline Amostras & $\begin{array}{c}\text { Min. } \\
(\mathbf{V})\end{array}$ & $\begin{array}{c}\text { Máx. } \\
(\mathbf{V})\end{array}$ \\
\hline $\boldsymbol{a m}-\mathbf{3 . 2}$ & 1,226 & 1,258 \\
\hline $\boldsymbol{a m}-\mathbf{4 . 2}$ & 1,225 & 1,256 \\
\hline $\boldsymbol{a m}-\mathbf{5 . 2}$ & 1,221 & 1,252 \\
\hline
\end{tabular}


Observando a Tabela 10 verifica-se que, em relação à tensão de saída desejada, 1,25 V para tensão de alimentação de 3,3 V, a amostra am-5.2 apresentou o menor desvio, $2 \mathrm{mV}$, e a amostra am-3.2, o maior, $8 \mathrm{mV}$. Estes valores poderiam ser reduzidos se os trimpot's utilizados como $R_{2}$ permitissem um ajuste mais fino.

A taxa de variação da tensão de saída com a tensão de alimentação foi de 20 $\mathrm{mV} / \mathrm{V}$ nas amostras am3.2 e am4.2, resultado semelhante aos resultados das amostras do circuito anterior. Em am5.2 esta taxa foi maior, de $28 \mathrm{mV} / \mathrm{V}$.

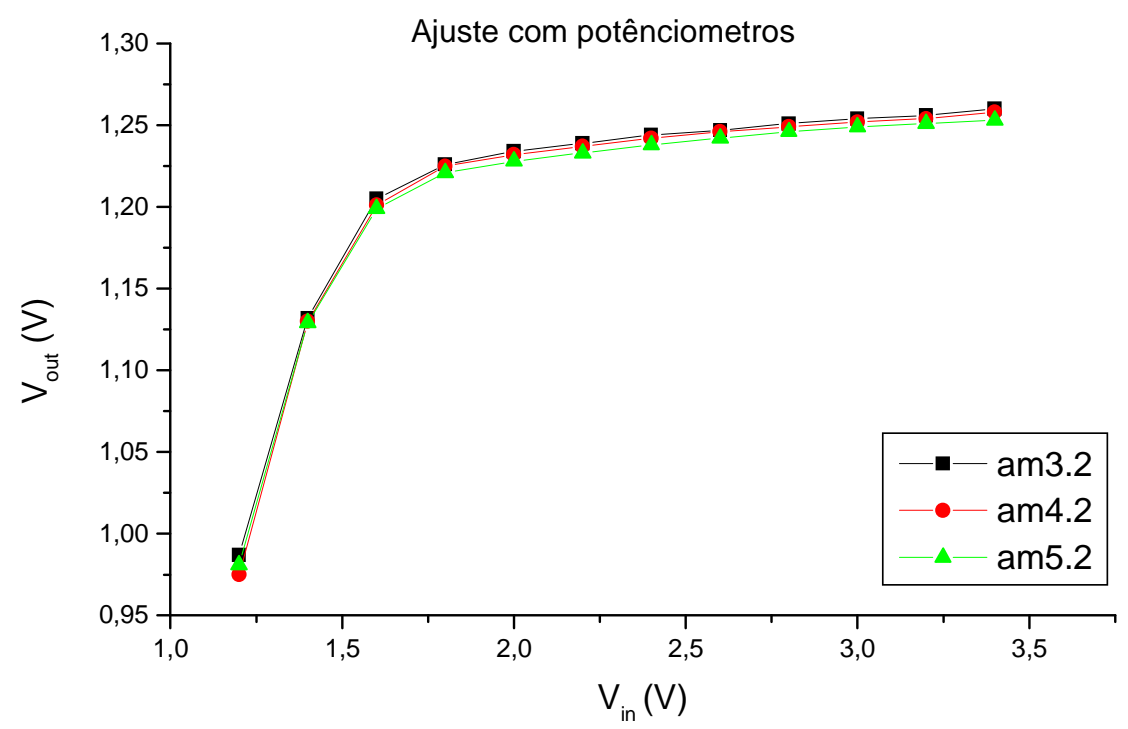

Figura 34. Medidas da tensão de saída em relação à alimentação dos circuitos com resistores externos, realizadas à temperatura ambiente de $27^{\circ} \mathrm{C}$.

\subsubsection{Caracterização com a temperatura}

Apresentamos nesta seção os resultados de caracterização dos circuitos com a temperatura que foi executada na câmara climática de acordo com o procedimento descrito anteriormente. Nestes testes as medidas dos dois circuitos contidos em cada encapsulamento foram realizadas juntas para reduzir o tempo de caracterização.

Na Figura 35 são apresentadas as tensões de saída das duas amostras testadas para o circuito com resistores integrados em função da temperatura de operação. A tensão de saída à temperatura de $50^{\circ} \mathrm{C}$ e o coeficiente de temperatura são de $1,256 \mathrm{~V}$ e $40 \mathrm{ppm} /{ }^{\circ} \mathrm{C}$, para a amostra $\boldsymbol{a m 3 . 1}$, e de $1,184 \mathrm{~V}$ e $35 \mathrm{ppm} /{ }^{\circ} \mathrm{C}$ para a amostra $\boldsymbol{a m 4 . 1}$. Para obter os coeficientes de temperatura foi utilizada a equação (32). Há uma 
diferença de aproximadamente $72 \mathrm{mV}$ entre as tensões de saída e de $5 \mathrm{ppm} /{ }^{\circ} \mathrm{C}$ entre os coeficientes de temperatura das duas amostras.

Podemos comparar o gráfico da Figura 35 com o gráfico da Figura 27, onde estão apresentados os resultados de simulação. Na Figura 35 as curvas são crescentes enquanto na Figura 27 elas são côncavas tendo um ponto de mínimo. A possível razão para a diferença é que o ponto onde a derivada da função da tensão se anula, derivada em relação à temperatura, está abaixo de $-30{ }^{\circ} \mathrm{C}$ ou acima de $100{ }^{\circ} \mathrm{C} . \mathrm{O}$ valor deste ponto depende, como visto, do comportamento dos transistores e também das relações entre os resistores e entre os transistores.

Medidas de temperatura

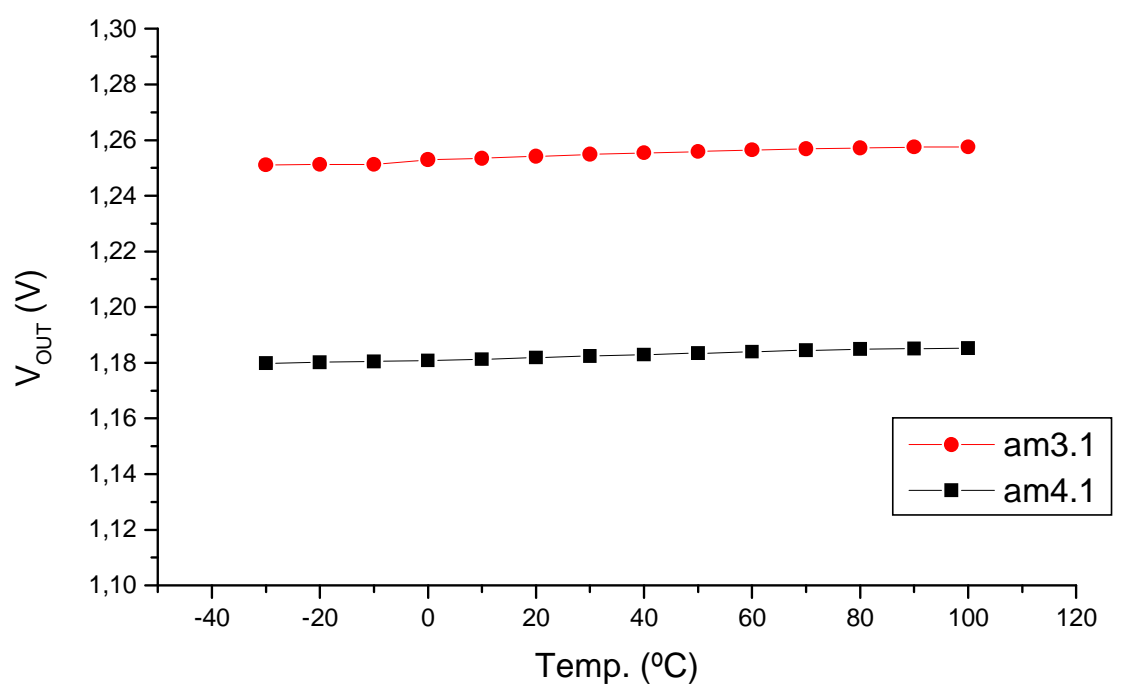

Figura 35. Medidas da tensão de saída em relação à temperatura, dos circuitos com resistores integrados $\left(V_{D D}=3,3 \mathrm{~V}\right)$.

Após apresentar as medidas de caracterização nas amostras do circuito com resistor integrado, apresentamos os resultados das três amostras do circuito sem resistor.

Na Figura 36 são apresentadas as tensões de saída das três amostras testadas para o circuito sem resistores integrados em função da temperatura de operação. A tensão de saída à temperatura de $50^{\circ} \mathrm{C}$ e o coeficiente de temperatura são de $1,254 \mathrm{~V}$ e $95 \mathrm{ppm} /{ }^{\circ} \mathrm{C}$, para a amostra $\boldsymbol{a m 3 . 2}$, de $1,259 \mathrm{~V}$ e $51 \mathrm{ppm} /{ }^{\circ} \mathrm{C}$, para a amostra $\boldsymbol{a m 4 . 2}$, e de $1,247 \mathrm{~V}$ e 31 ppm/ ${ }^{\circ} \mathrm{C}$ para a amostra am5.2. As amostras am4.2 e am5.2 apresentaram resultados satisfatórios, o que não acontece com a amostra am3.2 que tem alto coeficiente de temperatura. 
Comparando o gráfico da Figura 36 com o gráfico da Figura 27 podemos observar que: as medidas para as três amostras são mais irregulares do que aquelas da simulação; agora apenas a curva da amostra am3.2 é estritamente crescente.

O comportamento mais irregular apresentado no gráfico da Figura 36 pode ter sido causado pelo o ruído introduzido pelos potenciômetros externos. $\mathrm{O}$ procedimento de ajuste de $R_{2}$, que não necessariamente zera o coeficiente de temperatura na temperatura de $50^{\circ} \mathrm{C}$, pode ser o maior responsável pelo alto valor do coeficiente de temperatura determinado com a amostra $\mathbf{a m 3 . 2}$.

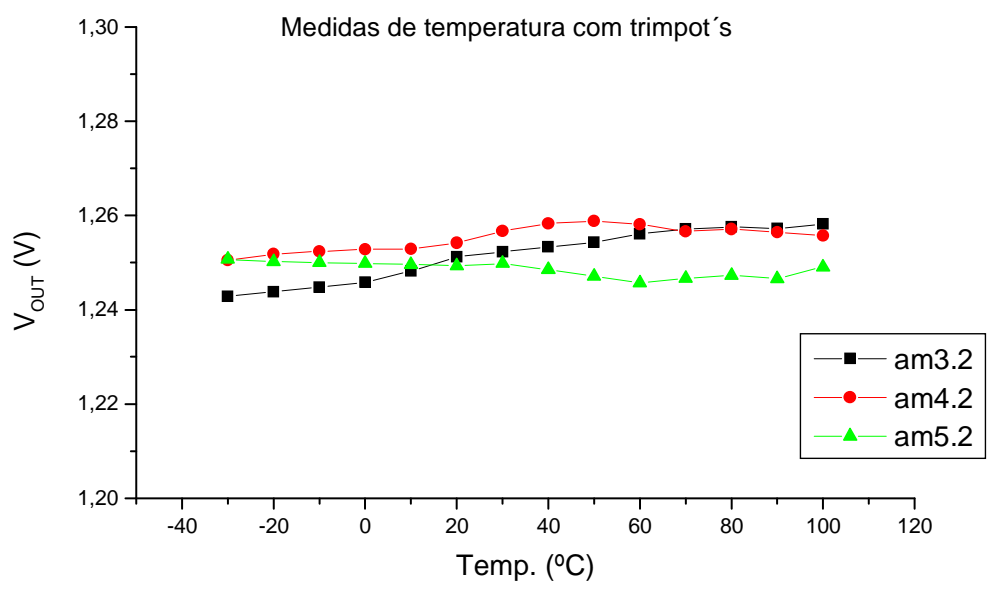

Figura 36. Medidas da tensão de saída em relação à temperatura, dos circuitos sem resistores integrados $\left(V_{D D}=3,3 \mathrm{~V}\right)$. 


\section{CONCLUSÕES}

Para este projeto foi feito o estudo de algumas das topologias mais conhecidas de fontes de tensão de referência. A partir deste estudo foi escolhida a topologia mais adequada para atingir especificações desejadas, tais como: o coeficiente de temperatura, tensão de alimentação além de permitir a integração completa.

Uma vez escolhida a topologia foi feito o projeto e realizada a simulação do circuito. Verificado seu correto funcionamento realizou-se seu layout e procedeu-se a extração dos netlists para novas simulações, executadas com o software ELDO.

Conforme descrito anteriormente todos os circuitos foram projetados para a foundry AMS com tecnologia CMOS de $0,35 \mu \mathrm{m}$, sendo que a dimensão total dos dois circuitos mais os $P A D s$ de entrada/saída é de $771 \mu \mathrm{m} \times 327 \mu \mathrm{m}$.

Durante a caracterização dos circuitos foram danificadas as amostras am1.1, am2.1 e am5.1 do circuito com resistores e as amostras am1.2 e am2.2 do circuito sem resistores, não obstante o cuidado no manuseio dos chips, com a utilização constante de pulseira e superfícies anti-estáticas. Foram feitos alguns testes com algumas amostras com problemas e verificou-se que estas possuíam fuga de corrente pela porta do transistor $M_{S}$, sugerindo ter havido o rompimento no óxido de porta, dano que normalmente ocorre devido a cargas eletrostática (ESD).

Das medidas experimentais verificamos que os circuitos com resistor integrado podem ser utilizados com tensões de alimentação abaixo da especificação inicial, uma vez que sua saída varia pouco a partir de tensões de alimentação acima de 1,8 V. Além disso, as amostras tiveram uma taxa de variação na saída com a tensão de alimentação próxima de $19 \mathrm{mV} / \mathrm{V}$ (tensão de alimentação variando entre 1,8 V e 3,3 V).

Em relação ao comportamento com a temperatura observou-se que as amostras am3.1 e am4.1 apresentam tensão de saída a temperatura de $50{ }^{\circ} \mathrm{C}$ e o coeficiente de temperatura de $1,256 \mathrm{~V}$ e $40 \mathrm{ppm} /{ }^{\circ} \mathrm{C}$ e de $1,184 \mathrm{~V}$ e $35 \mathrm{ppm} /{ }^{\circ} \mathrm{C}$ respectivamente.

A Tabela 11 apresenta as especificações iniciais desejadas e os resultados obtidos para o circuito com resistores integrados. Verifica-se que os valores medidos nas amostras estão dentro das especificações. É importante observar que a tensão na saída varia de amostra para amostra em dezenas de $\mathrm{mV}$ (para as quatro amostras na 
temperatura de $27^{\circ} \mathrm{C}$, a variação máxima da tensão entre amostras é de $79 \mathrm{mV}$ ). Isto indica que não é possível, sem ajustes, obter uma tensão pré-determinada com precisão.

Tabela 11: Tabela comparativa entre os resultados de medidas e as especificações iniciais para os circuitos com resistores integrados.

\begin{tabular}{|l|c|c|c|c|c|c|}
\hline & Espec. & am2.1 & am3.1 & am4.1 & am5.1 & Unid. \\
\hline T. de saída & $\begin{array}{c}1,10 \text { a } 1,40 \\
\left(50^{\circ} \mathrm{C}\right)\end{array}$ & $\begin{array}{c}1,238 \\
\left(27^{\circ} \mathrm{C}\right)\end{array}$ & $\begin{array}{c}1,256 \\
\left(50{ }^{\circ} \mathrm{C}\right)\end{array}$ & $\begin{array}{c}1,184 \\
\left(50{ }^{\circ} \mathrm{C}\right)\end{array}$ & $\begin{array}{c}1,229 \\
\left(27^{\circ} \mathrm{C}\right)\end{array}$ & $\mathrm{V}$ \\
\hline Coef. de Temp. & 24 a 50 & ${ }^{*}$ & 40 & 35 & ${ }^{*}$ & $\mathrm{ppm} /{ }^{\circ} \mathrm{C}$ \\
\hline T. de alimentação & 3,3 & 3,3 & 3,3 & 3,3 & 3,3 & $\mathrm{~V}$ \\
\hline Temperatura & -30 a 100 & -30 a 100 & -30 a 100 & -30 a 100 & -30 a 100 & ${ }^{\circ} \mathrm{C}$ \\
\hline
\end{tabular}

*Amostra queimada

**Valores de medida descartados devido ao procedimento de medida inadequado

Verificamos também, através das medidas experimentais, que os circuitos com resistor externo podem ser utilizados com tensões de alimentação de até 1,8 V. Além disso, as amostras tiveram uma taxa de variação na saída com a tensão de alimentação entre $20 \mathrm{mV} / \mathrm{V}$ e $28 \mathrm{mV} / \mathrm{V}$ (tensão de alimentação variando entre 1,8 V e $3,3 \mathrm{~V})$.

Em relação ao comportamento com a temperatura observou-se que as amostras am3.3, am4.2 e am5.2 apresentam tensão de saída a temperatura de $50{ }^{\circ} \mathrm{C}$ e o coeficiente de temperatura de $1,254 \mathrm{~V}$ e $95 \mathrm{ppm} /{ }^{\circ} \mathrm{C}$, de $1,259 \mathrm{~V}$ e $51 \mathrm{ppm} /{ }^{\circ} \mathrm{C}$ e de $1,247 \mathrm{~V}$ e $31 \mathrm{ppm} /{ }^{\circ} \mathrm{C}$ respectivamente.

A Tabela 12 apresenta as especificações iniciais e os resultados obtidos para o circuito sem resistores integrados. Verifica-se que os valores medidos nas amostras, exceção do valor do coeficiente de temperatura de am3.2, estão dentro das especificações. Neste circuito, se obteve a tensão de saída bem próximo ao valor típico desejado de $1,25 \mathrm{~V}$ (variação máxima de $9 \mathrm{mV}$ em $50{ }^{\circ} \mathrm{C}$ e de $8 \mathrm{mV}$ na temperatura ambiente). Ajuste melhor depende apenas de um ajuste mais fino no trimpot's utilizados como $R_{2}$. 
Tabela 12: Tabela comparativa entre os resultados de medidas e as especificações iniciais para os circuitos sem resistores integrados.

\begin{tabular}{|l|c|c|c|c|c|}
\hline & Espec. & am3.2 & am4.2 & am5.2 & Unid. \\
\hline Tensão de saída & $\begin{array}{c}1,10 \text { a } 1,40 \\
\left(50^{\circ} \mathrm{C}\right)\end{array}$ & $\begin{array}{c}1,253 \\
\left(50{ }^{\circ} \mathrm{C}\right)\end{array}$ & $\begin{array}{c}1,259 \\
\left(50{ }^{\circ} \mathrm{C}\right)\end{array}$ & $\begin{array}{c}1,247 \\
\left(50{ }^{\circ} \mathrm{C}\right)\end{array}$ & $\mathrm{V}$ \\
\hline Coef. de Temperatura & 24 a 50 & 91 & 51 & 31 & $\mathrm{ppm} /{ }^{\circ} \mathrm{C}$ \\
\hline Tensão de alimentação & 3,3 & 3,3 & 3,3 & 3,3 & $\mathrm{~V}$ \\
\hline Faixa de temperatura & -30 a 100 & -30 a 100 & -30 a 100 & -30 a 100 & ${ }^{\circ} \mathrm{C}$ \\
\hline
\end{tabular}

Para todos os circuitos o consumo de corrente foi de aproximadamente $14 \mu \mathrm{A} \mathrm{e}$ um consumo de potência de aproximadamente $58 \mu \mathrm{W}$, para $V_{D D}$ de $3,3 \mathrm{~V}$, valor baixo, mas que pode ser reduzido.

Em relação ao transistor de start-up que foi adicionado ao circuito, em nenhum dos testes foi necessário acioná-lo.

De forma geral vimos que

- Valores de coeficiente de temperatura da ordem de $40 \mathrm{ppm} /{ }^{\circ} \mathrm{C}$ podem ser obtidos com implementações CMOS simples;

- Tensões de alimentação tão baixas quanto 2 V podem ser utilizadas;

- Valor preciso na tensão de saída exige ajustes de componentes após fabricação;

- Bandgaps com resistores externos podem ser utilizados. Neste caso se obtêm uma precisão maior no valor da tensão de saída mas, aparentemente, com o sacrifício do coeficiente de temperatura.

\subsection{Sugestões para trabalhos futuros}

O tema de geradores para tensão de referência Bandgap foi apenas iniciado neste trabalho e, portanto, existe uma grande quantidade de estudos que podem ser realizados:

- Medir outras amostras (amostras que se encontram com outros grupos que dividiram a área útil do circuito integrado) para melhor conhecer o comportamento dos circuitos implementados. 
- Utilizar espelhos de corrente mais robustos a variações da tensão de alimentação;

- Estudar e implementar configurações de ajuste da tensão de saída do circuito bandgap, de baixo custo e com precisão; 


\section{ANEXO A}

\section{Cálculos da Tensão Base-Emissor do Transistor Bipolar em Função da Temperatura}

Os circuitos bandgap normalmente utilizam transistores bipolares, portanto, é importante conhecer como a tensão base emissor, $V_{B E}$, varia com a temperatura. A seguir serão descritas as relações para determinar a tensão $V_{B E}$ do transistor bipolar e sua dependência com relação à temperatura. Também serão mostradas as relações utilizadas no simulador.

\section{A.1 Método de Cálculo de $V_{B E}$ Desenvolvido por Tsividis [8]}

Esta análise descreve o meio para o cálculo da tensão base-emissor que foi adotado no projeto apresentado neste trabalho. Ele é mais preciso do que outras análises.

Primeiro considerando-se que o transistor esta operando na região ativa e desprezando o efeito Early, teremos que a corrente de coletor, em função da temperatura, é dada por:

$I_{C(T)}=I_{S(T)} e^{\frac{q V_{B E}}{k T}}$

onde $I_{C}$ é a corrente de coletor, $I_{S}$ é a corrente de saturação, $T$ é a temperatura absoluta, $q$ é a carga do elétron e $k$ é a constante de Boltzmann.

Para calcular $V_{B E}$ em função da temperatura consideramos a relação entre as correntes de coletor do transistor operando à temperaturas diferentes, obtendo:

$$
\frac{I_{C(T)}}{I_{C\left(T_{R}\right)}}=\frac{I_{S(T)} e^{\frac{q V_{B E(T)}}{k T}}}{I_{S\left(T_{R}\right)} e^{\frac{q V_{B E\left(T_{R}\right)}}{k T_{R}}}}
$$

onde $T_{R}$ é uma temperatura de referência. 
Da expressão acima podemos isolar $V_{B E}$ na temperatura $T$ :

$V_{B E(T)}=T\left[\frac{V_{B E\left(T_{R}\right)}}{T_{R}}+\frac{k}{q} \ln \left(\frac{I_{C(T)}}{I_{C\left(T_{R}\right)}} \frac{I_{S\left(T_{R}\right)}}{I_{S(T)}}\right)\right]$

A corrente $I_{S}$ na equação (3) pode ser escrita em função de parâmetros do transistor, conforme mostra a relação abaixo:

$$
I_{S(T)}=\frac{q A n_{i}^{2}(T) \bar{D}_{(T)}}{N_{B}}
$$

onde $A$ é a área da junção base-emissor, $n_{i(T)}$ é a concentração intrínseca de portadores (seu valor depende da temperatura), $\bar{D}_{(T)}$ é a constante de difusão efetiva dos portadores minoritários na base (seu valor depende da temperatura) e $N_{B}$ é o número Gummel ou o número total de impurezas por unidade de área na base.

Substituindo (4) em (3) obteremos:

$V_{B E(T)}=T\left[\frac{V_{B E\left(T_{R}\right)}}{T_{R}}+\frac{k}{q} \ln \left(\frac{I_{C(T)}}{I_{C\left(T_{R}\right)}} \frac{\frac{q A n i^{2}{ }_{\left(T_{R}\right)} \bar{D}_{\left(T_{R}\right)}}{N B}}{\frac{q A n i^{2}(T)}{N B} \bar{D}_{(T)}}\right)\right]$

Para detalhar mais a expressão, utilizou-se a seguinte relação para a concentração de portadores intrínsecos :

$n_{i}^{2}(T)=E T^{3} e^{\left[-\frac{q V_{G O(T)}}{k T}\right]}$

onde $V_{G O(T)}$ é a tensão de bandgap a uma temperatura $T$ e E é uma constante.

Substituindo temos a expressão

$$
V_{B E(T)}=T\left[\frac{V_{B E\left(T_{R}\right)}}{T_{R}}+\frac{k}{q} \ln \left(\frac{I_{C(T)}}{I_{C\left(T_{R}\right)}} \frac{\frac{q A E T_{R}{ }^{3} e^{\left[-\frac{q V_{G O\left(T_{R}\right)}}{k T_{R}}\right]_{\left(T_{R}\right)} \bar{D}_{\left(T_{R}\right)}}}{N_{B}}}{\frac{q A E T^{3} e^{\left[-\frac{q V_{G O(T)}}{k T}\right]_{(T)} \bar{D}_{(T)}}}{N_{B}}}\right]\right)
$$


que simplificada resulta em

$V_{B E(T)}=T\left[\frac{V_{B E\left(T_{R}\right)}}{T_{R}}+\frac{k}{q} \ln \left(\frac{I_{C(T)}}{I_{C\left(T_{R}\right)}} \frac{q \bar{D}_{\left(T_{R}\right)}}{q \bar{D}_{(T)}} \frac{T_{R}^{3}}{T^{3}} e^{\left.\left(-\frac{\left.V_{G O\left(T_{R}\right)}+\frac{V_{G O(T)}}{T}\right)}{T_{R}}\right)\right]}\right.\right.$

Assumindo que a mobilidade efetiva dos portadores minoritários na base pode ser obtida pela relação de Einstein

$\bar{\mu}_{(T)}=\frac{q \bar{D}_{(T)}}{k T}$

podemos reescrever a equação (8) como:

$V_{B E(T)}=T\left[\frac{V_{B E\left(T_{R}\right)}}{T_{R}}-\frac{V_{G O\left(T_{R}\right)}}{T_{R}}+\frac{V_{G O(T)}}{T}+\frac{k}{q} \ln \left(\frac{I_{C(T)}}{I_{C\left(T_{R}\right)}} \frac{\bar{\mu}_{\left(T_{R}\right)} k T_{R}}{\bar{\mu}_{(T)} k T} \frac{T_{R}{ }^{3}}{T^{3}}\right)\right]$

onde não mais aparece $\bar{D}_{(T)}$. Para concluir e obter uma relação para a tensão $V_{B E}$ que mostre sua dependência com a temperatura foi aplicada a expressão abaixo que indica a dependência da mobilidade com a temperatura.

$\bar{\mu}_{(T)}=C T^{-\eta}$

onde C e $\eta$ são constantes.

A expressão final para $V_{B E}$ será

$V_{B E(T)}=T\left[\frac{V_{B E\left(T_{R}\right)}}{T_{R}}-\frac{V_{G O\left(T_{R}\right)}}{T_{R}}+\frac{V_{G O(T)}}{T}+\frac{k}{q} \ln \left(\frac{I_{C(T)}}{I_{C\left(T_{R}\right)}} \frac{C T_{R}^{-\eta}}{C T^{-\eta}}\left(\frac{T_{R}}{T}\right)^{4}\right)\right]$

ou

$V_{B E(T)}=T\left[\frac{V_{B E\left(T_{R}\right)}}{T_{R}}-\frac{V_{G O\left(T_{R}\right)}}{T_{R}}+\frac{V_{G O(T)}}{T}\right]-\frac{k T}{q} \ln \left(\frac{T}{T_{R}}\right)^{4-\eta}+\frac{k T}{q} \ln \left(\frac{I_{C(T)}}{I_{C\left(T_{R}\right)}}\right)$ 


\section{A.2 Equações do simulador}

Dado um modelo do transistor bipolar e seus parâmetros, ficam definidas quais são as equações que o simulador utiliza. Vamos aplicar estas equações para determinar o valor de $V_{B E}$ e posteriormente comparar com o resultado apresentado acima.

Iniciamos escrevendo a expressão para $I_{C}$ que agora é

$I_{C(T)}=\frac{I_{S(T)}}{q_{b}} e^{\frac{q V_{B E}}{k T N_{F}}}$

onde $q_{b}$ depende de vários parâmetros tais como tensão de Early direta e reversa, $V_{\text {be }}$, etc. mas que está próximo de um para nosso caso e $N_{F}=0.9925$ é um expoente para modelar a variação de $\beta$ com a corrente.

Ainda, no simulador a corrente $I_{S}$, como função da temperatura, é determinada pelas expressões

$I_{S(T)}=I_{S} e^{f a c I_{(T)}}$

$\operatorname{efacl}_{(T)}=\frac{q V_{G}}{k T_{\text {nom }}}-\frac{q V_{G}}{k T}+X T / \ln \left(\frac{1}{T}\right)$

onde $I_{S}=0,233 \mathrm{fA}$ é a corrente de saturação, $V_{G}=1.115 \mathrm{~V}$ é a tensão de bandgap, $\mathrm{XTI}=5,53$ é o expoente de temperatura para a corrente de saturação e $T_{\text {nom }}$ é a temperatura nominal $\left(27^{\circ} \mathrm{C}\right)$.

Observemos que estas expressões são usadas devido ao valor de um parâmetro chamado TLEV (default=1); outras expressões seriam usadas se este parâmetro tivesse outro valor.

A partir das expressões (2) e (14) chegamos a expressão

$V_{B E(T)}=T\left[\frac{V_{B E\left(T_{R}\right)}}{T_{R}}+N_{F} \frac{k}{q} \ln \left(\frac{I_{C(T)}}{I_{C\left(T_{R}\right)}} \frac{I_{S\left(T_{R}\right)}}{I_{S(T)}}\right)\right]$

Utilizando então as relações para $I_{S}$ obtemos o resultado abaixo

$V_{B E(T)}=T\left[\frac{V_{B E\left(T_{R}\right)}}{T_{R}}-\frac{V_{G}}{T_{R}}+\frac{V_{G}}{T}\right]-\frac{k T}{q} \ln \left(\frac{T_{R}}{T}\right)^{N_{F} X T I}+N_{F} \frac{k T}{q} \ln \left(\frac{I_{C(T)}}{I_{C\left(T_{R}\right)}}\right)$ 
Observe que a expressão acima é semelhante a (13). Lembrando que $N_{F}$ é praticamente igual a um, vemos que a única diferença real entre elas está no fato da tensão de bandgap $V_{G}$ para o simulador ser constante com a temperatura. 


\section{ANEXO B}

\section{Parâmetros de Simulação}

Parâmetros Típicos: Modelo para Transistor Tipo P .MODEL MODP PMOS LEVEL=53 MODTYPE=ELDO

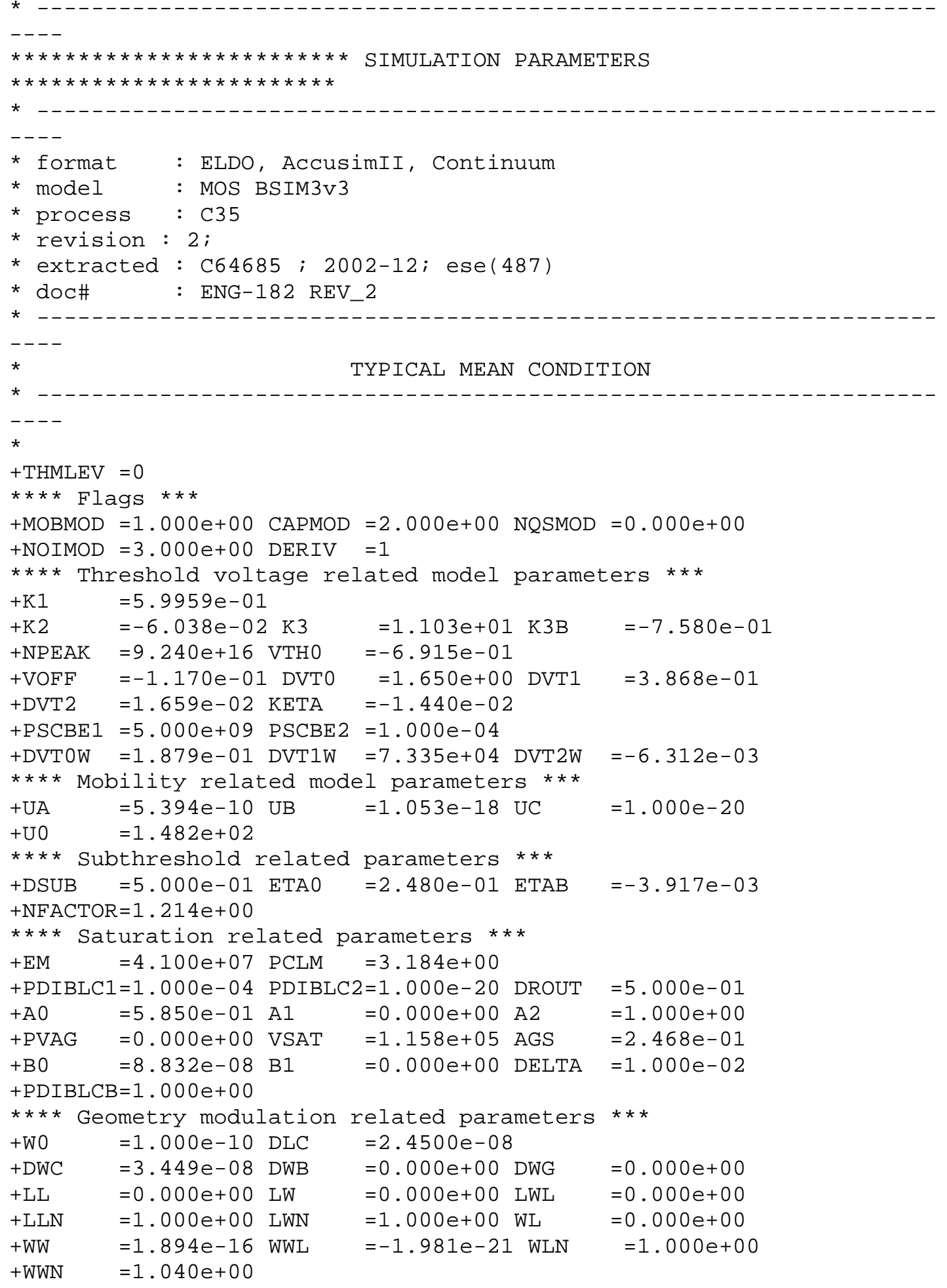




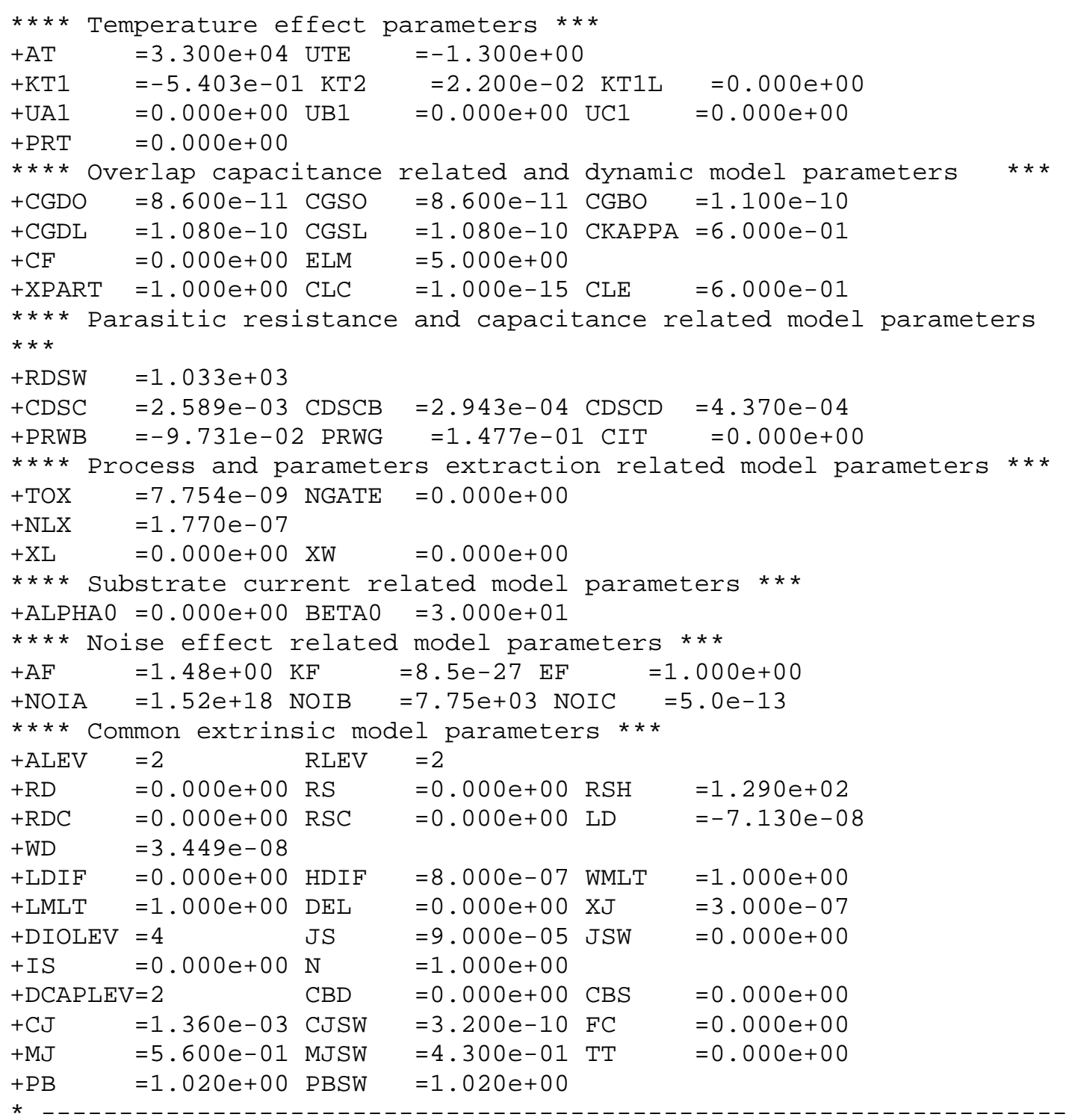

Parâmetros Típicos: Modelo para Transistor Tipo N .MODEL MODN NMOS LEVEL $=53$ MODTYPE=ELDO

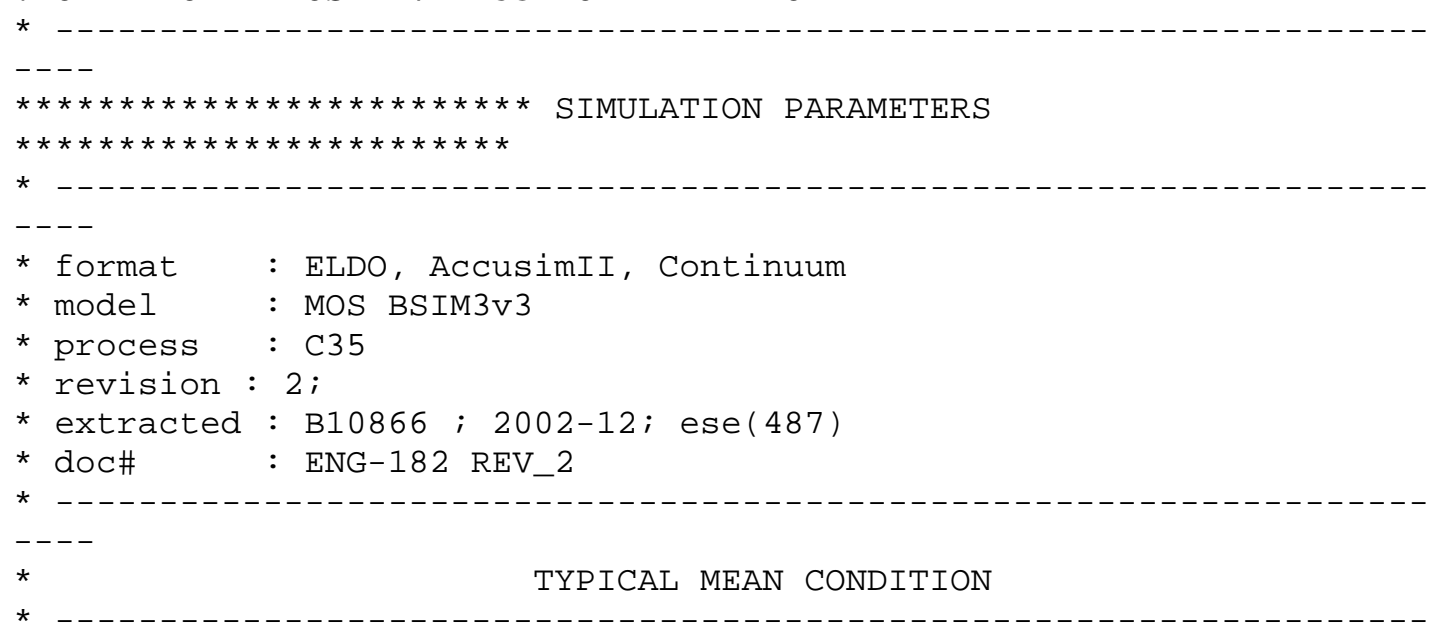




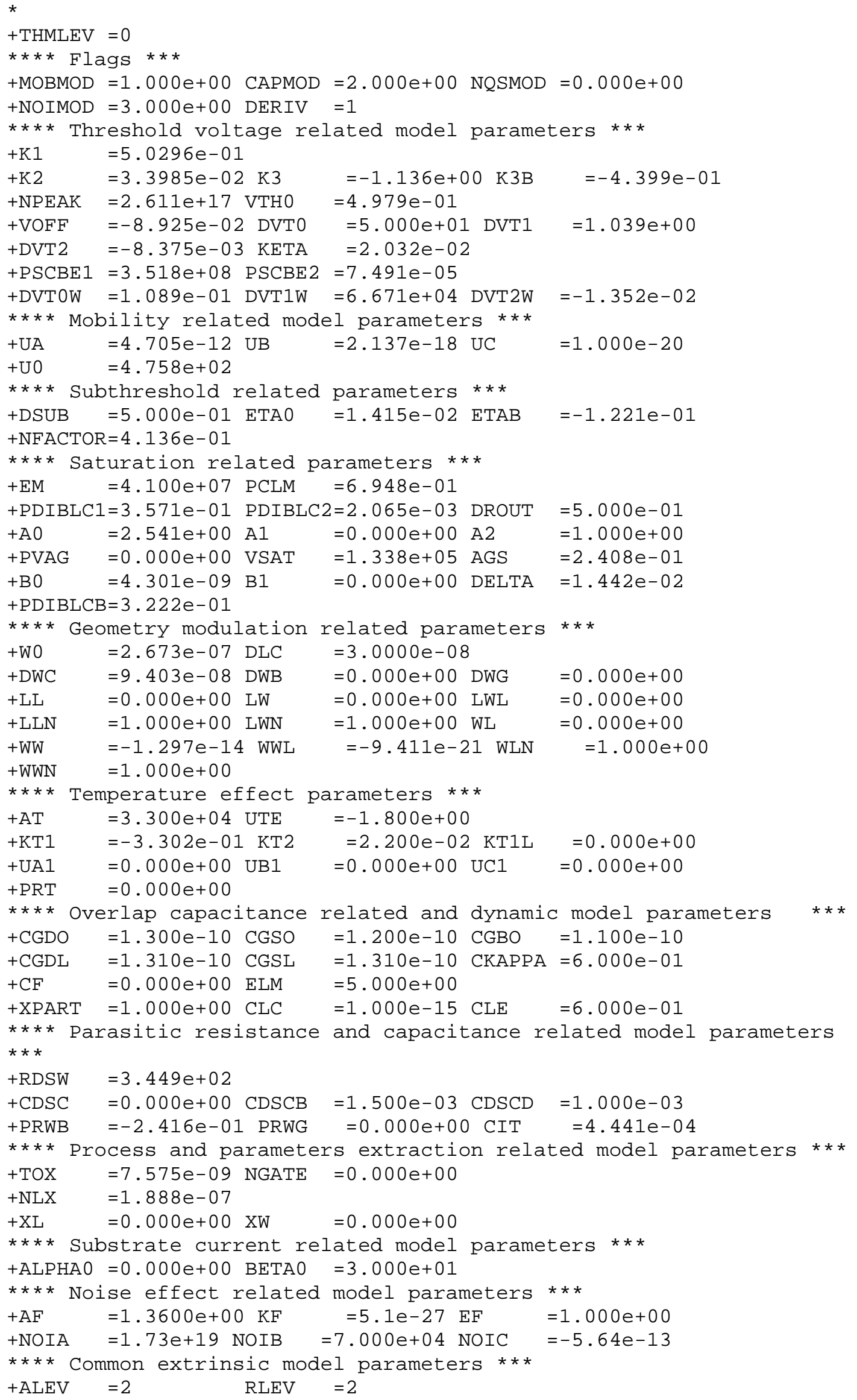




\begin{tabular}{|c|c|c|c|c|c|}
\hline$+\mathrm{RD}$ & $=0.000 e+00$ & RS & $=0.000 e+00$ & RSH & $=7.000 e+01$ \\
\hline$+\mathrm{RDC}$ & $=0.000 e+00$ & $\mathrm{RSC}$ & $=0.000 e+00$ & LD & $=-5.005 e-08$ \\
\hline$+W D$ & $=9.403 e-08$ & & & & \\
\hline$+\mathrm{LDIF}$ & $=0.000 e+00$ & HDIF & $=8.000 e-07$ & WMLT & $=1.000 e+00$ \\
\hline+ LMLT & $=1.000 e+00$ & DEL & $=0.000 e+00$ & $\mathrm{XJ}$ & $=3.000 e-07$ \\
\hline +DIOLEV & $=4$ & $\mathrm{JS}$ & $=1.000 e-05$ & JSW & $=0.000 e+00$ \\
\hline$+I S$ & $=0.000 e+00$ & $\mathrm{~N}$ & $=1.000 e+00$ & & \\
\hline +DCAP LEV & $7=2$ & $\mathrm{CBD}$ & $=0.000 e+00$ & CBS & $=0.000 e+00$ \\
\hline$+\mathrm{CJ}$ & $=9.400 e-04$ & CJSW & $=2.500 \mathrm{e}-10$ & $\mathrm{FC}$ & $=0.000 e+00$ \\
\hline$+\mathrm{MJ}$ & $=3.400 e-01$ & MJSW & $=2.300 e-01$ & $\mathrm{TT}$ & $=0.000 e+00$ \\
\hline $\mathrm{PB}$ & $=6.900 \mathrm{e}-01$ & PBSW & $=6.900 \mathrm{e}-01$ & & \\
\hline
\end{tabular}

Parâmetros Típicos: Modelo para Transistor Bipolar PNP Vertical .MODEL VERT10 PNP MODTYPE=ELDO

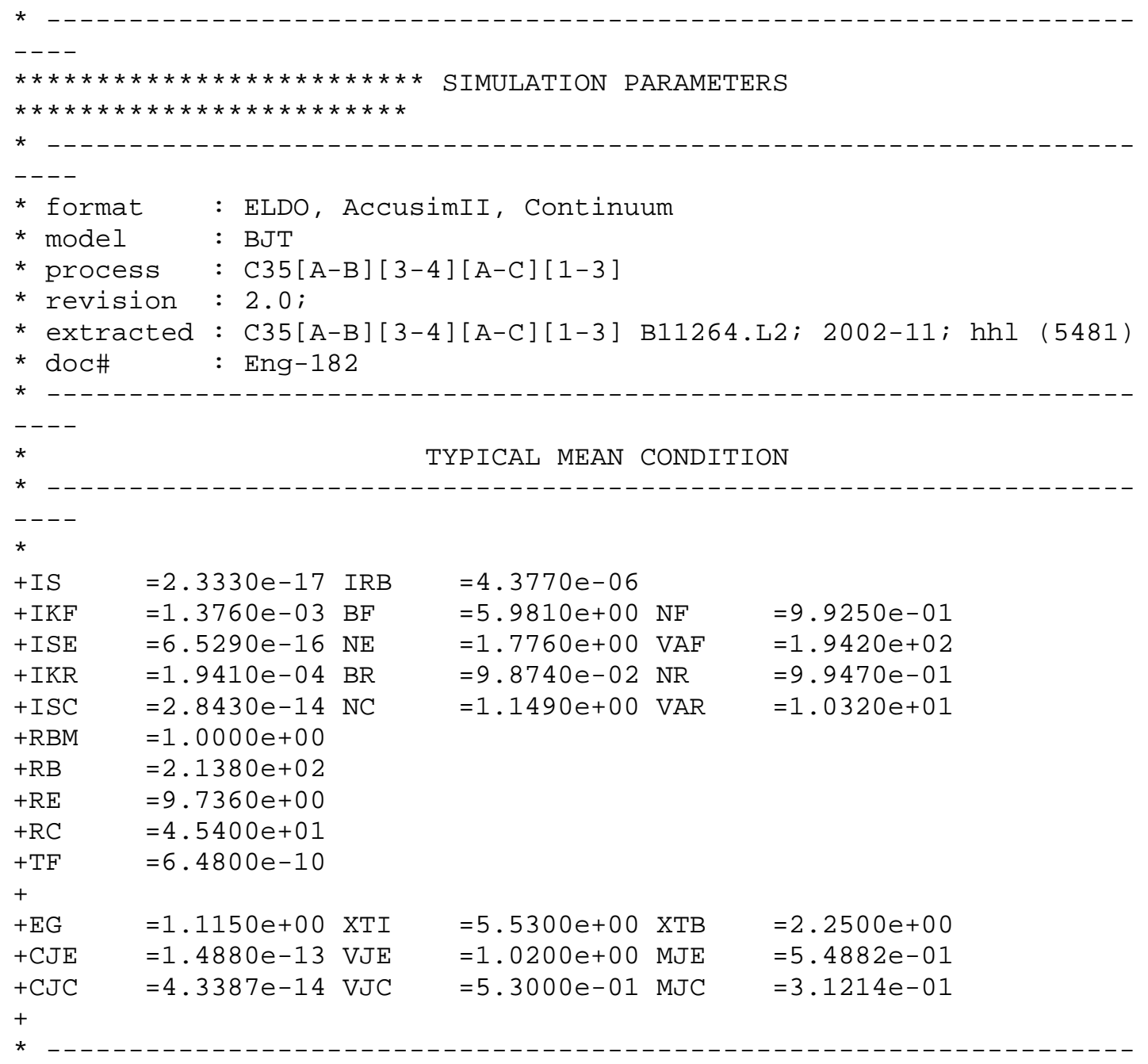

Parâmetros Típicos: Modelo para o resistor de alta resistividade .MODEL RPOLYH RES TC1 $=-0.400 \mathrm{e}-03$ MODTYPE $=E L D O$

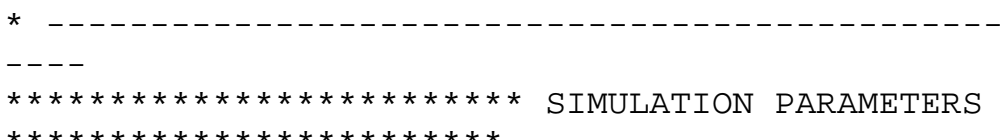




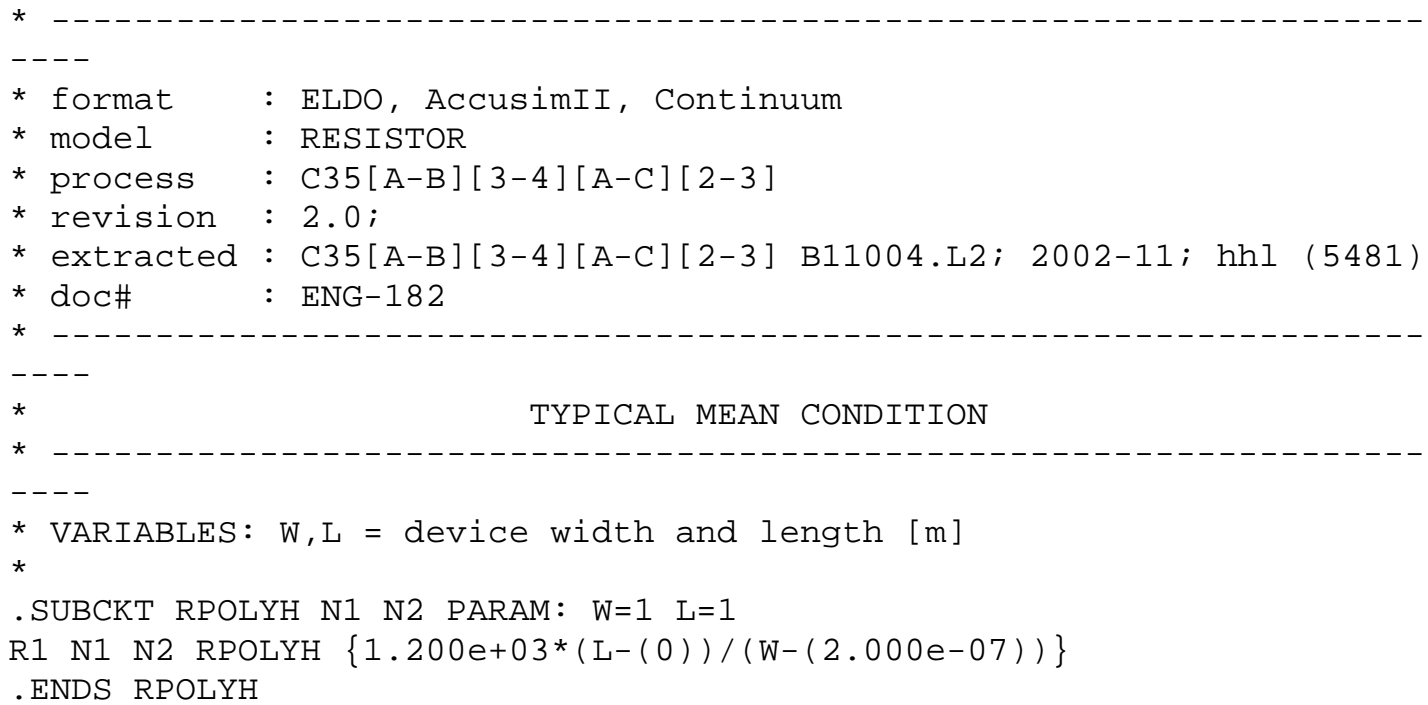

Parâmetros Worst Speed: Modelo para Transistor Tipo P .MODEL MODP PMOS LEVEL=53 MODTYPE=ELDO

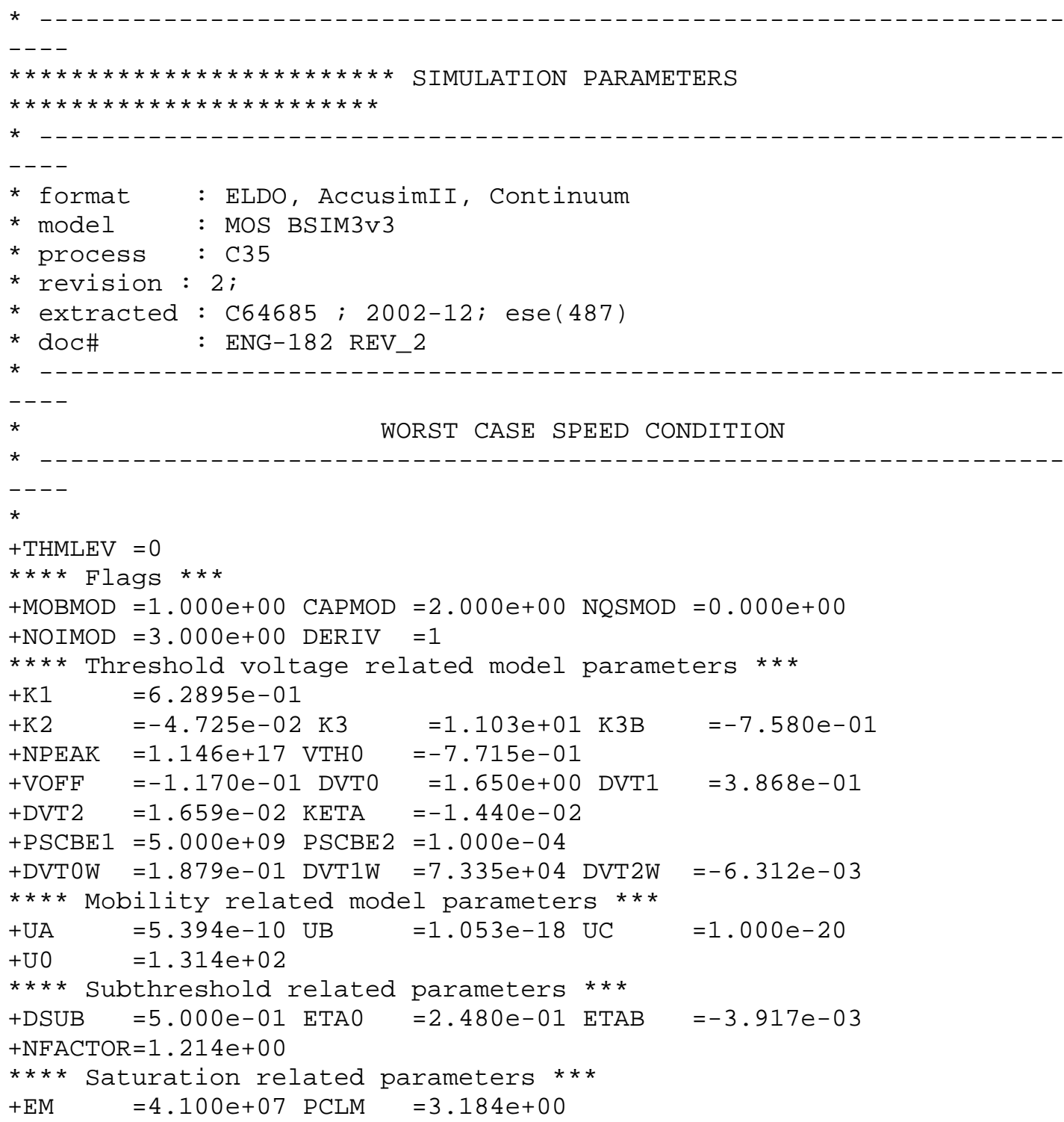




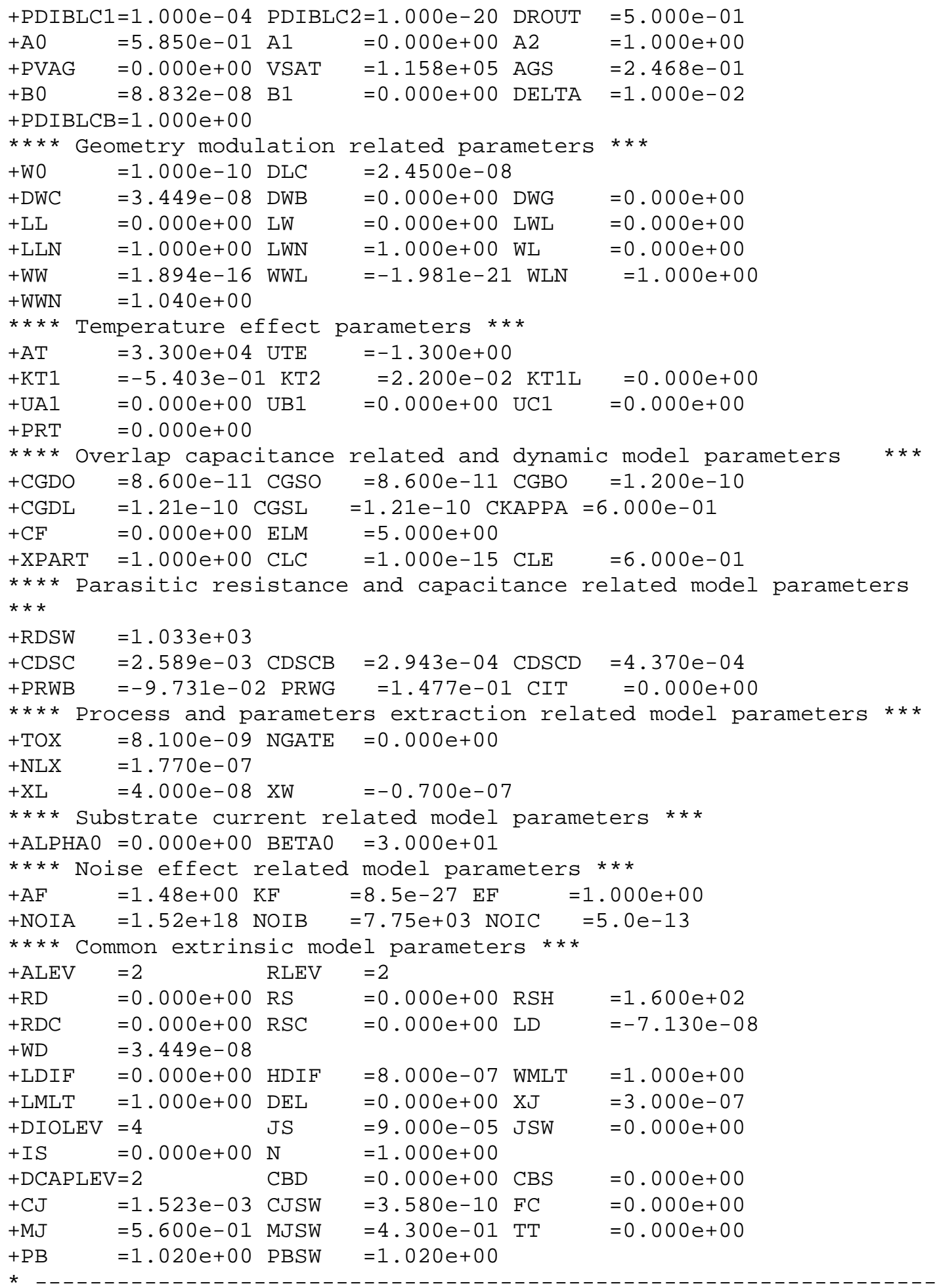

Parâmetros Worst Speed: Modelo para Transistor Tipo N .MODEL MODN NMOS LEVEL=53 MODTYPE=ELDO

$---1$

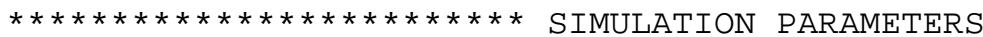

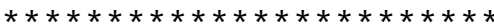




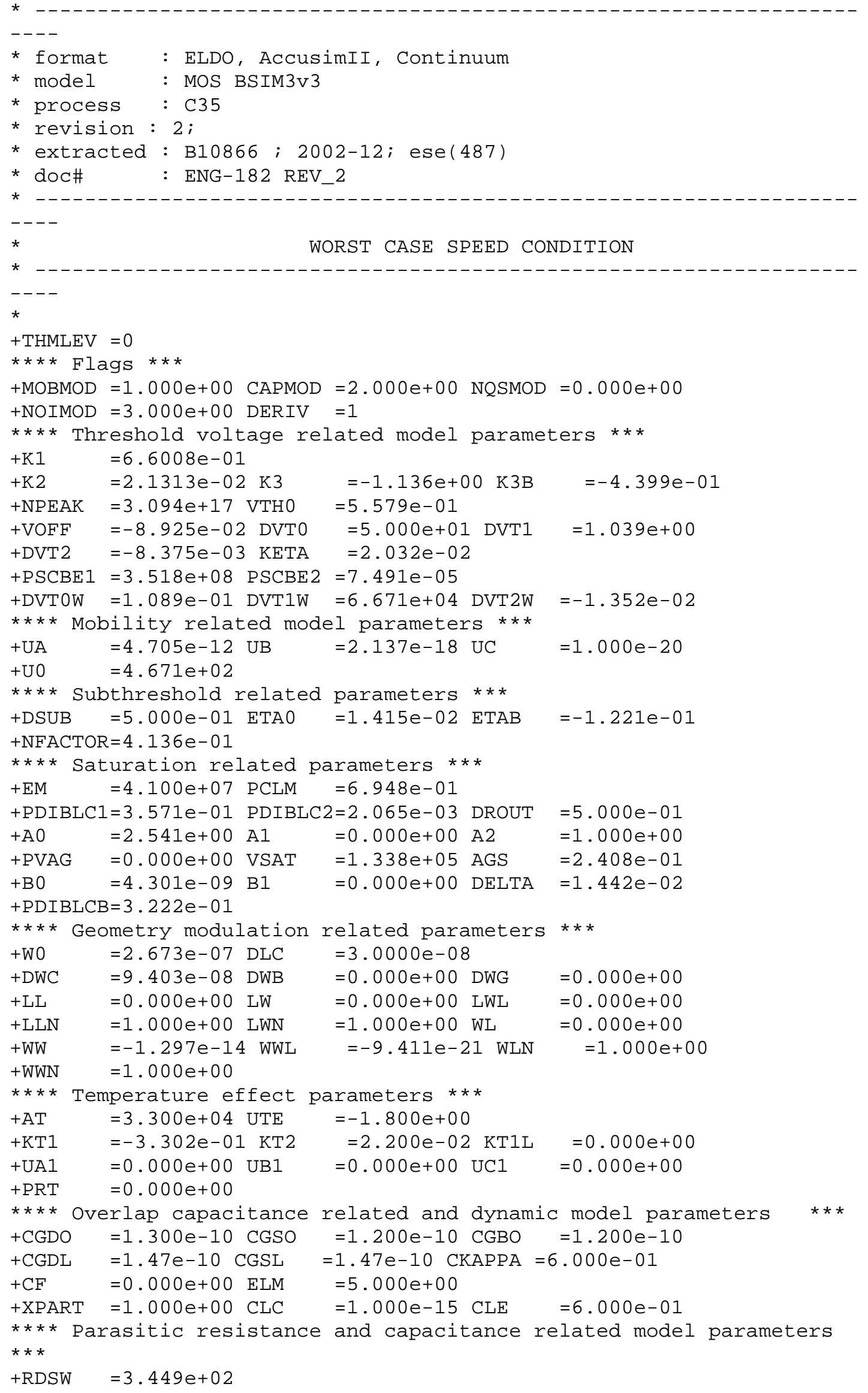




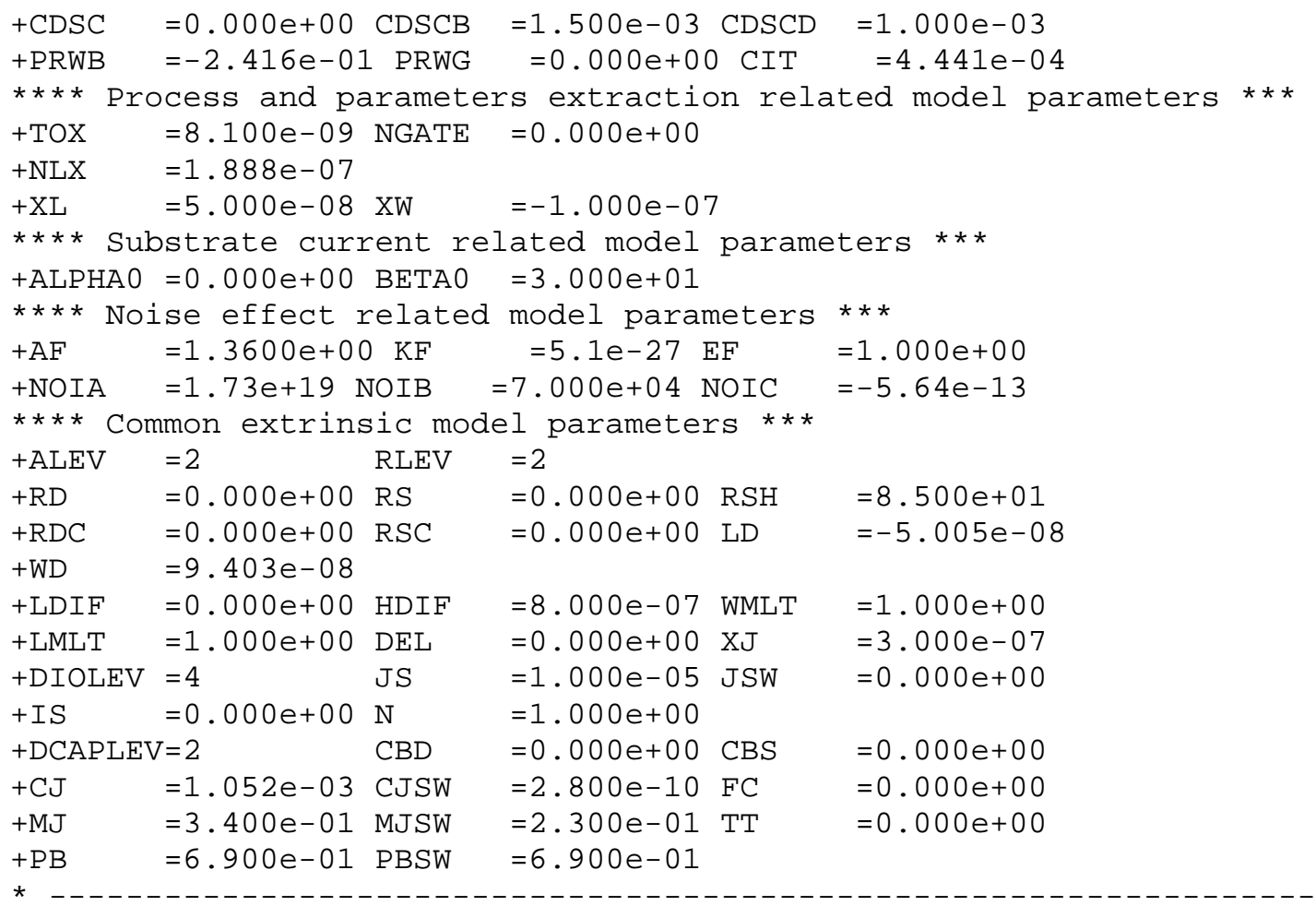

Parâmetros Worst Speed: Modelo para Transistor Bipolar PNP Vertical .MODEL VERT10 PNP MODTYPE=ELDO

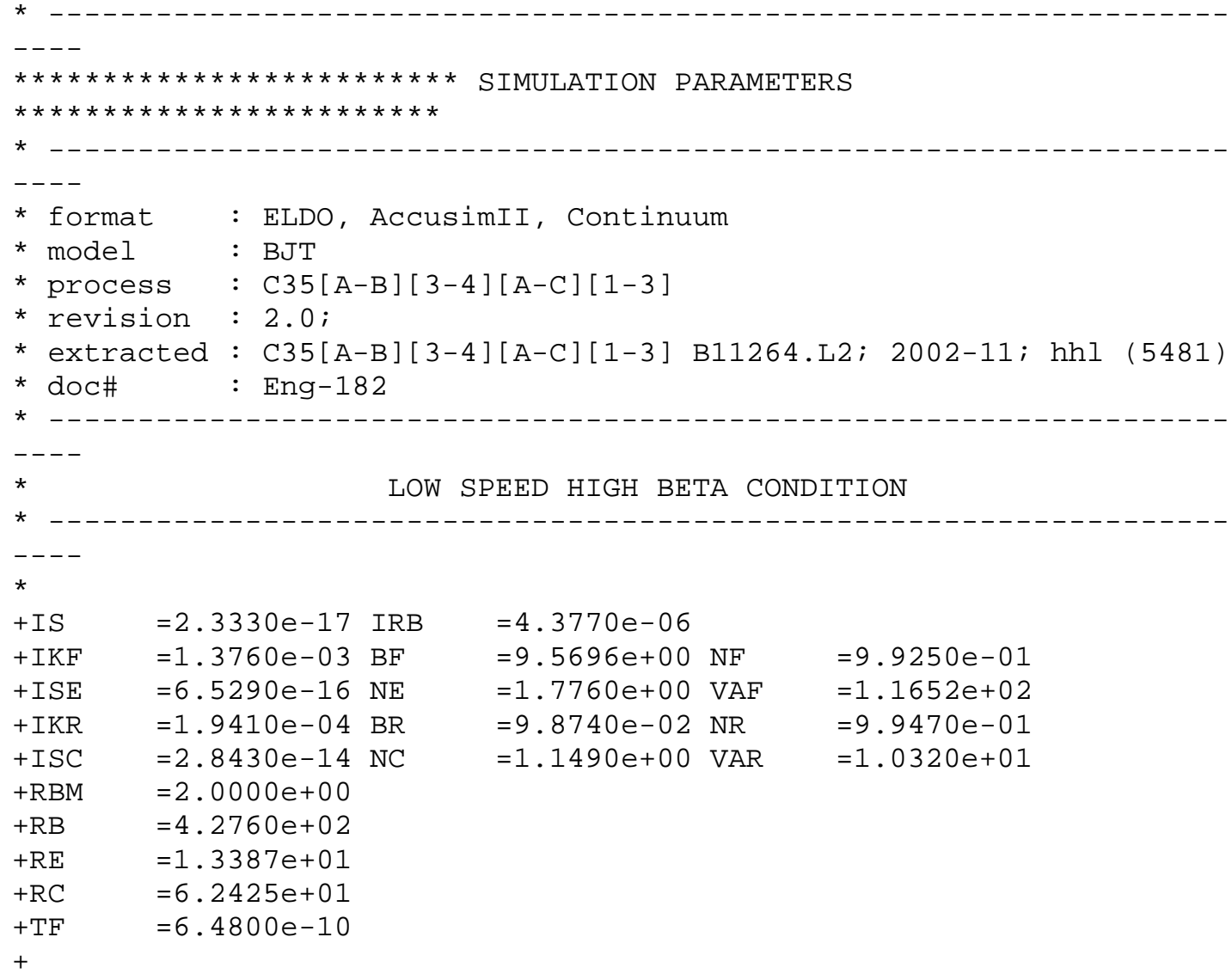




$\begin{array}{lllll}+\mathrm{EG} & =1.1150 \mathrm{e}+00 \mathrm{XTI} & =5.5300 \mathrm{e}+00 \mathrm{XTB} & =2.2500 \mathrm{e}+00 \\ +\mathrm{CJE} & =1.7856 \mathrm{e}-13 \mathrm{VJE} & =1.0200 \mathrm{e}+00 \mathrm{MJE} & =5.4882 \mathrm{e}-01 \\ +\mathrm{CJC} & =5.2065 \mathrm{e}-14 \mathrm{VJC} & =5.3000 \mathrm{e}-01 \mathrm{MJC} & =3.1214 \mathrm{e}-01 \\ + & \end{array}$

Parâmetros Worst Speed: Modelo para o resistor de alta resistividade .MODEL RPOLYH RES TC1=-0.400e-03 MODTYPE=ELDO

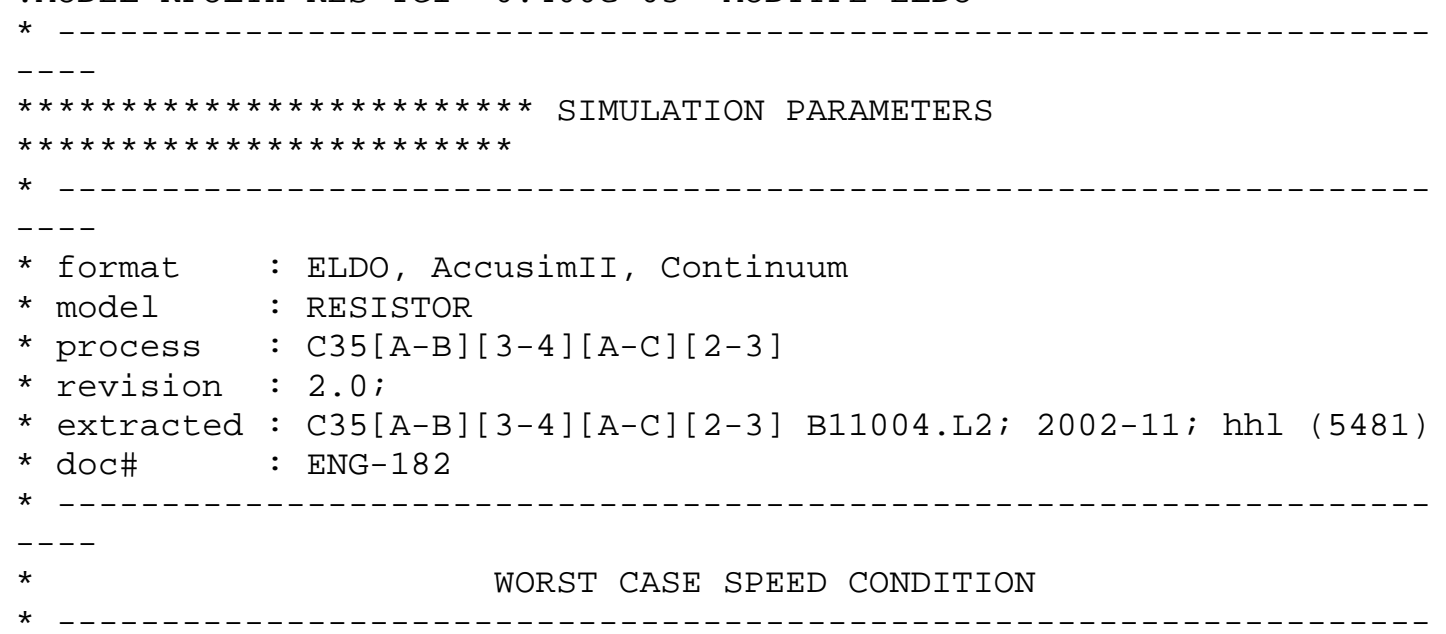

* VARIABLES: $\mathrm{W}, \mathrm{L}=$ device width and length [m]

. SUBCKT RPOLYH N1 N2 PARAM: $W=1 \quad \mathrm{~L}=1$

R1 N1 N2 RPOLYH $\{1.500 e+03 *(L-(0)) /(W-(3.500 e-07))\}$

- ENDS RPOLYH

Parâmetros Worst Power: Modelo para Transistor Tipo P

. MODEL MODP PMOS LEVEL=53 MODTYPE=ELDO

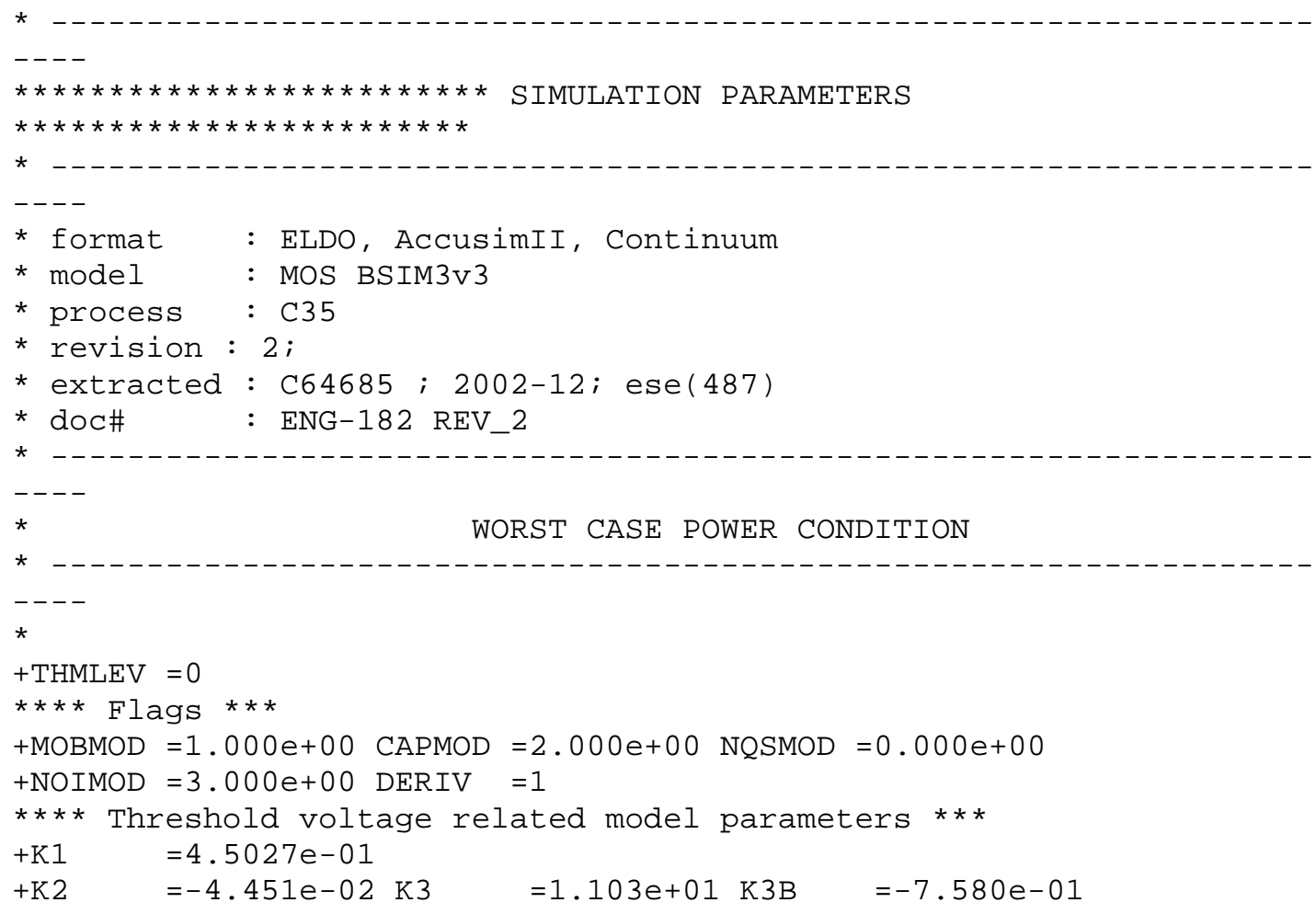




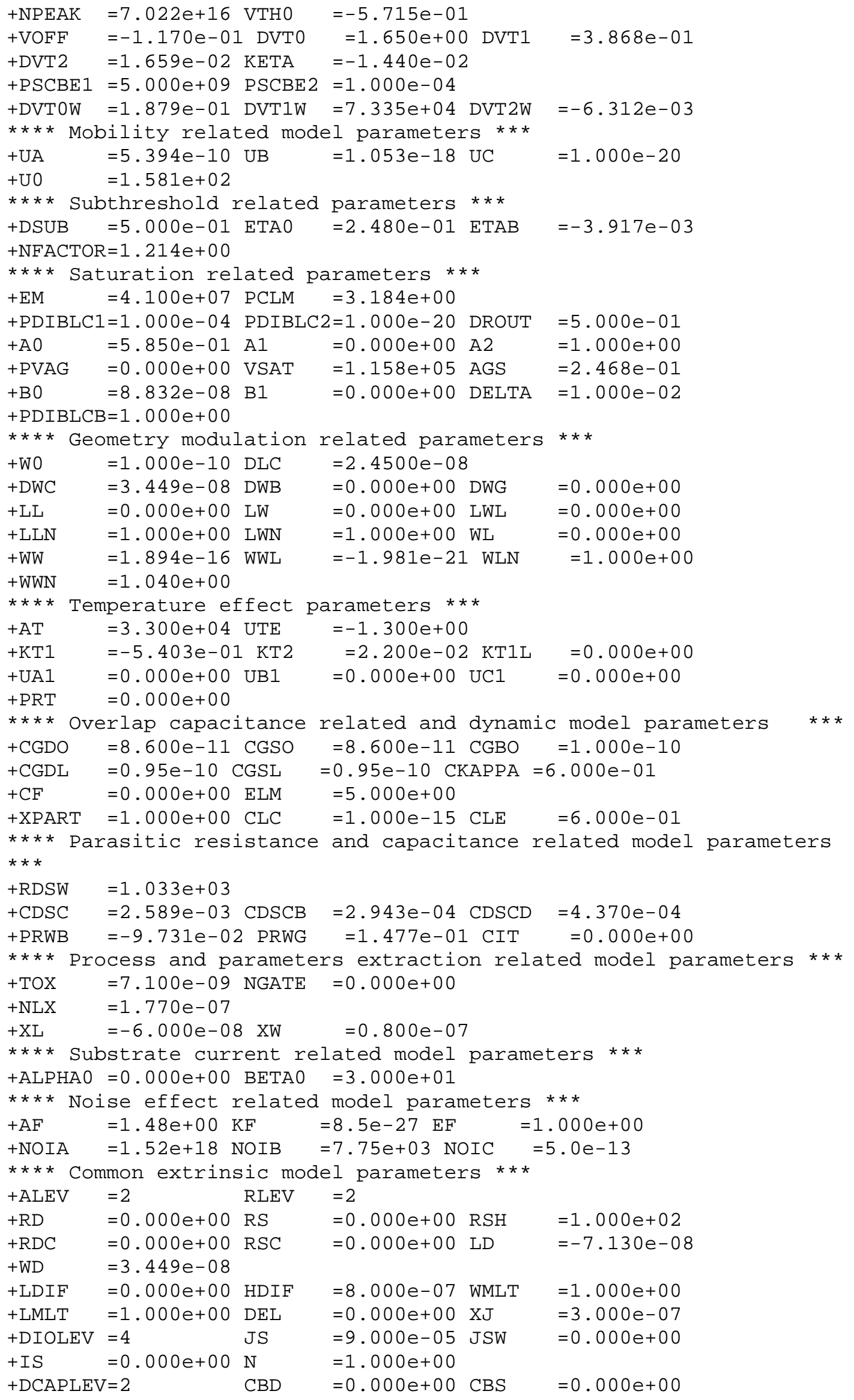




$\begin{array}{lllll}+\mathrm{CJ} & =1.197 \mathrm{e}-03 \mathrm{CJSW} & =2.810 \mathrm{e}-10 \mathrm{FC} & =0.000 \mathrm{e}+00 \\ +\mathrm{MJ} & =5.600 \mathrm{e}-01 \mathrm{MJSW} & =4.300 \mathrm{e}-01 \mathrm{TT} & =0.000 \mathrm{e}+00 \\ +\mathrm{PB} & =1.020 \mathrm{e}+00 \mathrm{PBSW} & =1.020 \mathrm{e}+00 & \\ *--------------------------------------------------------------\end{array}$

Parâmetros Worst Power: Modelo para Transistor Tipo N

.MODEL MODN NMOS LEVEL=53 MODTYPE=ELDO

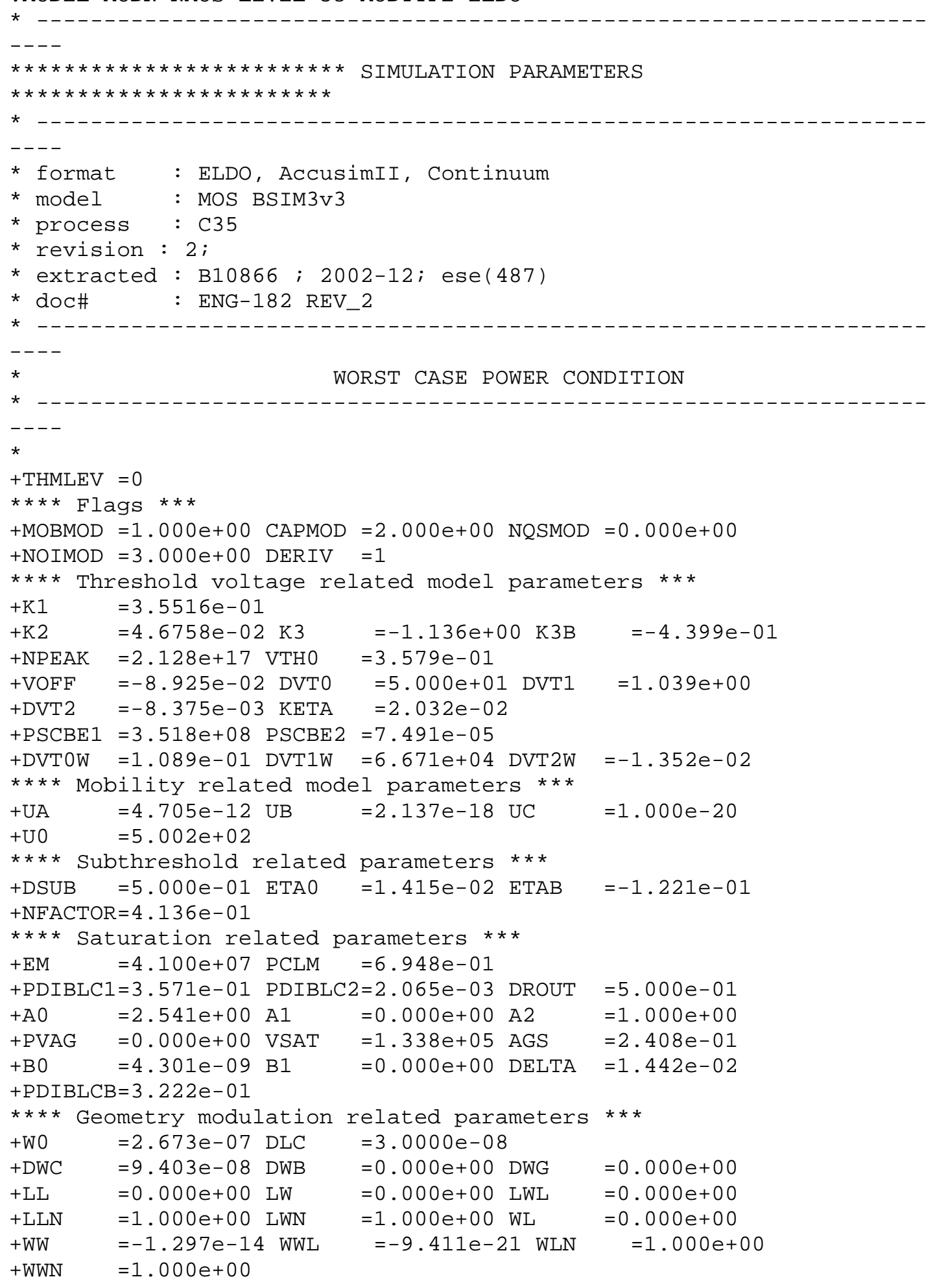




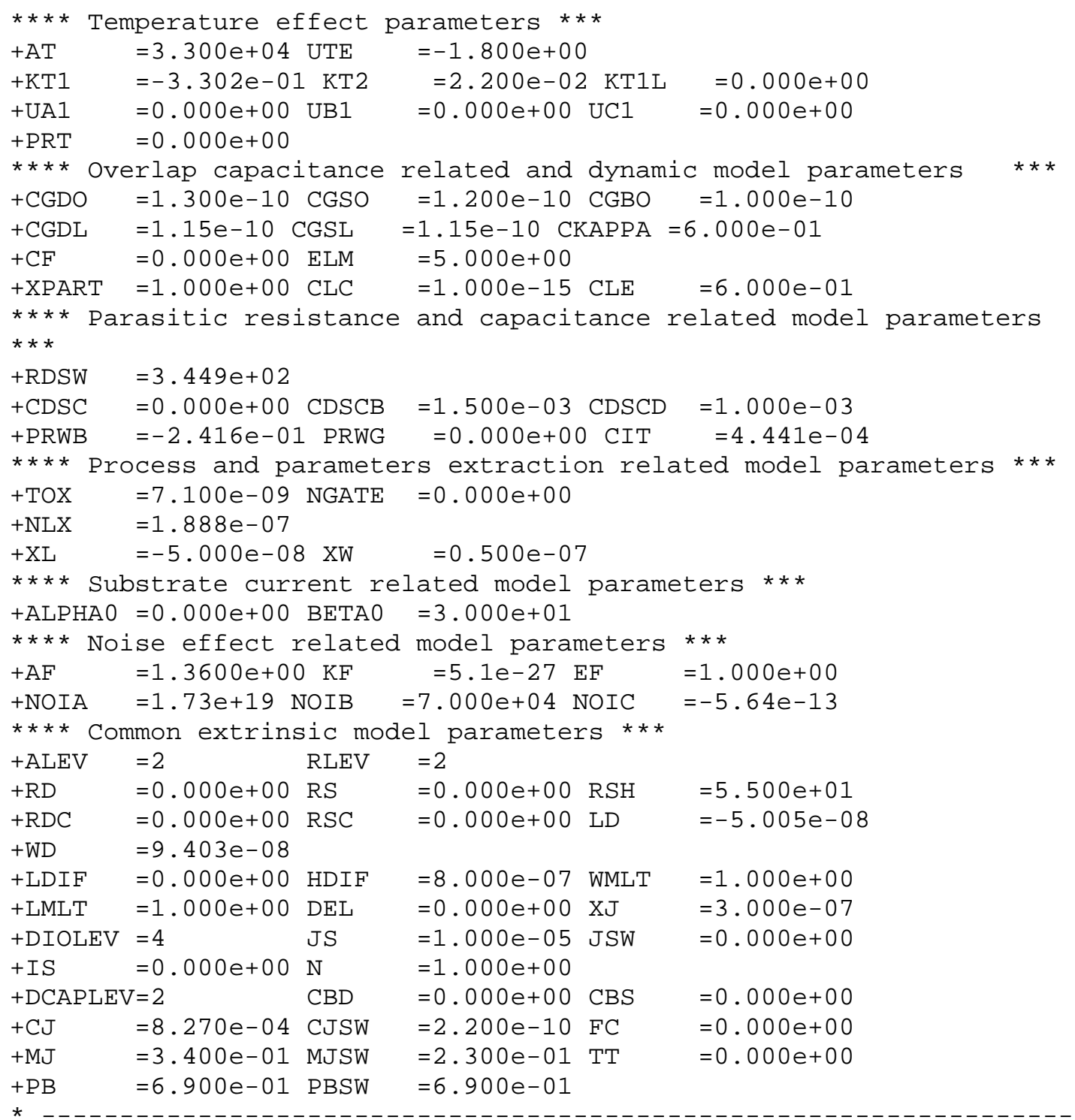

Parâmetros Worst Power: Modelo para Transistor Bipolar PNP Vertical

.MODEL VERT10 PNP MODTYPE=ELDO
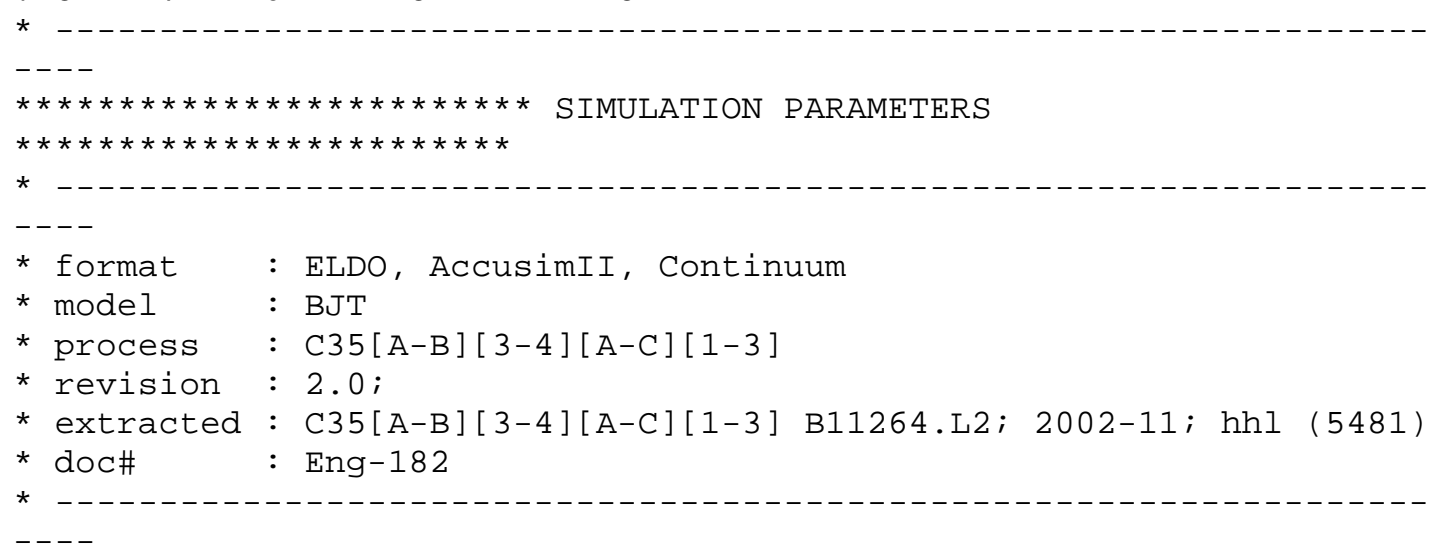


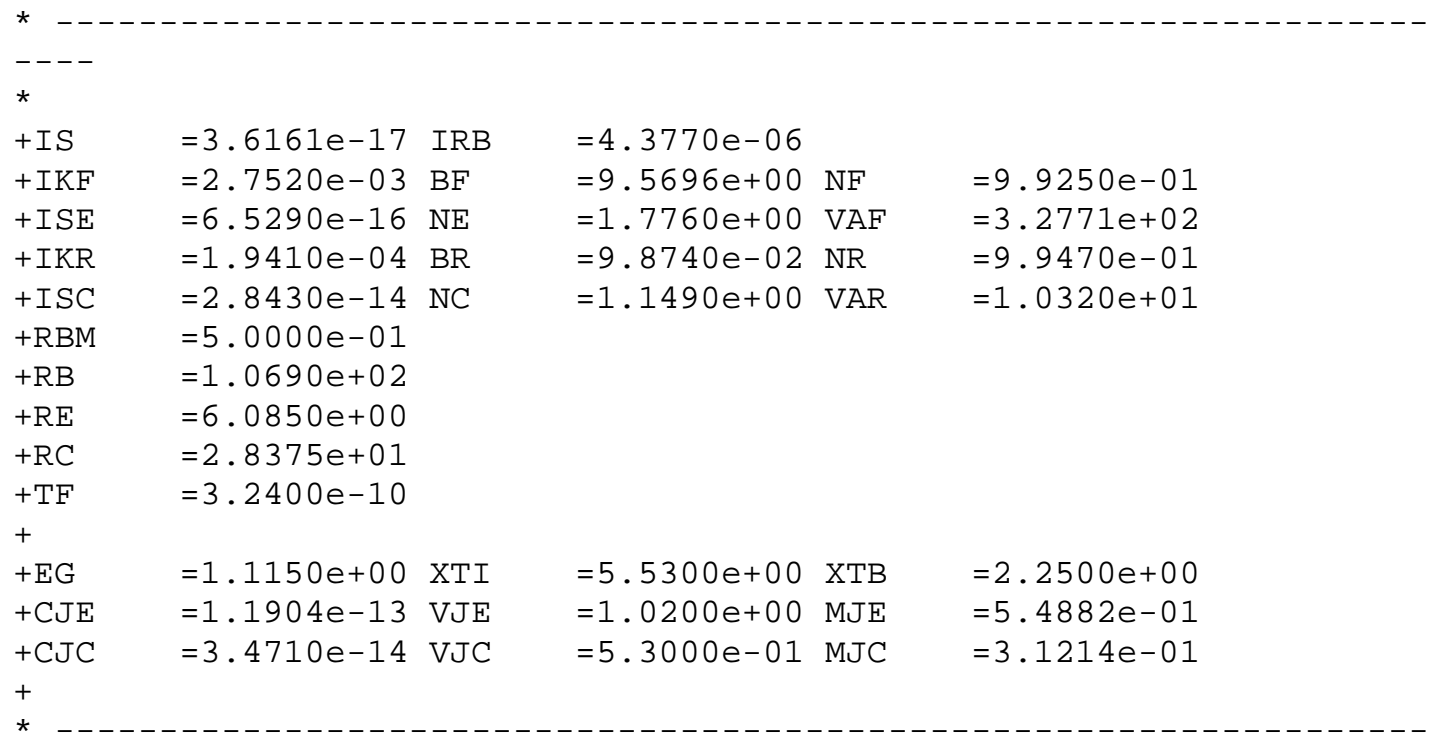

Parâmetros Worst Power: Modelo para o resistor de alta resistividade .MODEL RPOLYH RES TC1=-0.400e-03 MODTYPE=ELDO

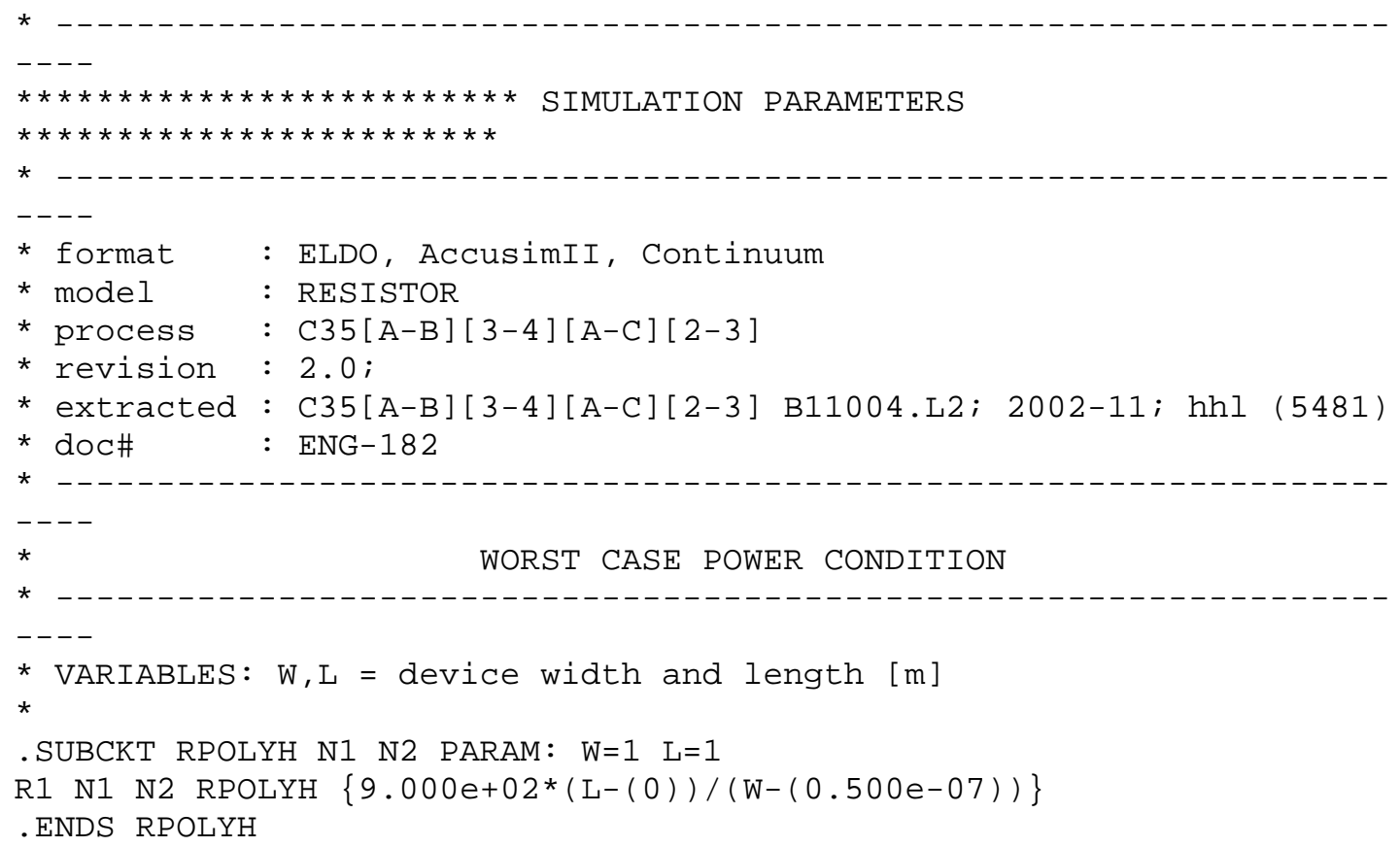




\section{ANEXO C}

\section{Tabelas com os resultados das medidas com variação da tensão de alimentação}

Todas as medidas foram realizadas na temperatura ambiente de $27^{\circ} \mathrm{C}$ e foram utilizados equipamentos de proteção contra descarga eletrostática.

Tabela 13. Valores da tensão de saída em função da tensão de alimentação para o circuito bandgap com resistores integrados..

\begin{tabular}{|c|c|c|c|c|}
\hline Vin (V) & $\boldsymbol{a m 2 . 1}(\mathbf{V})$ & $\boldsymbol{a m 3 . 1}(\mathbf{V})$ & $\boldsymbol{a m 4 . 1}(\mathbf{V})$ & $\boldsymbol{a m 5 . 1}(\mathbf{V})$ \\
\hline $\mathbf{3 , 3}$ & 1,238 & 1,257 & 1,178 & 1,229 \\
\hline $\mathbf{3 , 0}$ & 1,234 & 1,252 & 1,176 & 1,224 \\
\hline $\mathbf{2 , 8}$ & 1,231 & 1,249 & 1,174 & 1,221 \\
\hline $\mathbf{2 , 6}$ & 1,228 & 1,245 & 1,170 & 1,218 \\
\hline $\mathbf{2 , 4}$ & 1,225 & 1,242 & 1,165 & 1,215 \\
\hline $\mathbf{2 , 2}$ & 1,221 & 1,238 & 1,162 & 1,211 \\
\hline $\mathbf{2 , 0}$ & 1,215 & 1,232 & 1,157 & 1,205 \\
\hline $\mathbf{1 , 8}$ & 1,207 & 1,223 & 1,147 & 1,195 \\
\hline $\mathbf{1 , 6}$ & 1,196 & 1,193 & 1,128 & 1,139 \\
\hline $\mathbf{1 , 4}$ & 1,120 & 1,130 & 1,074 & 1,085 \\
\hline $\mathbf{1 , 2}$ & 0,971 & 0,968 & 0,950 & 0,954 \\
\hline
\end{tabular}

Tabela 14. Valores da tensão de saída em função da tensão de alimentação para o circuito bandgap utilizando resistores externos, com $\mathrm{R}_{1}=68,79 \mathrm{~K} \Omega$.

\begin{tabular}{|c|c|c|c|}
\hline Vin (V) & $\boldsymbol{a m 3 . 2}(\mathbf{V})$ & $\boldsymbol{a m 4 . 2}(\mathbf{V})$ & $\boldsymbol{a m 5 . 2}(\mathbf{V})$ \\
\hline $\mathbf{3 , 3}$ & 1,258 & 1,256 & 1,252 \\
\hline $\mathbf{3 , 0}$ & 1,254 & 1,252 & 1,249 \\
\hline $\mathbf{2 , 8}$ & 1,251 & 1,249 & 1,246 \\
\hline $\mathbf{2 , 6}$ & 1,247 & 1,246 & 1,242 \\
\hline $\mathbf{2 , 4}$ & 1,244 & 1,242 & 1,238 \\
\hline $\mathbf{2 , 2}$ & 1,239 & 1,237 & 1,233 \\
\hline $\mathbf{2 , 0}$ & 1,234 & 1,232 & 1,228 \\
\hline $\mathbf{1 , 8}$ & 1,226 & 1,225 & 1,221 \\
\hline $\mathbf{1 , 6}$ & 1,205 & 1,201 & 1,199 \\
\hline $\mathbf{1 , 4}$ & 1,132 & 1,130 & 1,129 \\
\hline $\mathbf{1 , 2}$ & 0,987 & 0,975 & 0,981 \\
\hline $\boldsymbol{R}_{\mathbf{2}}$ & $\mathbf{6 5 , 0 1}(\mathbf{K} \boldsymbol{\Omega})$ & $\mathbf{6 1 , 3 8}(\mathbf{K} \boldsymbol{\Omega})$ & $\mathbf{5 9 , 5 5}(\mathbf{K} \boldsymbol{\Omega})$ \\
\hline
\end{tabular}

\section{Tabelas com os resultados das medidas com variação da temperatura}

Todas as medidas foram realizadas com tensão de alimentação de $3,3 \mathrm{~V}$ e foram utilizados equipamentos de proteção contra descarga eletrostática. 
Tabela 15. Valores da tensão de saída em função da temperatura de operação para o circuito bandgap com resistores integrados.

\begin{tabular}{|c|c|c|c|c|}
\hline \multirow[t]{2}{*}{ Temp $\left({ }^{\circ} \mathrm{C}\right)$} & \multicolumn{2}{|c|}{$\operatorname{am} 2.1(\mathrm{~V})$} & \multirow[t]{2}{*}{$\operatorname{am3.1}(\mathrm{V})$} & \multirow[t]{2}{*}{$\operatorname{am4.1}(\mathrm{V})$} \\
\hline & Med1 & Med2 & & \\
\hline 27 & 1,2370 & 1,2431 & 1,2546 & 1,1819 \\
\hline 100 & 1,2630 & 1,2573 & 1,2576 & 1,1852 \\
\hline 90 & 1,2630 & 1,2554 & 1,2575 & 1,1852 \\
\hline 80 & 1,2630 & 1,2533 & 1,2572 & 1,1849 \\
\hline 70 & 1,2627 & 1,2513 & 1,2569 & 1,1845 \\
\hline 60 & 1,2618 & 1,2494 & 1,2565 & 1,1840 \\
\hline 50 & 1,2604 & 1,2476 & 1,2559 & 1,1835 \\
\hline 40 & 1,2588 & 1,2459 & 1,2554 & 1,1830 \\
\hline 30 & 1,2579 & 1,2442 & 1,2549 & 1,1824 \\
\hline 20 & 1,2578 & 1,2422 & 1,2542 & 1,1819 \\
\hline 10 & 1,2552 & 1,2406 & 1,2535 & 1,1813 \\
\hline $\mathbf{0}$ & 1,2536 & 1,2391 & 1,2530 & 1,1808 \\
\hline-10 & 1,2508 & 1,2377 & 1,2513 & 1,1805 \\
\hline-20 & 1,2490 & 1,2361 & 1,2513 & 1,1802 \\
\hline-30 & 1,2324 & 1,2347 & 1,2511 & 1,1798 \\
\hline
\end{tabular}

Tabela 16. Valores da tensão de saída em função da tensão temperatura de operação para amostras o circuito bandgap utilizando resistores externos, com $\mathrm{R}_{1}=68,79 \mathrm{~K} \Omega$.

\begin{tabular}{|c|c|c|c|}
\hline Temp. $\left({ }^{\mathbf{}} \mathbf{C}\right)$ & $\boldsymbol{a m 3 . 2}(\mathbf{V})$ & $\mathbf{a m 4 . 2}(\mathbf{V})$ & $\boldsymbol{a m 5 . 2}(\mathbf{V})$ \\
\hline $\mathbf{2 7}$ & 1,2526 & 1,2506 & 1,2510 \\
\hline $\mathbf{1 0 0}$ & 1,2582 & 1,2557 & 1,2491 \\
\hline $\mathbf{9 0}$ & 1,2572 & 1,2564 & 1,2466 \\
\hline $\mathbf{8 0}$ & 1,2576 & 1,2571 & 1,2473 \\
\hline $\mathbf{7 0}$ & 1,2571 & 1,2566 & 1,2467 \\
\hline $\mathbf{6 0}$ & 1,2561 & 1,2581 & 1,2457 \\
\hline $\mathbf{5 0}$ & 1,2543 & 1,2588 & 1,2471 \\
\hline $\mathbf{4 0}$ & 1,2533 & 1,2583 & 1,2485 \\
\hline $\mathbf{3 0}$ & 1,2523 & 1,2567 & 1,2498 \\
\hline $\mathbf{2 0}$ & 1,2512 & 1,2542 & 1,2493 \\
\hline $\mathbf{1 0}$ & 1,2482 & 1,2529 & 1,2496 \\
\hline $\mathbf{0}$ & 1,2458 & 1,2528 & 1,2498 \\
\hline $\mathbf{- 1 0}$ & 1,2448 & 1,2524 & 1,2500 \\
\hline $\mathbf{- 2 0}$ & 1,2438 & 1,2518 & 1,2502 \\
\hline $\mathbf{- 3 0}$ & 1,2428 & 1,2505 & 1,2507 \\
\hline $\boldsymbol{R}_{\mathbf{2}}$ & $\mathbf{6 6 , 7 7}(\mathbf{K} \boldsymbol{\Omega})$ & $\mathbf{6 4 , 9 3}(\mathbf{K} \boldsymbol{\Omega})$ & $\mathbf{6 2 , 6 1}(\mathbf{K} \boldsymbol{\Omega})$ \\
\hline
\end{tabular}




\section{BIBLIOGRAFIA}

[1] Wong, H.-S.P., "Nanoscale CMOS", Proceedings of the IEEE, v. 87, pp. 537570, 1999.

[2] International Technology Roadmap for Semiconductors, S.I.A Std., 2005. [Online]. Available: http://www.itrs.net/reports.html.

[3] Mori, C.R.T., Vermaas, L.L.G., Moreno, L.R., Pereira, A.M., and Charry, E., "Design Methodologies of a Bandgap Reference Source", IV Workshop Iberchip, pp. 43-50, Argentina, Mar. 1998.

[4] Widlar, R.J., "New Developments in IC Voltage Regulators" IEEE J. SolidState Circuits, vol. Sc-6, pp. 2-7, Feb. 1971.

[5] Mehrmanesh, S., Vahidfar, M.B., Aslanzadeh, H.A., and Atarodi, M., "A 1-Volt, high PSRR, CMOS Bandgap Voltage Reference" IEEE J. Solid-State Circuits, vol. Sc-6, pp. 381-384, Feb. 2003.

[6] Gray, P.R. and Meyer, G., Analysis and design of analog integrated circuits, $4^{\mathrm{a}}$ ed., John Wiley \& Sons, New York, 1984.

[7] Vittoz, E. and Fellrath, J., "CMOS analog integrated circuits based on weak inversion operation," IEEE J. Solid-State Circuits, vol. Sc-12, pp. 224-231, June 1977.

[8] Tsividis, Y.P., "Accurate Analysis of Temperature Effects in IC-VBE Characteristics with Application to Bandgap Reference Sources" IEEE J. Solid-State Circuits, vol. Sc-15, pp. 1076-1084, Dec. 1980.

[9] Song, B.S. and Gray, P.R., "A precision curvature-compensated CMOS bandgap reference", IEEE J. Solid-State Circuits, vol. Sc18, pp. 634-643, Dec. 1983. 
[10] Mok, P.K.T. and Leung, K.N., " Design Considerations of Recent Advanced Low-Voltage Low-Temperature-Coefficient CMOS Bandgap Voltage Reference", IEEE Custom Integrated Circuits Conference, pp. 635-642, 2004.

[11] Oliveira, C.A.S, "Estudo e Projeto de um Conversor D/A de Alta Velocidade em Tecnologia CMOS", Tese apresentada à Escola Politécnica da Universidade de São Paulo, 2005.

[12] Texas Instruments Incorporated, "Precision voltage references", Dallas-Texas, Perry Miller, Doug Moore, Analog Applications Journal, pp. 1-5, Nov. 1999.

[13] Allen, P.E. and Holberg E.R., "CMOS Analog Circuit Design", Oxford, Oxford University Press, Second Edition, 2002.

[14] Muller, R. S. and Kamins, T. I., "Device Electronics for Integrated Circuits", $2^{\text {a }}$ ed., John Wiley \& Sons, New York, 1986.

[15] Maxim Integrated Products, Inc., "Understanding Voltage-Reference Topologies and Specifications", Canada Application Note 719, Dec. 2000.

[16] Vittoz, E. A. and Neyroud, O., "A Low Voltage CMOS Bandgap Reference", IEEE J. Solid-State Circuits, vol. 14, pp. 573-577, June 1979.

[17] Hilbiber, D., "A new semiconductor voltage standard", IEEE J. Solid-State Circuits, vol. 7, pp. 32-33, February 1964.

[18] IDAC User's Guide - Analog Design Automation Tools, Centre Suisse D’Eletronic Et de Microtechnique S. A., software version 5.1, pp. 8-9, Apr. 1991.

[19] Lee, T.H., "The design of CMOS radio-frequency integrated circuits", Cambridge, Cambridge University Press, 1998.

[20] $0.35 \mu \mathrm{m}$ CMOS C35 Process Parameters, Austriamicrosystems, Mar. 2003. 
[21] Lee, I., Kim, G., and Kim, W., "Exponential Curvature-Compensated BiCMOS Bandgap References", IEEE J. Solid-State Circuits, vol. 29 no-11, pp. 13961403, Nov. 1994.

[22] Tzanateas, G., Salama, C.A.T., and Tsividis, Y.P., "A CMOS Bandgap Voltage Reference", IEEE J. Solid-State Circuits, vol. sc-14, pp. 655-657, June 1979.

[23] Forti, F. and Wright, M.E., "Measurement of MOS current mismatch in the weak inversion region," IEEE J. Solid-State Circuits, vol. 29, pp. 138-142, Feb. 1994.

[24] Circuits Multi-Projects, 2006. [Online]. Available: http://cmp.imag.fr/index.php.

[25] Degrauwe, M.G. et al., "CMOS Voltage Reference Using Lateral Bipolar Transistors", IEEE J. Solid-State Circuits, vol. SC-20, pp. 1151-1157, Dec. 1985.

[26] Degrauwe, M.G., et al., "IDAC: An Interactive Design Tool for Analog CMOS Circuits" IEEE J. Solid-State Circuits, vol. SC-22, pp. 1106-1116, Dec. 1987.

[27] Vittoz, E.A.; "MOS transistors operated in the lateral bipolar mode and their application in CMOS technology", IEEE J. Solid-State Circuits, vol. 18, pp. 273 - 279, Jun 1983.

[28] Meijer, G. C. M., Wang G., Fruett F., " Temperature Sensors and Voltage References Implemented in CMOS Technology", IEEE Sensors Journal, vol. 1, n. 3, October 2001.

[29] “ELDO”, Mentor Graphics Corporation, software version 6.3_1, Jan. 2004.

[30] Rabaey, J.M., Chandrakasan, A., Nikolic, B., Digital Integrated Circuits: A Design Perspective, $2^{\underline{a}}$ ed., Prentice Hall, New Jersey, 2003.

[31] BOURNS, Trimpot Product Catalog, datasheet 2006, 86 p. Disponível em: http://www.bourns.com/. Acesso em Junho de 2006. 